Aus der Abteilung Kardiologie und Pneumologie

(Prof. Dr. med. G. Hasenfuß)

im Zentrum Innere Medizin

der Medizinischen Fakultät der Universität Göttingen

\title{
Die prognostische Bedeutung der Adipozytokine Leptin und Adiponectin bei der akuten Lungenembolie
}

\author{
Inaugural-Dissertation \\ zur Erlangung des Doktorgrades \\ der Medizinischen Fakultät \\ der Georg-August-Universität zu Göttingen \\ vorgelegt von \\ Christian Reiner \\ aus Kassel
}

Göttingen 2011 
Dekan:

Prof. Dr. med. C. Frömmel

I. Berichterstatterin: Priv.-Doz. Dr. med. C. Dellas

II. Berichterstatter/in:

III. Berichterstatter/in:

Tag der mündlichen Prüfung: 


\section{Inhalt}

$1 \quad$ Einleitung $\quad 1$

1.1 Allgemeines 1

1.2 Pathophysiologie 1

1.3 Diagnostik 3

1.3.1 Basisdiagnostik 3

1.3.2 Spezielle Diagnostik 3

1.4 Aktuelle Diagnosealgorithmen bei Patienten mit einer Lungenembolie 4

1.5 Risikofaktoren für das Auftreten einer Lungenembolie 8

$\begin{array}{lll}1.6 & \text { Adipozytokine } & 8\end{array}$

1.7 Das Ziel der vorliegenden Studie 11

$2 \quad$ Patienten und Methoden 12

$2.1 \quad$ Einführung 12

2.2 Das Patientenkollektiv der Fallgruppe 12

2.3 Das Patientenkollektiv der Kontrollgruppe 12

$2.4 \quad$ Datenerhebung 13

$2.5 \quad$ Echokardiographie 14

$2.6 \quad$ Labordiagnostik 14

2.7 Bildgebende Verfahren der Lungenembolie-Diagnostik 15

2.8 Ergänzende Untersuchungen 17

$2.9 \quad$ Die Therapie von Patienten mit einer akuten Lungenembolie 17

$2.10 \quad$ Die Endpunkte der Studie 17

$2.11 \quad$ Statistische Auswertung 18

$\begin{array}{llr}3 & \text { Ergebnisse } & 20\end{array}$

3.1 Alter, Geschlecht und Body-Mass-Index (BMI) in der Fall- und der 20

Kontrollgruppe

3.2 Vorerkrankungen in der Fall- und der Kontrollgruppe 20

$\begin{array}{lll}3.3 & \text { Fallgruppe } & 21\end{array}$

3.3.1 Klinische Symptomatik der Lungenemboliepatienten bei Aufnahme 21

3.3.2 Aufnahme-EKG der Lungenemboliepatienten 22

3.3.3 Risikofaktoren für das Auftreten einer Lungenembolie 22

3.3.4 Inhospital-Komplikationen bei Patienten mit einer akuten Lungenembolie 23 
3.4 Die Echokardiographie bei Patienten mit einer akuten Lungenembolie $\quad 24$

3.5 Die Therapie bei Patienten mit einer akuten Lungenembolie 24

3.6 Basale Labordiagnostik 25

$3.7 \quad$ Spezielle Labordiagnostik 25

3.7.1 Der Leptinspiegel in der Fall- und der Kontrollgruppe 26

3.7.2 Der Lösliche Leptinrezeptor-Spiegel (sobR-Spiegel) in der Fall- und der 28

3.7.3 Der Free-Leptin-Index (FLI) in der Fall- und der Kontrollgruppe 29

3.7.4 Der Adiponectinspiegel in der Fall- und der Kontrollgruppe 31

3.7.5 Zusammenhang zwischen Leptin, sobR, Adiponectin und den kardialen 33 Biomarkern

3.8 Parameter mit prognostischer Bedeutung für den Inhospital-Verlauf nach 34 einer akuten Lungenembolie

3.8.1 Zusammenhang zwischen klinischen Parametern und dem Echokardio- $\quad 34$ graphiebefund mit dem Auftreten von Komplikationen

3.8.2 Zusammenhang zwischen den kardialen Biomarkern mit dem Auftreten von 34 Komplikationen

3.8.3 Zusammenhang zwischen den Adipozytokinspiegeln mit dem Auftreten von 37 Komplikationen

3.8.4 Prädiktoren für einen komplikationsreichen Inhospital-Verlauf bei Patienten 37 mit einer akuten Lungenembolie

3.9 Das Langzeit-Überleben nach einer akuten Lungenembolie 39

3.10 Der Zusammenhang zwischen dem Leptinspiegel mit dem Langzeit- $\quad 41$ Überleben

$4 \quad$ Diskussion $\quad 45$

$\begin{array}{lll}4.1 & \text { Allgemeines } & 45\end{array}$

4.2 Der prädiktive Wert etablierter Parameter einer myokardialen Ischämie und 47 RV-Dysfunktion

4.3 Die Bedeutung der Adipozytokine bei Patienten mit einer akuten $\quad 48$ Lungenembolie

4.3.1 Referenzwerte 48

4.3.2 Geschlechtsspezifische Unterschiede der Adipozytokine 49 
4.3.3 Der Zusammenhang zwischen den Adipozytokinen mit dem Body-MassIndex (BMI) und dem Alter

4.3.4 Der Zusammenhang der Adipozytokine mit den kardialen Biomarkern 50

4.3.5 Haben Patienten mit einer akuten Lungenembolie erhöhte Leptin- und 51 erniedrigte Adiponectinspiegel?

4.3.6 Haben die Adipozytokine eine prognostische Bedeutung? 53

4.4 Limitationen der vorliegenden Studie 55

$\begin{array}{lll}4.5 & \text { Ausblick } & 55\end{array}$

$5 \quad$ Zusammenfassung $\quad 57$

$6 \quad$ Literaturverzeichnis $\quad 59$

$7 \quad$ Anhang: Dokumentationsbogen und Wells-Score $\quad 67$ 


\section{Abkürzungen}

Abb.

AUC

BMI

BNP

cGMP

CRP

CT

EDTA

EF

ELISA

ESC

FLI

GFR

HF

HR

JAK

kDA

KHK

KI

LE

m-RNA

NPV

NT-pro BNP

NYHA

OR

$\mathrm{p}_{\text {co2 }}$

$\mathrm{p}_{02}$

PPV

RHB

ROC

rpm
Abbildung

area under curve

Body-Mass-Index

Brain Natriuretic Peptide

zyklisches Guanosin Monophosphat

C-reaktives Protein

Computertomographie

Ethylendiamin-tetraessigsäure

Ejektionsfraktion

Enzyme-linked immunosorbent-assay

European Society of Cardiology

Free-Leptin-Index

glomeruläre Filtrationsrate

Herzfrequenz

Hazard ratio

Januskinase

Kilo-Dalton

koronare Herzkrankheit

Konfidenzintervall

Lungenembolie

messenger RNA

negativ prädiktiver Wert

N-terminal Brain Natriuretic Peptide

New York Heart Association

Odds ratio

Kohlendioxid-Partialdruck

Sauerstoff-Partialdruck

positiv prädiktiver Wert

Rechtsherzbelastung

Receiver-operating-characteristic

Umdrehungen pro Minute 
$\mathrm{RR}_{\text {sys }}$

RV

sobR

STAT

TNF alpha

TnT

TVT

VCI

vS.

Z.n. 


\section{Einleitung}

\subsection{Allgemeines}

Schon im 19. Jahrhundert prägte der Pathologe Rudolf Virchow den Begriff des Embolus als „Loslösung von größeren oder kleineren Teilen vom Ende eines weichen Thrombus, die mit dem Blutfluss in Blutgefäße getragen werden” (Dalen 2002). Die Inzidenz der Lungenembolie wird mit 60 Fällen je 100.000 Einwohner pro Jahr angegeben (Oger 2000), was zeigt, dass die Lungenembolie ein häufiges Krankheitsbild ist. Der Schweregrad variiert vom asymptomatischen bis zum tödlichen Verlauf. Bei einer durchschnittlichen Mortalität von 11\% versterben pro Jahr in Deutschland 40.000 Patienten an den Folgen einer Lungenembolie (Konstantinides et al. 2009), wobei 85\% der Patienten in den ersten zweieinhalb Stunden nach dem Ereignis versterben (Stein und Henry 1995). Somit kommt der frühzeitigen Identifikation der Patienten, die von einer erhöhten Mortalität durch eine akute Lungenembolie betroffen sind, eine zentrale Bedeutung zu.

\subsection{Pathophysiologie}

Eine Lungenembolie führt zum Verschluss des Pulmonalarterienstammes oder seiner Äste. Die Ursache ist meistens ein venöser Thrombus aus dem Bereich der unteren Hohlvene (Becken-, Oberschenkel-, Unterschenkelvene), seltener kann auch ein Thrombus aus dem Bereich der oberen Hohlvene oder des rechten Herzens die Ursache sein. Ein vollständiger oder partieller Verschluss der pulmonalarteriellen Strombahn führt zu einem Anstieg des pulmonalarteriellen Widerstandes, der durch die Ausschüttung vasoaktiver Substanzen wie Thromboxan A2 und Serotonin aus aktivierten Thrombozyten auf der Oberfläche des Embolus und der Gefäßwand noch verstärkt wird (Kreit 2004).

Diese Widerstandserhöhung zieht einen Anstieg der rechtsventrikulären Nachlast und Wandspannung nach sich. Dadurch kommt es zu einer Verschlechterung der rechtsventrikulären Funktion mit Dilatation des rechten Ventrikels, einer akuten Trikuspidalklappeninsuffizienz und einem erhöhten rechtsventrikulären enddiastolischen Druck und Volumen mit paradoxer Septumbewegung (Goldhaber und Elliott 2003). Dies kann dann zu einer Verminderung der linksventrikulären Compliance führen.

Durch die Verschlechterung der rechtsventrikulären Funktion und der linksventrikulären Compliance vermindert sich die Füllung des linken Ventrikels und es kommt zum Abfall 
des Schlagvolumens. Eine verminderte Ejektionsfraktion mit arterieller Hypotension $\left(\mathrm{RR}_{\text {sys }}<90 \mathrm{mmHg}\right)$ bis hin zum Vollbild eines kardiogenen Schocks kann die Folge sein. Im Rahmen dessen kommt es $\mathrm{zu}$ einer verminderten Koronarperfusion mit Myokardischämie sowie zum Abfall der Lungendurchblutung mit einer Zunahme des funktionellen pulmonalen Totraums und resultierender Hypoxämie.

Die Auswirkungen der akuten Lungenembolie hängen aber neben dem Ausmaß der pulmonalarteriellen Widerstandserhöhung auch von begleitenden kardialen und pulmonalen Erkrankungen und der Effektivität kompensatorischer Mechanismen ab, die den kardialen Auswurf und die systemische Perfusion aufrecht erhalten (Kreit 2004, Goldhaber 2002). In Abbildung 1.1 ist die Pathophysiologie nochmals graphisch dargestellt.

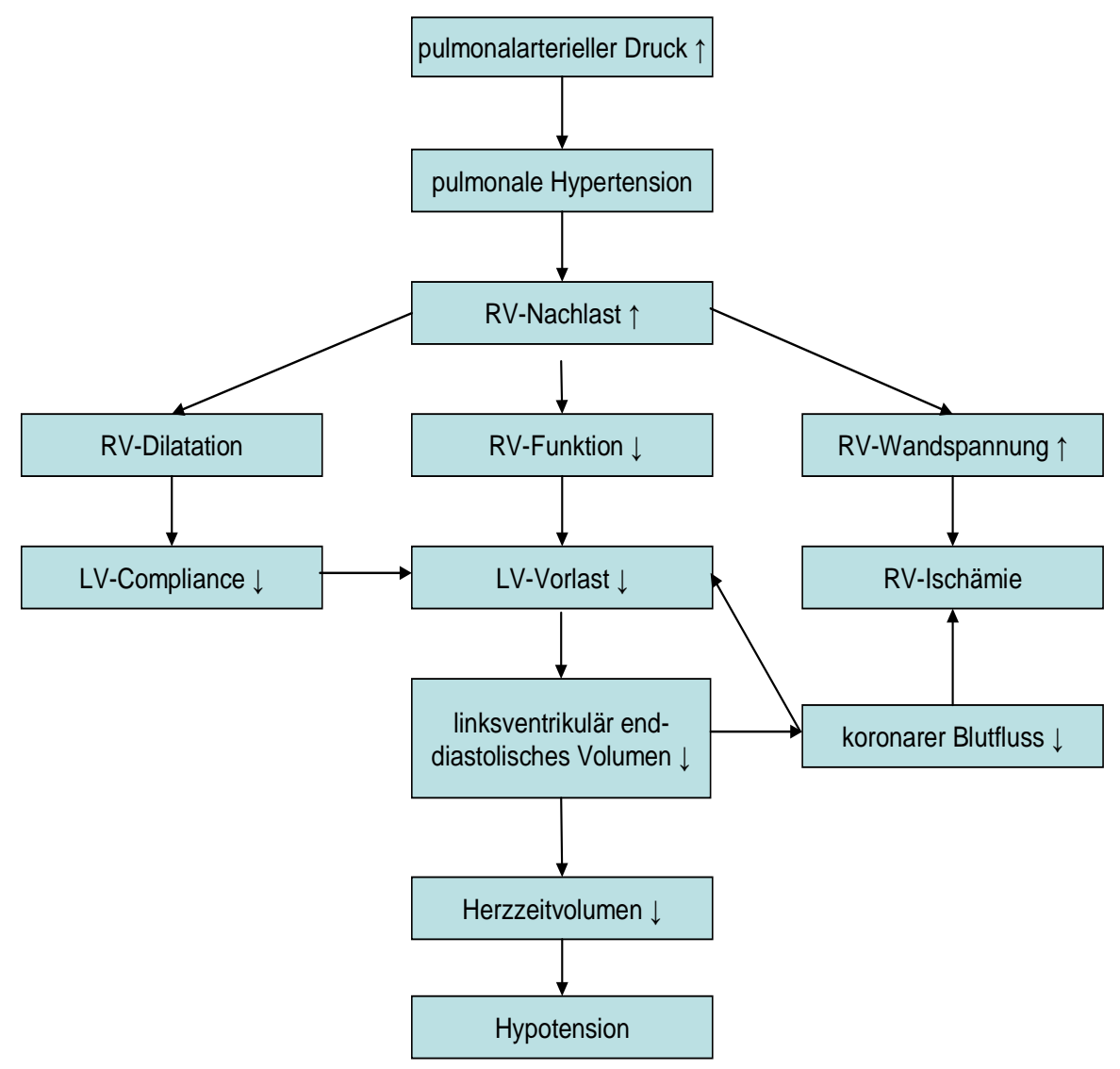

Abbildung 1.1: Flussdiagramm zur Pathophysiologie der akuten Lungenembolie. 


\subsection{Diagnostik}

\subsubsection{Basisdiagnostik}

Patienten mit einer akuten Lungenembolie berichten über unspezifische Symptome wie Dyspnoe, Tachypnoe, Thoraxschmerzen, Synkope, Tachykardie oder selten auch Hämoptysen (Grifoni et al. 2000). Daher ist es oft schwierig, die akute Lungenembolie anhand des klinischen Bildes von anderen kardialen und pulmonalen Erkrankungen abzugrenzen.

Die im Rahmen der Basisdiagnostik durchgeführten Untersuchungen können den Verdacht auf eine Lungenembolie nur erhärten oder entkräften, jedoch nicht definitiv bestätigen oder widerlegen.

So können sich im EKG neben einer Sinustachykardie, der häufigsten EKG-Veränderung bei der akuten Lungenembolie, Zeichen der Rechtsherzbelastung wie ein neu aufgetretener kompletter oder inkompletter Rechtsschenkelblock, ein $\mathrm{S}_{\mathrm{I}} \mathrm{Q}_{\mathrm{III}}$-Typ, T-Negativierungen in den Ableitungen V1-V3 oder ein P-pulmonale zeigen (Ferrari et al. 1997). In der arteriellen Blutgasanalyse ist eine Hypoxämie mit Hypokapnie (Ausdruck der kompensatorischen Hyperventilation) typisch (Rodger et al. 2000). Bei Patienten mit Dyspnoe wird in der Regel auch ein Röntgen-Thorax-Bild angefertigt, das unspezifische Befunde wie regionale Transparenzerhöhungen (Westermark-Zeichen), eine gestaute Arteria pulmonalis, eine Rechtsherzvergrößerung, einen einseitigen Zwerchfellhochstand oder einen Pleuraerguss als Hinweis auf eine Lungenembolie zeigen kann (American Thoracic Society 1999).

\subsubsection{Spezielle Diagnostik}

Der einzige etablierte Laborparameter in der Lungenembolie-Diagnostik sind die D-Dimere. D-Dimere sind Fibrinogen-Fibrin-Spaltprodukte, die aufgrund der körpereigenen Spontanfibrinolyse bei einer Thromboembolie entstehen. Für den Nachweis von D-Dimeren steht neben einem ELISA-Test auch ein Bedside-Latex-Agglutinationstest zur Verfügung. Beide Testverfahren zeichnen sich durch eine hohe Sensitivität von bis zu $96 \%$ bei gleichzeitig niedriger Spezifität aus und sind somit zum Ausschluss, nicht jedoch zur Bestätigung eines thromboembolischen Ereignisses geeignet (Goldhaber und Elliott 2003). 
Bildgebende Verfahren, die zur Diagnose einer Lungenembolie eingesetzt werden, sind die Spiral-Computertomographie (Spiral-CT), die Ventilations-/Perfusionsszintigraphie, die Pulmonalisangiographie und die Echokardiographie.

Heute ist die Spiral-CT die Methode der Wahl. Nach intravenöser Kontrastmittelgabe ist der Embolus als Kontrastmittelaussparung darstellbar. Die heute eingesetzten Scanner haben eine Auflösung im Millimeter-Bereich, die auch die Darstellung kleiner Emboli im Subsegmentalbereich erlaubt (Schoepf et al. 2004). Die Szintigraphie kommt als kombinierte Ventilations-/ Perfusionsszintigraphie oder als Perfusionsszintigraphie in Kombination mit einem Röntgen-Thorax-Bild zum Einsatz, hat jedoch in den letzten Jahren an Bedeutung verloren. Von Nachteil ist hierbei die große Anzahl nicht eindeutiger Befunde. Als historischer Goldstandard gilt die Pulmonalisangiographie. Durch ihre Invasivität und das damit verbundene Komplikationsrisiko ist sie nur noch in Ausnahmefällen, z.B. bei geplanter Thrombolektomie, indiziert.

Die Echokardiographie spielt für die Diagnose einer Lungenembolie nur bei hämodynamisch instabilen Patienten eine Rolle, ansonsten dient sie der Risikostratifikation (siehe Kapitel 1.4).

\subsection{Aktuelle Diagnosealgorithmen bei Patienten mit einer Lungenembolie}

Besteht der Verdacht auf eine akute Lungenembolie, sollte man umgehend eine Unterteilung in Patienten mit stabilen und instabilen Kreislauf-Verhältnissen vornehmen, da hiervon das weitere diagnostische und therapeutische Vorgehen abhängt.

In den Leitlinien der ESC (European Society of Cardiology) zur Diagnostik und Therapie der Lungenembolie aus dem Jahre 2008 wird deswegen eine sofortige Risikostratifikation anhand klinischer Parameter mit der Einteilung in drei Gruppen mit hohem, mittlerem und niedrigem Komplikationsrisiko empfohlen.

Lungenemboliepatienten, die mit einem kardiogenen Schock oder Hypotonie $\left(\mathrm{RR}_{\text {sys }}<90 \mathrm{mmHg}\right)$ zur Aufnahme kommen, sind von einer Mortalität von über $15 \%$ betroffen (Hoch-Risiko-Gruppe). In der ICOPER-Studie, einer prospektiven Lungenembolie-Studie mit fast 2400 Patienten, waren zwar nur $5 \%$ der Patienten hämodynamisch instabil, jedoch wurde für diese eine 90-Tages-Mortalität von $52 \%$ beschrieben (Kucher et al. 2006). Deshalb sollte bei diesen Patienten eine umgehende bildgebende Diagnostik durchgeführt werden, möglichst die Spiral-CT. Ist diese nicht 
verfügbar, ist auch der echokardiographische Nachweis einer Rechtsherzbelastung beweisend für eine Lungenembolie (siehe Abb. 1.2). Für diese Patienten wird bei Bestätigung der Verdachtsdiagnose einer akuten Lungenembolie eine Thrombolysetherapie empfohlen (Torbicki et al. 2008). Invasive Behandlungsalternativen wie die Kathetergesteuerte Defragmentation oder die operative Thrombolektomie können bei Kontraindikationen für eine Thrombolyse zur Anwendung kommen.

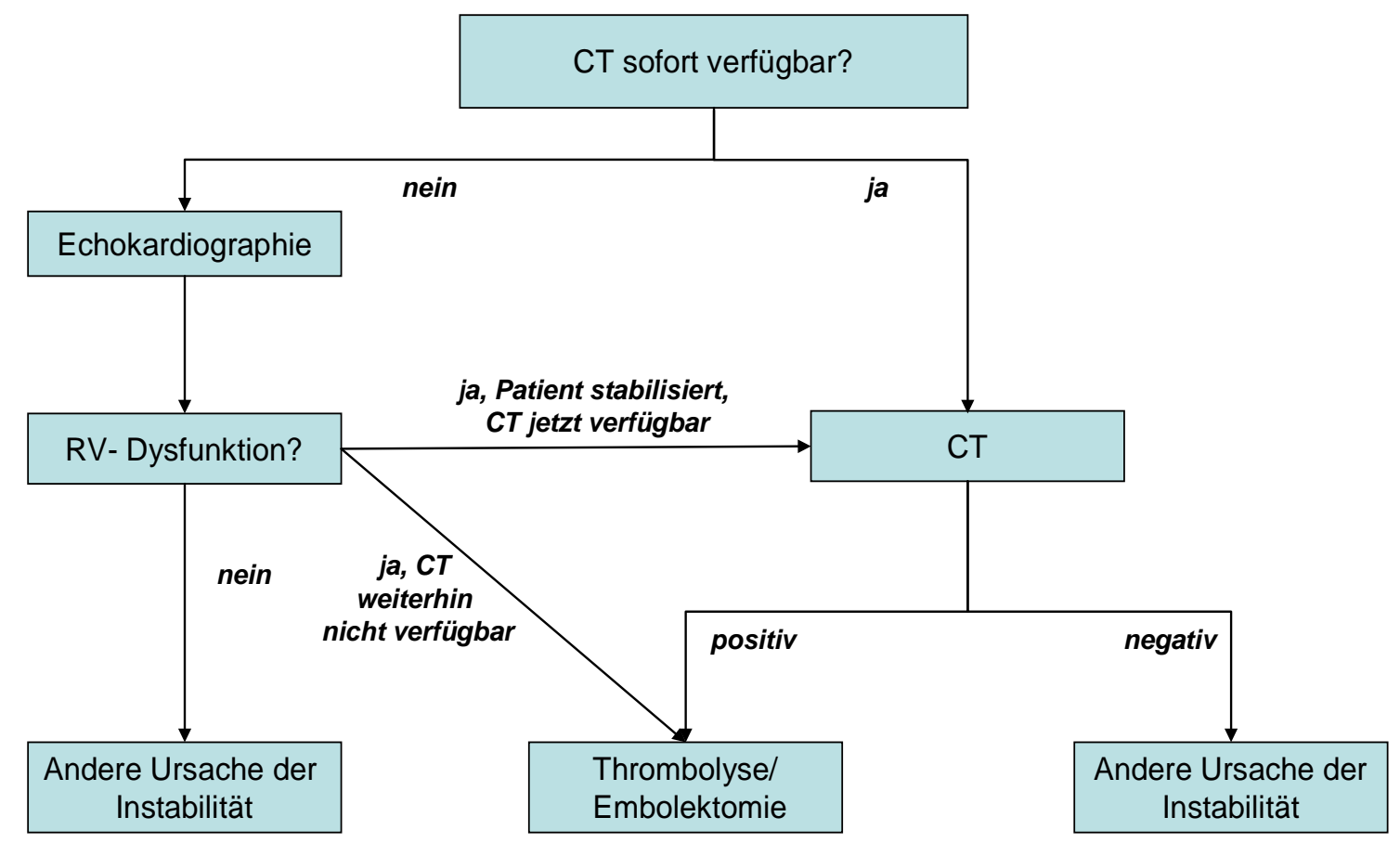

Abbildung 1.2.: Diagnostischer Algorithmus bei hämodynamisch instabilen Patienten mit Verdacht auf eine akute Lungenembolie (nach den ESC-Leitlinien; Torbicki et al. 2008, Seite 2288).

Bei Patienten mit initial stabilen Kreislaufverhältnissen (Intermediär- und Niedrig-RisikoGruppe) liegt die Mortalität unter $15 \%$, bei dieser Patientengruppe steht die diagnostische Sicherheit im Vordergrund.

Es erfolgt zunächst die Einschätzung der klinischen Wahrscheinlichkeit für eine Lungenembolie. Hierfür werden standardisierte Scores wie der Wells Score (siehe Anhang) oder der revidierte Genfer-Risiko-Score angewendet, mit denen unter Einbeziehung klinischer und anamnestischer Angaben die klinische Wahrscheinlichkeit für eine akute Lungenembolie bestimmt werden kann.

Bei hoher klinischer Wahrscheinlichkeit wird eine Spiral-CT durchgeführt, ist diese nicht hoch, erfolgt ein D-Dimer-Test. Bei positivem D-Dimer-Test wird eine Spiral-CT durchgeführt. Bei negativem D-Dimer-Test gilt eine Lungenembolie als ausgeschlossen 
(siehe Abb. 1.3). In einer großen prospektiven Studie zeigte sich die diagnostische Sicherheit dieses Algorithmus: nur 0,5\% der Patienten, bei denen eine Lungenembolie anhand einer nicht-hohen klinischen Wahrscheinlichkeit in Kombination mit einem negativen D-Dimer-Test ausgeschlossen worden war, hatten im Follow-Up während der nächsten drei Monate eine venöse Thromboembolie (The Christopher Study Investigators 2006).

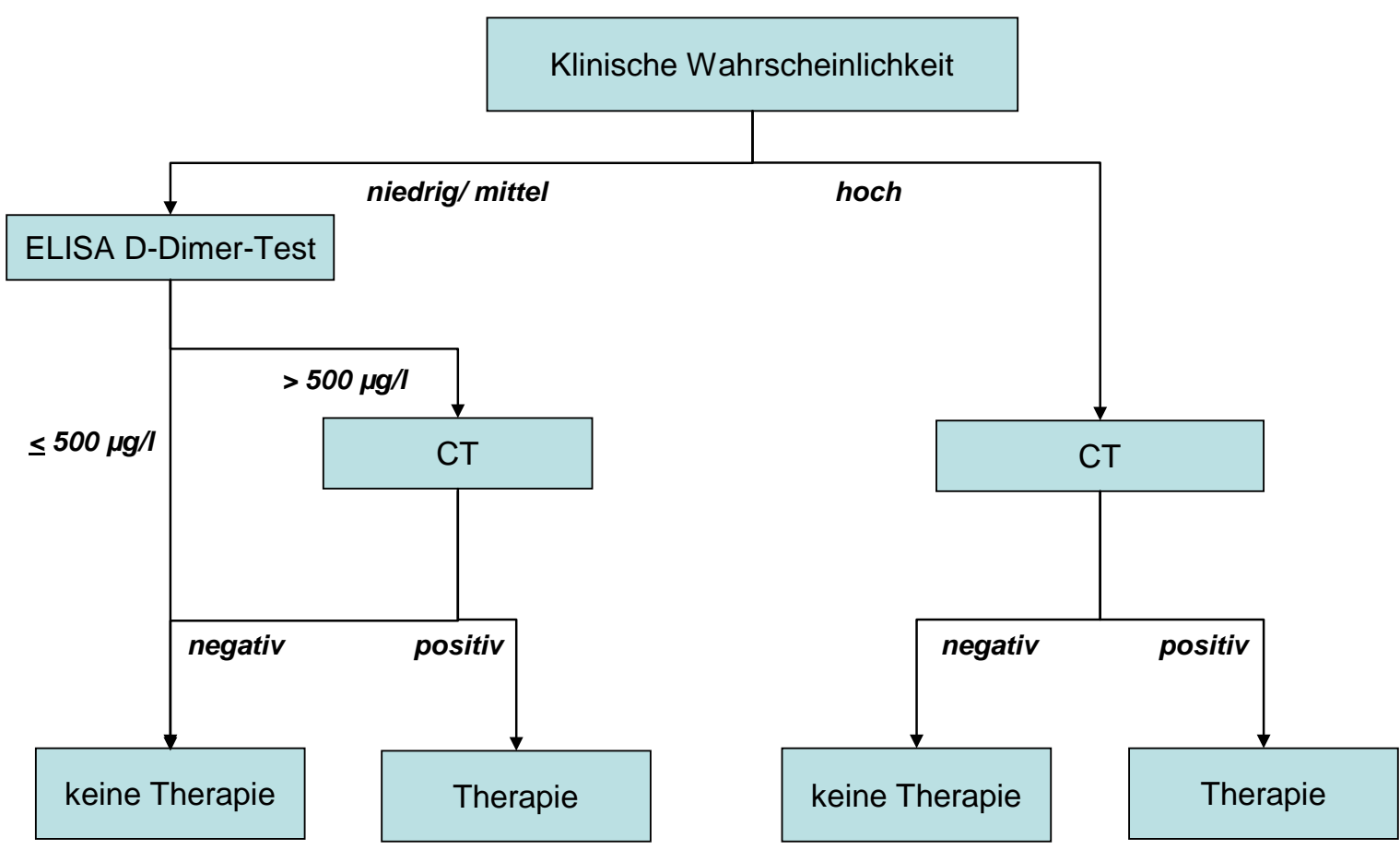

Abbildung 1.3.: Diagnostischer Algorithmus bei hämodynamisch stabilen Patienten mit Verdacht auf eine akute Lungenembolie (nach den ESC-Leitlinien; Torbicki et al. 2008, Seite 2289).

Mindestens $25 \%$ der hämodynamisch stabilen Patienten weisen Zeichen einer rechtsventrikulären Dysfunktion oder einer Myokardläsion auf (Kreit 2004). Diese Patienten sind von einer Mortalität von 3-15\% betroffen und nehmen bezüglich des Komplikationsrisikos eine Mittelstellung ein (Intermediär-Risiko-Gruppe). Patienten ohne Zeichen einer Rechtsbelastung und einer Myokardläsion sind von einer Mortalität unter $1 \%$ betroffen und werden einer Niedrig-Risiko-Gruppe zugeordnet (Torbicki et al. 2008).

Zur Unterscheidung zwischen Patienten der Intermediär- und der Niedrig-Risiko-Gruppe werden bildgebende Verfahren und Laborparameter (Troponine, natriuretische Peptide) eingesetzt.

Methode der Wahl zum Nachweis einer Rechtsherzbelastung ist die Echokardiographie als nicht-invasives und am Patientenbett durchführbares Verfahren. 
Typische echokardiographische Zeichen der Rechtsherzbelastung sind eine paradoxe Septumbewegung, ein vergrößerter rechter Ventrikel sowie eine gestaute Vena cava inferior (VCI). Auch in der Spiral-CT kann das Vorliegen einer Rechtsherzbelastung beurteilt werden.

Etablierte laborchemische Marker in der Risikostratifikation der Lungenembolie sind die Troponine T und I sowie die natriuretischen Peptide (BNP, NT-pro BNP).

Die Troponine T und I sind intrazelluläre Strukturproteine des Herzmuskels, die bei einer myokardialen Ischämie freigesetzt werden und in der Diagnostik koronarer Ereignisse etabliert sind. Bei einer Lungenembolie korreliert ein Troponin-T-Wert $\geq 0,04 \mathrm{ng} / \mathrm{ml} \mathrm{mit}$ einer erhöhten Komplikations- und Sterblichkeitsrate (Konstantinides et al. 2002 a).

Natriuretische Peptide wie NT-pro BNP werden bei atrialer und ventrikulärer Dehnung aus dem Myokard sezerniert und können deshalb bei einer akuten Lungenembolie mit Rechtsherzbelastung in erhöhter Konzentration im Plasma nachgewiesen werden. Erhöhte NT-pro-BNP-Werte sind mit einer schlechten Prognose nach einer Lungenembolie vergesellschaftet. Binder et al. (2005) beschrieben einen NT-pro-BNP-Spiegel $\geq 1000 \mathrm{pg} / \mathrm{ml}$ als sinnvollen Cut-off-Wert.

Die Patienten der Intermediär-Risiko-Gruppe weisen Rechtsherzbelastungszeichen und/oder erhöhte Werte von Troponin oder natriuretischen Peptiden auf. Es sollte eine therapeutische Antikoagulation mit Heparin (niedermolekular oder unfraktioniert) erfolgen. Ob diese Patienten von einer Thrombolysetherapie profitieren, ist Gegenstand klinischer Studien. Bisher liegt nur eine klinische Studie zum Vergleich von Heparin versus Heparin plus Thrombolytikum bei diesen Patienten vor. Hier wurde keine signifikante Reduktion der Mortalität und der Komplikationsrate nach einer Thrombolyse gegenüber der alleinigen Antikoagulation beschrieben, jedoch musste bei Patienten mit alleiniger Antikoagulation die Therapie häufiger eskaliert werden (Konstatinides et al. 2002 b). Unter Berücksichtigung potentieller Komplikationen einer Thrombolysetherapie und aufgrund unzureichender Daten großer Studien empfehlen die aktuellen Leitlinien derzeit die alleinige Antikoagulation.

Patienten der Niedrig-Risiko-Gruppe weisen keine Rechtsherzbelastungszeichen und normwertige Spiegel der genannten Laborparameter auf. Hier ist die therapeutische Antikoagulation die alleinige Therapie. 


\subsection{Risikofaktoren für das Auftreten einer Lungenembolie}

Risikofaktoren für eine Lungenembolie sind unter anderem Immobilisation, Trauma, operative Eingriffe, Malignome, Schwangerschaft, die orale Kontrazeption und angeborene Thrombophilien wie die Faktor-V-Leiden-Mutation, der Protein-C/S-Mangel und der Antithrombin-III-Mangel (Goldhaber und Elliott 2003). Kontrovers diskutiert wird, ob die Adipositas ebenfalls ein Risikofaktor für venöse Thromboembolien (LE und/oder TVT) ist. In den letzten Jahren haben sich die Hinweise gemehrt, dass venöse Thromboembolien bei adipösen häufiger als bei normalgewichtigen Patienten auftreten. So zeigten Goldhaber et al. (1997) in einer großen prospektiven Studie an mehr als 112.000 Frauen, dass die Adipositas ein unabhängiger Risikofaktor für das Auftreten einer Lungenembolie ist. Sugimura et al. (2006) beschrieben den BMI als unabhängigen Risikofaktor für eine venöse Thromboembolie. Diese Beobachtungen wurden von anderen Arbeitsgruppen bestätigt (Blaszyk und Björnsson 2000, Hansson et al. 1999, Kucher et al. 2005). Mögliche Ursachen für einen Einfluss der Fettleibigkeit auf die Entstehung venöser Thromboembolien könnten, neben der durch die Bewegungsarmut bedingten venösen Stase, die Veränderungen des Gerinnungsstatus sein, die bei adipösen Patienten beobachtet wurden (Konstantinides et al. 2001 a, Ögren et al. 2005). In diesem Zusammenhang ist auch die endokrine Funktion des Fettgewebes in den Fokus gerückt und somit die dort produzierten und sezernierten Hormone, die Adipozytokine.

\subsection{Adipozytokine}

Hormone, die in Adipozyten produziert und von ihnen sezerniert werden, werden als Adipozytokine bezeichnet. Zu dieser Substanzklasse zählen auch Leptin und Adiponectin. Leptin ist ein Proteohormon, bestehend aus 167 Aminosäuren, das seine Wirkung über den Leptinrezeptor entfaltet. Dieser Rezeptor liegt in einer langen und mehreren kurzen Isoformen vor. Die lange Isoform findet man im zentralen Nervensystem (Hypothalamus), die kurzen Formen in vielen peripheren Geweben. Die Bindung von Leptin an die lange Isoform des Leptinrezeptors führt über die Aktivierung einer Januskinase (JAK) und Signal transducers and activators of transcription (STAT) zu einer Translokation von STAT in den Zellkern und der nachfolgenden Regulation der Transkriptionsaktivität (Tartaglia 1997, Houseknecht et al. 1998). 
Schon in den neunziger Jahren wurde die zentrale Bedeutung von Leptin als „Adipostat“, also als Regulator des Fett- und Energiestoffwechsels bei Mensch und Nagetier erkannt. Als kataboles Hormon erhöht Leptin den Energieumsatz, senkt das Körpergewicht und verringert das Hungergefühl und die Nahrungsaufnahme. Es besteht eine starke Korrelation zwischen Leptin und dem Körperfettgehalt bzw. dem BMI (Considine et al. 1996). Ein schlanker Mensch weist also niedrigere Leptinspiegel als ein adipöser Mensch auf. Sinkt mit dem Körpergewicht die Masse des produzierenden Fettgewebes, so sinkt auch der Leptinspiegel und umgekehrt. Bei adipösen Patienten kommt es also zu einem steigenden Leptinspiegel, resultierend müsste es aufgrund der katabolen Funktionen des Leptins zu einer verringerten Nahrungszufuhr und zu einer Abnahme des Körpergewichtes kommen. Dass dies nicht der Fall ist, liegt in einer zentralen Leptinresistenz begründet, deren molekularbiologische Ursache bisher noch nicht eindeutig identifiziert worden ist (Scarpace und Zhang 2008, Kalra 2008). Neben der Bedeutung für den Fett- und Energiestoffwechsel scheint Leptin aber auch zahlreiche andere Funktionen zu erfüllen. So konnte, neben einem Einfluss auf die Fortpflanzung und die Hämatopoese, auch ein Einfluss auf kardiovaskuläre Erkrankungen nachgewiesen werden (Houseknecht et al. 1998). Ein erhöhter Leptinspiegel ist nicht nur mit den Komponenten des metabolischen Syndroms (arterieller Hypertonus, Diabetes mellitus Typ 2, Hyperlipoproteinämie) assoziiert (Leyva et al. 1998). In der West of Scotland Coronary Prevention Study (WOSCOPS), einer großen PrimärpräventionsStudie, wurde unter anderem die Bedeutung von Leptin bei der koronaren Herzkrankheit untersucht. Es zeigte sich hier, dass ein erhöhter Leptinspiegel ein unabhängiger Risikofaktor für das Auftreten einer koronaren Herzkrankheit ist (Wallace et al. 2001).

Experimentelle Arbeiten an Mäusen zeigten, dass Leptin zu einer verstärkten Arteriosklerose- und Thrombusbildung beiträgt (Bodary et al. 2002, Konstantinides et al. 2001 b). Aus diesen Beobachtungen lässt sich der Verdacht auf eine prothrombotische Wirkung des Leptins ableiten. Die Beobachtung, dass Leptin über Leptinrezeptoren auf der Oberfläche von Thrombozyten zu einer direkten Thrombozytenaktivierung führt, unterstreicht diesen Verdacht (Dellas et al. 2007, Giandomenico et al. 2005, Elbatarny und Maurice 2005).

Ein möglicher Einfluss von Leptin auf venöse Thromboembolien lässt sich bisher nur aus einer experimentellen Arbeit mit Mäusen zu diesem Thema ableiten. Konstantinides et al. (2004) zeigten, dass die Inhibition von endogenem Leptin sowohl vor Thrombosen im arteriellen als auch im venösen Gefäßsystem schützt. Klinische Studien zu diesem Thema existieren zum jetzigen Zeitpunkt noch nicht. 
Leptin lässt sich im Blut sowohl in freier als auch in gebundener Form nachweisen (Sinha et al. 1996). Der lösliche Leptinrezeptor (sobR), der nur aus der extrazellulären Komponente des membrangebundenen Leptinrezeptors besteht (Ogawa et al. 2004), stellt hierbei das Hauptbindungsprotein dar (Lammert et al. 2001). Für die Konzentration des sobR wird eine negative Korrelation mit dem BMI beschrieben (Sinha et al. 1996).

Der Quotient aus Leptin/sobR, der so genannte Free-Leptin-Index (FLI), ist der Anteil an nicht Protein-gebundenem, also freiem Leptin. Landt et al. (2000) zeigten, dass freies Leptin die biologisch aktive Form des Leptins zu sein scheint. Dieser freie Anteil ist bei adipösen größer als bei normalgewichtigen Personen (Wu et al. 2002). So beschrieben van Dielen et al. (2002) bei schlanken Patienten ein Verhältnis von Leptin/sobR von 1:1, bei sehr adipösen Patienten hingegen ein Verhältnis von 25:1. Der Anteil von freiem Leptin scheint also variabel zu sein und durch den sobR reguliert zu werden.

Wie Leptin gehört auch Adiponectin, das aus 244 Aminosäuren besteht, zu den Adipozytokinen (Kintscher 2007). Adiponectin wird hauptsächlich in den Adipozyten produziert, jedoch ist auch eine Adiponectinexpression im Herzen nachgewiesen worden (Ding et al. 2007). Die Wirkung erfolgt über zwei Rezeptoren: AdipoR1 wird hauptsächlich im Skelettmuskel exprimiert, AdipoR2 vornehmlich in der Leber. Zwischen dem BMI und Adiponectin besteht eine inverse Korrelation, d.h. adipöse Patienten weisen niedrigere Adiponectinspiegel als normalgewichtige Patienten auf, bei Gewichtsabnahme kommt es zum Anstieg des Adiponectin-Plasmaspiegels (Ryo et al. 2004). Der Adiponectinspiegel korreliert mit den Faktoren des metabolischen Syndroms (Ryo et al. 2004). Für die koronare Herzkrankheit konnte gezeigt werden, dass ein erniedrigter Adiponectinspiegel bei Männern ein unabhängiger Risikofaktor für eine koronare Herzkrankheit ist (Kumada et al. 2003). Adiponectin scheint also bei gesunden Personen präventiv gegenüber Gefäßveränderungen zu wirken (Matsuzawa et al. 2004). Kato et al. (2006) beobachteten bei AdiponectinKnockout-Mäusen eine verstärkte Ausbildung von Thromben und eine verstärkte Thrombozytenaggregation nach einer arteriellen Gefäßverletzung. Niedrige Adiponectinspiegel scheinen also die Thromboseentstehung in arteriellen Gefäßen zu begünstigen. Zur Bedeutung von Adiponectin bei der akuten Lungenembolie existieren bisher keine Untersuchungen. 


\subsection{Das Ziel der vorliegenden Studie}

Das Ziel der vorliegenden Untersuchung ist es, die Bedeutung der Adipozytokine Leptin, Adiponectin sowie des löslichen Leptinrezeptors bei der akuten Lungenembolie zu untersuchen. Dabei sollen folgende Fragen beantwortet werden:

- Haben Patienten mit einer akuten Lungenembolie erhöhte Leptinspiegel und ist dies mit einer schlechten Prognose assoziiert?

- Haben Patienten mit einer akuten Lungenembolie einen erniedrigte Adiponectinspiegel und ist dies mit einer schlechten Prognose assoziiert? 


\section{Patienten und Methoden}

\subsection{Einführung}

In der vorliegenden prospektiven Fall-Kontroll-Studie wurden zwischen 2003 und 2006 am Universitätsklinikum Göttingen 97 Patienten mit einer akuten Lungenembolie in die Fallgruppe eingeschlossen. In die Kontrollgruppe wurden 40 Patienten aufgenommen. Alle Patienten erklärten schriftlich ihr Einverständnis zur Studienteilnahme. Die Studie wurde durch die Ethikkommission der Universität Göttingen genehmigt.

\subsection{Das Patientenkollektiv der Fallgruppe}

Eingeschlossen in die Fallgruppe wurden Patienten, bei denen eine akute Lungenembolie durch eines der folgenden bildgebenden Verfahren diagnostiziert worden war (Details siehe Kapitel 2.7):

1. Spiral-CT des Thorax

2. Ventilations-Perfusionsszintigraphie der Lunge

3. Perfusionsszintigraphie der Lunge in Kombination mit einem Röntgen-Thorax-Bild

4. Pulmonalisangiographie

5. hämodynamische Instabilität mit dem Nachweis einer akuten Rechtsherzbelastung in der Echokardiographie

6. Nachweis einer tiefen Venenthrombose im Ultraschall in Kombination mit dem Nachweis einer Rechtsherzbelastung in der Echokardiographie.

Nicht in die Studie aufgenommen wurden Patienten, bei denen die Lungenembolie eine Zufallsdiagnose darstellte sowie Patienten, die ihr Einverständnis zur Teilnahme an der Studie nicht gaben oder zurückgezogen hatten.

\subsection{Das Patientenkollektiv der Kontrollgruppe}

Da ein erhöhter Leptinspiegel als unabhängiger Risikofaktor für eine koronare Herzkrankheit identifiziert wurde (Wallace et al. 2001), wurden nur Patienten ohne signifikante Stenose der Koronararterien in die Kontrollgruppe eingeschlossen, um eine KHK als Ursache eines erhöhten Leptinspiegels auszuschließen. 
Deshalb wurden in die Kontrollgruppe 40 Patienten eingeschlossen, die sich zur Abklärung von Dyspnoe oder thorakalen Schmerzen in der zentralen Notaufnahme am Universitätsklinikum Göttingen vorstellten und bei denen im Rahmen der Routinediagnostik eine Koronarangiographie im Herzkatheterlabor der Abteilung Kardiologie und Pneumologie am Universitätsklinikum Göttingen durchgeführt wurde. Als Einschlusskriterien galten:

1. Ausschluss einer Lungenembolie durch eine niedrige klinische Wahrscheinlichkeit für eine Lungenembolie gemäß Wells-Score (siehe Anhang) in Kombination mit einem negativen D-Dimer-Test $(<0,5 \mu \mathrm{g} / \mathrm{ml})$

2. Ausschluss einer signifikanten Stenosierung der Koronargefäße in der Koronarangiographie (Stenosegrad $<50$ \%)

3. eine normale linksventrikuläre Pumpfunktion (Ejektionsfraktion $>50 \%$ ), gemessen in der Linksherzkatheter-Untersuchung oder der Echokardiographie

4. schriftliche Einwilligung zur Teilnahme an der Studie.

\subsection{Datenerhebung}

Die Datenerhebung erfolgte bei den Fall- und den Kontrollgruppenpatienten mit dem im Anhang aufgeführten Dokumentationsbogen.

Das Geschlecht, das Alter sowie die Größe und das Gewicht zur Berechnung des BMI wurden erfasst. Weiterhin wurden die Symptome, die zur Vorstellung in der Klinik führten, erfasst: Dyspnoe, thorakale Schmerzen, Synkope, Schock, Herzstillstand/Reanimation. Der Puls und der Blutdruck bei Aufnahme wurden dokumentiert.

Folgende Risikofaktoren für eine Lungenembolie wurden erfragt: Immobilisation, vorausgegangenes Trauma oder Operation, Schwangerschaft, orale Kontrazeption, Malignom und vorausgegangene tiefe Venenthrombose oder Lungenembolie.

Wichtige Vor- und Begleiterkrankungen wurden dokumentiert: chronisch obstruktive Bronchitis (COPD), Herzinsuffizienz, vorausgegangener Apoplex cerebri, Diabetes mellitus sowie arterieller Hypertonus.

Schließlich wurden die Methoden der Diagnosestellung sowie die Art der Therapie der Lungenembolie erfasst.

Die Aufnahme-EKG`s aller Lungenemboliepatienten wurden ausgewertet und es erfolgte die Dokumentation des po2 $_{\mathrm{O}}$ und des p $_{\mathrm{CO} 2}$ oder des peripheren Sauerstoffsättigungswertes. 


\subsection{Echokardiographie}

Die Untersuchungen wurden im Rahmen der Lungenembolie-Routinediagnostik aus den Standardpositionen parasternal, apikal sowie subkostal in der Abteilung Kardiologie und Pneumologie am Universitätsklinikum Göttingen durchgeführt.

Wie in anderen prospektiven klinischen Lungenemboliestudien (Grifoni et al. 2000, Binder et al. 2005), wurde in der vorliegenden Arbeit als Rechtherzbelastung gewertet:

1. ein rechter Ventrikel, der enddiastolisch einen größeren Durchmesser aufweist als der linke Ventrikel von apikal oder subkostal und/oder

2. ein rechtsventrikulär enddiastolischer Durchmesser $>30 \mathrm{~mm}$ in der parasternalen Achse

in Kombination mit einem fehlenden inspiratorischen Kollaps der Vena cava inferior.

\subsection{Labordiagnostik}

Bei allen Lungenemboliepatienten erfolgten zwei Blutabnahmen zu den Zeitpunkten 0 und 24 Stunden. Dabei wurden pro Blutentnahme drei Monovetten (Heparinat-, EDTA-Plasma, Serum) mit einem Inhalt von je $10 \mathrm{ml}$ entnommen. Bei den Kontrollgruppenpatienten erfolgte eine Blutabnahme nach der Koronarangiographie. Hier wurden ebenfalls drei Monovetten (Citrat-, Heparinat-Plasma, Serum) entnommen. Direkt nach der Entnahme wurden die Vollblutproben bei 3000 rpm für 10 Minuten zentrifugiert, die Plasmaproben wurden bei $-80^{\circ} \mathrm{C}$ in der Abteilung Klinische Chemie des Universitätsklinikums Göttingen eingefroren.

Die basale Labordiagnostik (Kreatinin, Blutbild, CRP) sowie die D-Dimer-Tests wurden bei Patienten der Lungenemboliegruppe im Rahmen der Routinediagnostik im Zentrallabor der Abteilung Klinische Chemie am Universitätsklinikum Göttingen durchgeführt, ebenso die D-Dimer-Tests bei Patienten der Kontrollgruppe.

Bei dem verwendeten Tina-quant ${ }^{\circledR}$ D-Dimer-Test (Roche Diagnostics, Mannheim) handelt es sich um einen Latex-Agglutinationstest. Gemäß Herstellerangaben wurde ein Cut-OffWert von $0,5 \mu \mathrm{g} / \mathrm{ml}$ verwendet. Hierfür wird in der Literatur eine Sensitivität von 94-95 \% und eine Spezifität von 64-65 \% angegeben (Dempfle 2005).

Die Messung der Troponin-T- und NT-pro-BNP-Serumspiegel erfolgte im Zentrallabor der Abteilung Klinische Chemie unter Verwendung eines quantitativen 
Elektrochemilumineszenz-Tests (Elecsys 2010 Immunoanalyzer Test, Roche Diagnostics, Mannheim). Der vom Hersteller empfohlene Cut-Off-Wert für Troponin T wird mit $\leq 0,03$ ng/ml angegeben, für NT-pro BNP wurde ein Cut-Off-Wert von 1000 pg/ml eingesetzt, wie er von Binder et al. (2005) bei Patienten mit einer Lungenembolie bestimmt worden war (PPV und NPV sind in Kapitel 3.8.2 aufgeführt).

Die Messungen der Serumspiegel von Leptin, sobR und Adiponectin erfolgten mittels eines kommerziellen ELISA`s. Hierbei werden spezifische, gegen die Oberfläche des zu messenden Moleküls gerichtete Antikörper auf einer Mikroplatte fixiert. Die im zugegebenen Probenmaterial enthaltenen Moleküle binden an diesen Antikörper. Nach dem Entfernen von ungebundenen Molekülen erfolgt die Zugabe eines zweiten monoklonalen (gegen das Molekül gerichteten) und Enzym-gebundenen Antikörpers. Nicht gebundene Antikörper werden entfernt. Nun erfolgt die Zugabe einer Substratlösung und die Antikörper-gebundenen Enzyme setzen in dem Maße Substrat um, in dem im initialen Schritt Moleküle gebunden worden sind. Die Intensität der Farbentwicklung kann photometrisch gemessen und so auf die Konzentration des zu untersuchenden Moleküls geschlossen werden.

Die Leptin-Bestimmung erfolgte mit dem Quantikine ${ }^{\circledR}$ DLP00 Testkit von R\&D Inc., Minneapolis (mittlere untere Nachweisgrenze 7,8 pg/ml). Die Bestimmung des sobR erfolgte mit dem Quantikine DOBR00 ELISA von R\&D Inc., Minneapolis (mittlere untere Nachweisgrenze 0,057 ng/ml). Die Bestimmung des Adiponectinspiegels erfolgte mittels des Human Adiponectin/Acrp 30 DRP 300 ELISA von R\&D Inc., Minneapolis (mittlere untere Nachweisgrenze 0,246 ng/ml).

Die Untersucher waren über den klinischen Verlauf der Patienten nicht informiert. Ebenso wenig wurden die behandelnden Ärzte der Patienten über die Ergebnisse der im Rahmen der Studie durchgeführten Labormessungen informiert.

\subsection{Bildgebende Verfahren der Lungenembolie-Diagnostik}

Alle Untersuchungen wurden im Rahmen der Routinediagnostik durchgeführt und nicht durch das Studienprotokoll beeinflusst.

Bei 48 Patienten (57,1\%) wurde die Lungenembolie durch eine Spiral-CT diagnostiziert. Die Untersuchungen wurden im Rahmen der Routinediagnostik in der Abteilung Diagnostische Radiologie am Universitätsklinikum Göttingen mit einem GE Lightspeed 16Zeiler-Computertomographen durchgeführt. Die Abbildung 2.1 zeigt eine typische 
Darstellung von Lungenembolien in der Computertomographie nach intravenöser Gabe von Kontrastmittel.

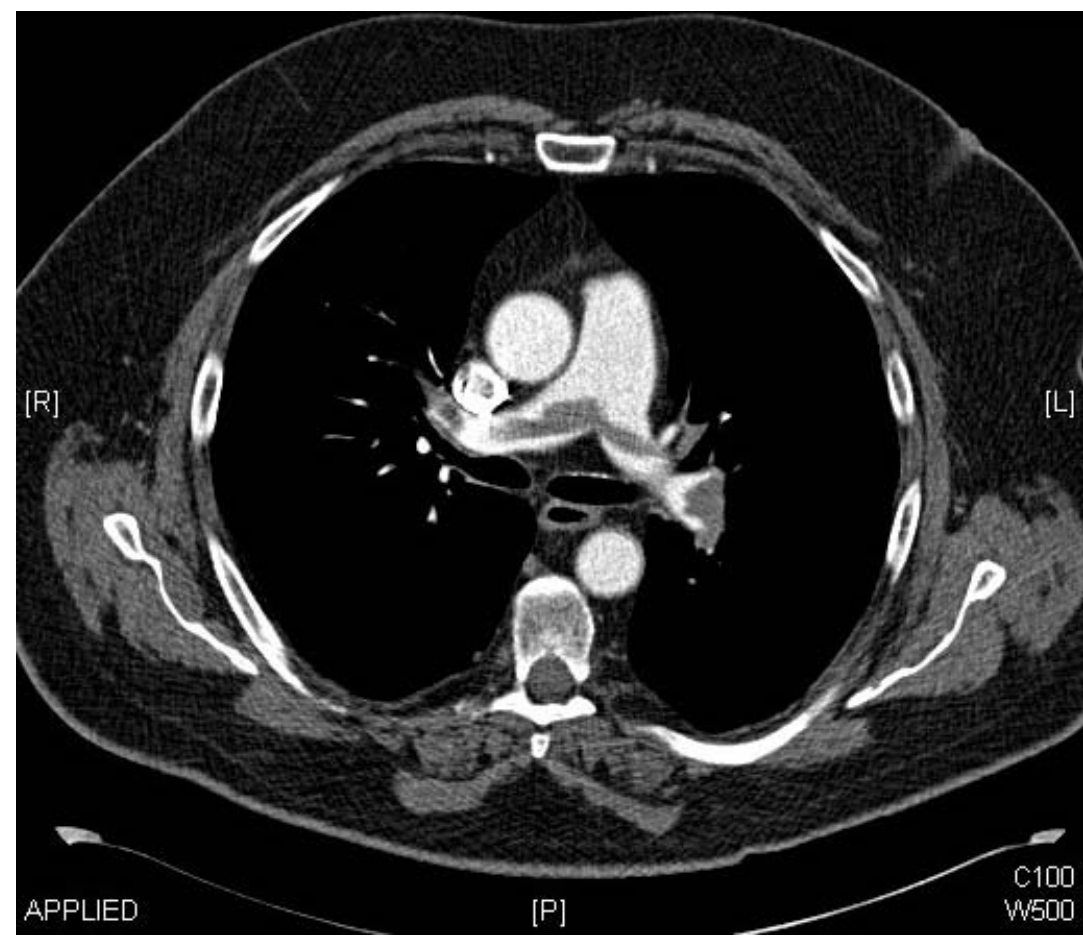

Abbildung 2.1: Spiral-CT des Thorax im Transversalschnitt: Lungenembolien im Truncus pulmonalis sowie der rechten und linken $\mathrm{A}$. pulmonalis.

Bei 38 Patienten (41,4\%) erfolgte der Nachweis einer Lungenembolie durch eine Szintigraphie, entweder als kombinierte Ventilations-/ Perfusionsszintigraphie oder als alleinige Perfusionsszintigraphie in Verbindung mit einem Röntgen-Thorax-Bild. Die Untersuchungen wurden in der Abteilung Nuklearmedizin am Universitätsklinikum Göttingen durchgeführt. Die Diagnose einer Lungenembolie wurde gestellt, wenn eines oder beide der folgenden Kriterien zutrafen (Miniati et al. 1999):

1. ein keilförmiger Defekt in der Perfusionsszintigraphie

2. ein „mismatch“, d.h. ein Missverhältnis zwischen gestörter Perfusion und erhaltener Ventilation.

Bei 4 Studienpatienten (4,1\%) wurde die Diagnose durch eine Pulmonalisangiographie gestellt.

Bei 6 Studienpatienten (6,2 \%), bei denen aufgrund einer hämodynamischen Instabilität kein anderes bildgebendes diagnostisches Verfahren durchgeführt werden konnte, erfolgte die 
Diagnose der Lungenembolie durch den Nachweis einer Rechtsherzbelastung in der Echokardiographie (wie in Kap 2.5 definiert). Bei einem Patienten (1,0\%) wurde die Lungenembolie durch den sonographischen Nachweis einer tiefen Venenthrombose im Ultraschall in Kombination mit einer Rechtsherzbelastung in der Echokardiographie gestellt. Alle Pulmonalisangiographien und Echokardiographien wurden in der Abteilung Kardiologie und Pneumologie am Universitätsklinikum Göttingen durchgeführt.

\subsection{Ergänzende Untersuchungen}

Ergänzend wurde die weiterführende Untersuchung zur Diagnose einer tiefen Venenthrombose (TVT) als Ursache der Lungenembolie erfasst.

Bei 54 Patienten (56,3\%) wurde eine Kompressionsultrasonographie der Beinvenen durchgeführt, welche das Standardverfahren zur Diagnose einer TVT darstellt. Eine Phlebographie wurde bei 27 Patienten (28,4\%), eine CT-Venographie der Beine bei 28 Patienten (28,8 \%) durchgeführt.

Da bei einigen Patienten auch mehrere der genannten Verfahren eingesetzt wurden, entspricht die Summe der relativen Häufigkeiten mehr als 100 \%, die Summe der absoluten Häufigkeiten mehr als $n=97$.

\subsection{Die Therapie von Patienten mit einer akuten Lungenembolie}

Die Therapie wurde nicht durch das Studienprotokoll vorgegeben, sondern lediglich dokumentiert (siehe Ergebnisse, Abschnitt 3.5).

\subsection{Die Endpunkte der Studie}

Als primärer klinischer Endpunkt wurde das Eintreten eines oder mehrerer der folgenden Ereignisse im Inhospital-Verlauf festgelegt:

1. Tod infolge der Lungenembolie

2. Reanimation

3. Intubation

4. Katecholamingabe

5. Hypotonie $\left(\mathrm{RR}_{\mathrm{sys}}<90 \mathrm{mmHg}\right)$. 
Als sekundärer klinischer Endpunkt wurde das Langzeit-Überleben nach einer akuten Lungenembolie definiert. Dieses wurde alle sechs Monate telefonisch beim Patienten oder dem Hausarzt erfragt und sollte über vier Jahre erfasst werden.

\subsection{Statistische Auswertung}

Nach Einschluss von 97 Patienten in die Fall- und 40 Patienten in die Kontrollgruppe erfolgte die statistische Auswertung unter Benutzung von Graph Pad Prism 4 (Graph Pad Software Inc.) und SPS Statistics 17.0 (SPS Inc.).

Kontinuierliche Variablen werden als Mittelwerte \pm 1 Standardabweichung beschrieben, in Tabellen werden zusätzlich Minimum und Maximum aufgeführt. Diskrete Variablen werden als absolute Häufigkeiten mit relativen Häufigkeiten in Klammern angegeben. Da für einige Patienten einzelne Informationen nicht vorlagen, kann die Gesamtzahl der Angaben von n = 97 für die Fallgruppe und n = 40 für die Kontrollgruppe abweichen, die entsprechende Häufigkeit ist jeweils angegeben.

Mit dem modifizierten Kolmogorov-Smirnov-Tests (Lilliefors-Test) wurden kontinuierliche Variablen auf ihre Normalverteilung untersucht. Alle untersuchten Biomarker waren nicht normalverteilt, sodass der Mann-Whitney-U-Test zur Untersuchung auf signifikante Unterschiede zwischen kontinuierlichen Variablen eingesetzt wurde. Der Vergleich von diskreten Variablen erfolgte durch den Fisher`s Exact-Test. In Klammern angegeben sind die Odds Ratio, der positiv-prädiktive-Wert (PPV) und der negativ-prädiktive-Wert (NPV), in einigen Fällen auch die Spezifität und Sensitivität. Zusammenhänge zwischen verschiedenen kontinuierlichen Variablen wurden mit der Summen-Korrelation nach Spearman untersucht.

Für kontinuierliche Variablen wurden durch ROC-Analysen Cut-Off-Werte bezüglich der prognostischen Bedeutung nach einer Lungenembolie ermittelt. Variablen, für die sich kein sinnvoller Cut-Off-Wert ergab, wurden in den weiteren Analysen als natürlicher Logarithmus eingegeben.

Die prognostische Aussagekraft verschiedener Variablen hinsichtlich der 30-TagesKomplikationsrate wurde anhand einer binär logistischen Regressionsanalyse untersucht.

Der prädiktive Wert verschiedener Variablen für das Langzeit-Überleben wurde mit der univariaten Cox-Regressionsanalyse getestet. 
Nachdem mittels univariater Regressionsanalysen signifikante Prädiktoren für die 30-TagesKomplikationen und das Langzeit-Überleben identifiziert worden waren, wurden diese in einem multivariaten Modell getestet.

Die Ergebnisse sind als Odds Ratio für die 30-Tages-Komplikationen und als Hazard Ratio für das Langzeit-Überleben aufgeführt und wurden mit dem Wald`s-Test verglichen.

Für Leptin und den BMI wurden die Überlebensraten in Tertilen analysiert und mit der Methode nach Kaplan-Meier bewertet, Vergleiche erfolgten mit dem Logrank-Test.

Bei allen durchgeführten Tests wurde beidseitig ein Signifikanzniveau von 0,05 verwendet.

Signifikante Unterschiede sind in Tabellen in Fettdruck hervorgehoben, in Graphiken mit Sternchen gemäß ihrem Signifikanzniveau gekennzeichnet (***= hoch signifikant, ** = signifikant, *= wenig signifikant). 


\section{Ergebnisse}

\subsection{Alter, Geschlecht und Body-Mass-Index (BMI) in der Fall- und der Kontrollgruppe}

Von 97 Patienten mit einer akuten Lungenembolie waren 31 Patienten männlich (32 \%) und 66 weiblich (68\%). Die Kontrollgruppe, welche 40 Patienten umfasste, setzte sich aus 18 männlichen (45\%) und 22 weiblichen (55\%) Patienten zusammen. Die Geschlechterverteilung der beiden Studiengruppen war somit nicht signifikant verschieden $(\mathrm{p}=0,172)$.

Das mittlere Alter lag in der Lungenemboliegruppe bei 62,4 $\pm 15,5$ Jahren, in der Kontrollgruppe bei 58,6 \pm 10,9 Jahren. Dieser Unterschied war statistisch (knapp) nicht signifikant $(\mathrm{p}=0,051)$.

Der mittlere BMI lag in der Fallgruppe bei $28,4 \pm 5,9 \mathrm{~kg} / \mathrm{m}^{2}$, bei den Patienten der Kontrollgruppe bei $26,8 \pm 4,9 \mathrm{~kg} / \mathrm{m}^{2}$, womit sich kein signifikanter Unterschied ergab $(p=0,250)$.

\section{Tabelle 3.1: Basisdaten}

\begin{tabular}{|llll|}
\hline Befund & $\begin{array}{l}\text { Studiengruppe } \\
\mathrm{n}=97\end{array}$ & $\begin{array}{l}\text { Kontrollgruppe } \\
\mathrm{n}=40\end{array}$ & p-Wert \\
\hline Geschlecht $(\circlearrowleft / 9)$ & $31 / 66$ & $18 / 22$ & 0,172 \\
Alter (Jahre) & $62,4 \pm 15,5$ & $58,6 \pm 10,9$ & 0,051 \\
& $(20,0-88,0)$ & $(34,0-81,0)$ & \\
BMI $\left(\mathrm{kg} / \mathrm{m}^{2}\right)$ & $28,4 \pm 5,9$ & $26,8 \pm 4,9$ & 0,250 \\
& $(17,9-52,7)$ & $(16,0-37,7)$ & \\
\hline
\end{tabular}

\subsection{Vorerkrankungen in der Fall- und der Kontrollgruppe}

Die Häufigkeit des Auftretens folgender Erkrankungen unterschied sich nicht beim Vergleich der Fall- und der Kontrollgruppe: arterieller Hypertonus, Diabetes mellitus, Herzinsuffizienz, COPD und Z.n. Apoplex cerebri (siehe Tabelle 3.2). 
An einer malignen Tumorerkrankung litten 17 Patienten mit Lungenembolie, jedoch kein Patient in der Kontrollgruppe $(p=0,041)$, womit die Lungenemboliepatienten signifikant häufiger an einer malignen Tumorerkrankung erkrankt waren (siehe Tabelle 3.2).

\section{Tabelle 3.2: Vorerkrankungen}

\begin{tabular}{|llll|}
\hline Befund & $\begin{array}{l}\text { Studiengruppe } \\
\mathrm{n}(\%)\end{array}$ & $\begin{array}{l}\text { Kontrollgruppe } \\
\mathrm{n}(\%)\end{array}$ & p-Wert \\
\hline art. Hypertonus & $53 / 95(55,8)$ & $24 / 39(61,5)$ & 0,570 \\
COPD & $16 / 97(16,5)$ & $2 / 19(10,5)$ & 0,733 \\
Diabetes mellitus & $17 / 95(17,9)$ & $2 / 39(5,1)$ & 0,060 \\
Z.n. Apoplex & $7 / 97(7,2)$ & $2 / 19(8,8)$ & 0,640 \\
Herzinsuffizienz & $10 / 92(10,9)$ & $3 / 34(8,8)$ & 1,000 \\
Malignom & $17 / 97(17,5)$ & $0 / 20(0,0)$ & $\mathbf{0 , 0 4 1}$ \\
\hline
\end{tabular}

\subsection{Fallgruppe}

\subsubsection{Klinische Symptomatik der Lungenemboliepatienten bei Aufnahme}

Das häufigste Symptom bei Patienten mit einer Lungenembolie war die Dyspnoe, die 89 Patienten angaben, 43 Patienten klagten über Thoraxschmerzen. Eine Synkope trat bei 23 Patienten auf, ein Patient berichtete von Hämoptysen, siehe auch Tabelle 3.3. Bei 57 Patienten war die Symptomatik innerhalb von 24 Stunden aufgetreten, 14 Patienten klagten schon seit bis zu vier Tagen über Beschwerden, bei einem Patient ließ sich der Symptombeginn nicht eruieren.

\section{Tabelle 3.3: Symptome bei Aufnahme}

\begin{tabular}{|ll|}
\hline Symptom & $\begin{array}{l}\text { Studiengruppe } \\
\mathrm{n}(\%)\end{array}$ \\
\hline Dyspnoe & $89 / 97(91,8)$ \\
thorakale Schmerzen & $43 / 92(46,7)$ \\
Synkope & $23 / 97(23,7)$ \\
Hämoptysen & $1 / 95(1,1)$ \\
\hline
\end{tabular}




\subsubsection{Aufnahme-EKG der Lungenemboliepatienten}

Bei allen Fallgruppenpatienten wurde bei Aufnahme ein 12-Kanal-EKG im Rahmen der Routinediagnostik abgeleitet. Eine tachykarde Herzfrequenz (HF $\geq 100 / \mathrm{min}$ ) zeigte sich bei 39 Patienten, bei 23 Patienten traten T-Negativierungen in den Ableitungen V1-V3 auf. Ein $\mathrm{S}_{\mathrm{I}} \mathrm{Q}_{\mathrm{III}}$-Typ zeigte sich bei 24 Patienten, 11 Patienten wiesen einen neu aufgetretenen inkompletten oder kompletten Rechtsschenkelblock auf.

\section{Tabelle 3.4: EKG bei Aufnahme}

\begin{tabular}{|ll|}
\hline EKG-Veränderung & $\begin{array}{l}\text { Studiengruppe } \\
\mathrm{n}(\%)\end{array}$ \\
\hline Tachykardie & $39 / 97(40,2)$ \\
T-Negativierung in V1-V3 & $23 / 97(23,7)$ \\
S $Q_{\text {III-Typ }}$ & $24 / 97(24,7)$ \\
kompletter oder inkompletter Rechtsschenkelblock & $11 / 97(11,3)$ \\
\hline
\end{tabular}

\subsubsection{Risikofaktoren für das Auftreten einer Lungenembolie}

In der Fallgruppe berichteten 31 Patienten über eine venöse Thromboembolie in der Vergangenheit (Z.n. TVT bei 30 und/oder Z.n. LE bei 18 Patienten), 17 Patienten litten an einer malignen Tumorerkrankung. Bei 19 Patienten trat die Lungenembolie postoperativ auf, 7 Patienten berichteten von einem vorausgegangenen Trauma, bei 30 Patienten ging der Lungenembolie eine längere Immobilisation (> 3 Tage) voraus. Orale Kontrazeptiva wurden von 9 Patientinnen eingenommen, eine Patientin war schwanger. 
Tabelle 3.5: Risikofaktoren

\begin{tabular}{|ll|}
\hline Risikofaktor & $\begin{array}{l}\text { Studiengruppe } \\
\mathrm{n}(\%)\end{array}$ \\
\hline Z.n TVT & $30 / 97(30,9)$ \\
Z.n. LE & $18 / 97(18,6)$ \\
Malignom & $17 / 97(17,5)$ \\
Z.n. Operation & $19 / 97(19,6)$ \\
Z.n. Trauma & $7 / 97(7,2)$ \\
Immobilisation & $30 / 87(34,5)$ \\
orale Kontrazeptiva & $10 / 95(10,5)$ \\
Schwangerschaft & $1 / 97(1,0)$ \\
\hline
\end{tabular}

\subsubsection{Inhospital-Komplikationen bei Patienten mit einer akuten Lungenembolie}

Bei 12 Patienten (12,4 \%) trat ein Ereignis während des Krankenhausaufenthalts ein, das als primärer Endpunkt definiert war (Tod infolge einer Lungenembolie, Reanimation, Intubation, Katecholamingabe, Hypotonie). Insgesamt verstarben 6 Patienten an den Folgen der Lungenembolie (6,2 \%). Eine Reanimation war bei 6 Patienten notwendig, 9 Patienten mussten mit Katecholaminen behandelt werden und 9 Patienten intubiert werden, 5 Patienten waren bei Aufnahme hypoton (siehe Tabelle 3.6).

\section{Tabelle 3.6: Inhospital-Komplikationen}

\begin{tabular}{|lc|}
\hline Komplikation & $\begin{array}{l}\text { Studiengruppe } \\
\mathrm{n}(\%)\end{array}$ \\
\hline Hypotonie & $5 / 97(5,2)$ \\
Reanimation & $6 / 97(6,2)$ \\
Katecholamine & $9 / 97(9,3)$ \\
Intubation & $9 / 97(9,3)$ \\
Tod an einer LE & $6 / 97(6,2)$ \\
\hline
\end{tabular}




\subsection{Die Echokardiographie bei Patienten mit einer akuten Lungenembolie}

Eine Echokardiographie wurde bei 88 Lungenemboliepatienten (90,7\%) im Rahmen der Routinediagnostik durchgeführt. Bei 6 Patienten war die Echokardiographie aufgrund der instabilen Kreislaufsituation auch das einzige angewendete bildgebende Verfahren. Bei einem Patient wurde eine Lungenembolie bei Rechtsherzbelastungszeichen in der Echokardiographie in Kombination mit dem Nachweis einer tiefen Venenthrombose in der Sonographie diagnostiziert.

Die Echokardiographie wurde bei 81 Patienten zur Risikostratifikation eingesetzt, aufgrund eingeschränkter Untersuchungsbedingungen war bei 8 dieser Patienten (9,1\%) kein Befund zu erheben. Zeichen der akuten Rechtsherzbelastung wurden bei 34 Patienten (42,5 \%) mit einer akuten Lungenembolie nachgewiesen.

\subsection{Die Therapie bei Patienten mit einer akuten Lungenembolie}

Eine Therapie mit niedermolekularem oder unfraktioniertem Heparin erhielten 96 Patienten, bei einem Patienten erfolgte eine Thrombolysetherapie ohne vorherige Heparingabe. Insgesamt erhielten 14 Patienten eine Thrombolyse, eine operative Thrombolektomie wurde bei 3 Patienten durchgeführt, bei 2 Patienten wurde ein Vena-cava-Filter zum Schutz vor Rezidiv-Embolien implantiert.

\section{Tabelle 3.7: Therapie}

\begin{tabular}{|ll|}
\hline Befund & $\begin{array}{l}\text { Studiengruppe } \\
\mathrm{n}(\%)\end{array}$ \\
\hline Heparin & $96 / 97(99,0)$ \\
Thrombolyse & $14 / 97(14,4)$ \\
operative Thrombolektomie & $3 / 97(3,1)$ \\
Vena-cava-Filter & $2 / 97(2,1)$ \\
\hline
\end{tabular}




\subsection{Basale Labordiagnostik}

Im Vergleich mit der Kontrollgruppe war in der Lungenemboliegruppe der mittlere DDimer-Wert $(p<0,0001)$ signifikant höher. Außerdem wiesen die Lungenemboliepatienten eine signifikant verminderte mittlere GFR im Vergleich zur Kontrollgruppe auf ( $p=0,011)$. Weitere im Rahmen der Basisdiagnostik erhobene Laborwerte sind der Tabelle $3.8 \mathrm{zu}$ entnehmen.

\section{Tabelle 3.8: Labordiagnostik bei Aufnahme}

\begin{tabular}{|llll|}
\hline Parameter & Studiengruppe & Kontrollgruppe & p-Wert \\
\hline D-Dimere $(\mathrm{ng} / \mathrm{ml})$ & $11,93 \pm 33,49$ & $0,31 \pm 0,28$ & $<\mathbf{0 , 0 0 0 1}$ \\
& $(0,28-261,00)$ & $(0,03-1,35)$ & \\
GFR (ml/min) & $71,9 \pm 27,41$ & $83,99 \pm 20,25$ & $\mathbf{0 , 0 1 1}$ \\
& $(13,3-145,1)$ & $(51,7-147.6)$ & \\
Hämoglobin $(\mathrm{mg} / \mathrm{dl})$ & $13,39 \pm 1,81$ & & \\
& $(9,50-17,30)$ & & \\
CRP $(\mathrm{mg} / \mathrm{l})$ & $91,86 \pm 90,44$ & & \\
& $(1,90-449,60)$ & & \\
Leukozyten/ $\mu \mathrm{l}$ & $10.560 \pm 4.741$ & & \\
& $(2.900-29.600)$ & & \\
& $247.000 \pm 108.100$ & & \\
Thrombozyten/ $\mu \mathrm{l}$ & $(33.000-839.000)$ & \\
\end{tabular}

\subsection{Spezielle Labordiagnostik}

Um den Zusammenhang zwischen dem BMI und den Parametern Leptin, sobR, FLI und Adiponectin zu untersuchen, wurden die Patienten mit einer Lungenembolie in drei Gruppen von normalgewichtigen (BMI $<25 \mathrm{~kg} / \mathrm{m}^{2}, \mathrm{n}=27$ ), übergewichtigen (BMI 25$\left.29,9 \mathrm{~kg} / \mathrm{m}^{2}, \mathrm{n}=42\right)$ und adipösen Patienten (BMI $\left.>29,9 \mathrm{~kg} / \mathrm{m}^{2}, \mathrm{n}=28\right)$ eingeteilt. Auch in der Kontrollgruppe wurden die Patienten in normalgewichtige $(n=14)$, übergewichtige ( $\mathrm{n}=16)$ und adipöse Patienten $(\mathrm{n}=10)$ unterteilt. 


\subsubsection{Der Leptinspiegel in der Fall- und der Kontrollgruppe}

Der mittlere Leptinspiegel lag in der Lungenembolie-Gruppe bei 26,37 \pm 39,54 ng/ml, in der Kontrollgruppe bei 20,32 $\pm 25,84 \mathrm{ng} / \mathrm{ml}$, womit sich kein signifikanter Unterschied ergab $(\mathrm{p}=0,497)$.

Nachfolgend werden bei Patienten der Fallgruppe die Leptinspiegel in verschiedenen Subgruppen analysiert und miteinander verglichen.

Weibliche Patienten hatten signifikant höhere Leptinspiegel als männliche Patienten (33,88 $\pm 45,77$ ng/ml vs. 10,37 \pm 8,62 ng/ml, p < 0,0001), siehe Abbildung 3.1.

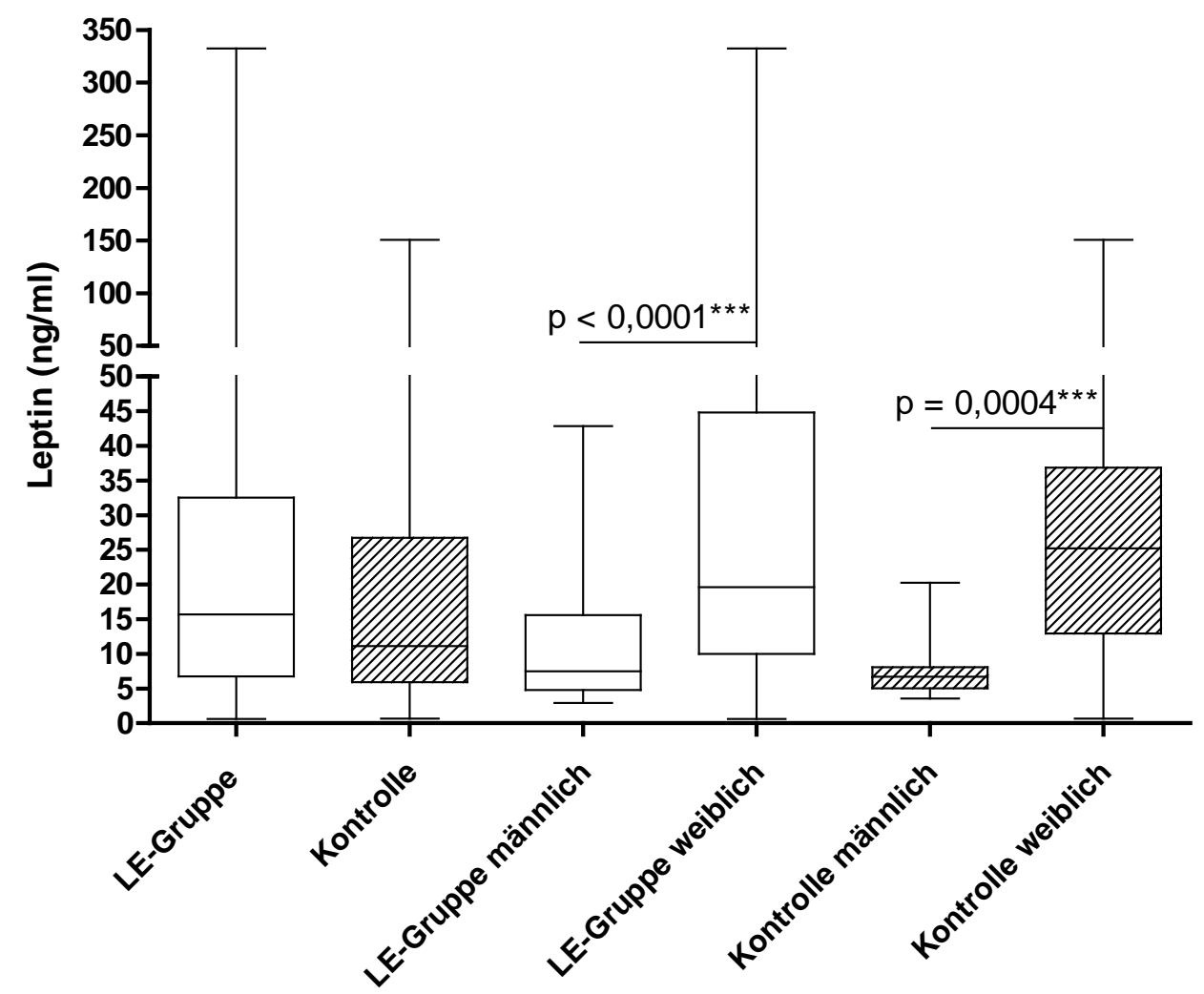

Abbildung 3.1: Der Leptinspiegel bei allen Patienten der Fall- und der Kontrollgruppe sowie unterteilt nach Geschlecht. Zur besseren Darstellung der Leptinkonzentrationen im unteren Bereich ist die Ordinate in zwei Segmente mit verschiedenen Skalierungen unterteilt.

Adipöse Patienten hatten signifikant höhere Leptinwerte als übergewichtige und normalgewichtige Patienten $\quad(50,25 \pm 60,69 \mathrm{ng} / \mathrm{ml} \quad$ vs. $19,48 \pm 21,94 \mathrm{ng} / \mathrm{ml} \quad$ vs $11,25 \pm 11,08 \mathrm{ng} / \mathrm{ml}$, adipös vs. übergewichtig: $\mathrm{p}<0,0001$, adipös vs. normalgewichtig: $\mathrm{p}<0,0001$ ). Der Leptinspiegel zwischen übergewichtigen und normalgewichtigen Lungenemboliepatienten hingegen unterschied sich nicht signifikant $(p=0,063)$. 
In der Fallgruppe korrelierte der Leptinspiegel mit dem BMI ( $p<0,0001, r=0,561)$, eine Korrelation mit dem Alter zeigte sich nicht $(\mathrm{p}=0,813)$.

Wie in Tabelle 3.9 dargestellt unterschied sich der Leptinspiegel nicht signifikant beim Vergleich von Patienten mit/ohne vorausgegangene Thromboembolie, mit/ohne Risikofaktoren (frühere Thromboembolie, vorausgegangene Immobilisation, Trauma oder Operation, Malignom, Schwangerschaft und Flugreise), mit/ohne Rechtsherzbelastung.

\section{Tabelle 3.9: Leptinspiegel in der Lungenemboliegruppe}

\begin{tabular}{|llll|}
\hline & $\begin{array}{l}\text { Ereignis ja } \\
\mathrm{ng} / \mathrm{ml}\end{array}$ & $\begin{array}{l}\text { Ereignis nein } \\
\mathrm{ng} / \mathrm{ml}\end{array}$ & p-Wert \\
\hline Z.n. TVT/LE & $35,34 \pm 60,18$ & $22,38 \pm 24,21$ & 0,243 \\
& $(0,89-332,40)$ & $(0,63-112,30)$ & \\
Risikofaktoren & $28,42 \pm 45,12$ & $21,70 \pm 24,32$ & 0,384 \\
& $(0,89-332,40)$ & $(0,63-100,60)$ & \\
Rechtsherzbelastung & $25,36 \pm 25,04$ & $24,99 \pm 45,72$ & 0,330 \\
& $(0,63-108,60)$ & $(0,89-332,40)$ & \\
\hline
\end{tabular}

Nachfolgend wird bei Patienten der Kontrollgruppe der Leptinspiegel in verschiedenen Subgruppen analysiert und verglichen:

Frauen hatten hier signifikant höhere Leptinwerte als Männer (30,64 $\pm 31,27 \mathrm{ng} / \mathrm{ml}$ vs. 7,71 $\pm 4,25 \mathrm{ng} / \mathrm{ml}, \mathrm{p}=0,0004$ ), siehe Abbildung 3.1.

Adipöse Patienten wiesen signifikant höhere Leptinspiegel als übergewichtige sowie normalgewichtige Patienten auf, übergewichtige Patienten hatten höhere Leptinwerte als normalgewichtige Patienten $(43,89 \pm 40,29 \mathrm{ng} / \mathrm{ml}$ vs. $14,02 \pm 10,13 \mathrm{ng} / \mathrm{ml}$ vs. 9,98 $\pm 13,43$ ng/ml, adipös vs. übergewichtig: $p=0,002$, adipös vs. normalgewichtig: $p=0,0006$, übergewichtig vs. normalgewichtig: $\mathrm{p}=0,043$ ).

In der Kontrollgruppe korrelierte der Leptinspiegel mit dem BMI ( $p=0,0002, r=0,559)$, jedoch nicht mit dem Alter $(\mathrm{p}=0,439)$ 


\subsubsection{Der Lösliche Leptinrezeptor-Spiegel (sobR-Spiegel) in der Fall- und der Kontrollgruppe}

Der sobR-Wert zwischen der Fall- und der Kontrollgruppe unterschied sich nicht signifikant (28,98 $\pm 11,89$ ng/ml vs. 27,77 $\pm 7,28, \mathrm{p}=0,978)$.

Nachfolgend werden die sobR-Werte der Fallgruppenpatienten in Subgruppen analysiert und verglichen:

Die sobR-Werte bei Frauen und Männern unterschieden sich nicht signifikant (30,43 $\pm 12,93 \mathrm{ng} / \mathrm{ml}$ vs. 5,88 \pm 8,69 ng/ml, p = 0,058).

Normalgewichtige Patienten hatten signifikant höhere sobR-Werte als übergewichtige und adipöse Patienten, zwischen übergewichtigen und adipösen Patienten bestand kein signifikanter Unterschied $(35,40 \pm 16,75 \mathrm{ng} / \mathrm{ml}$ vs. $26,79 \pm 9,12 \mathrm{ng} / \mathrm{ml}$ vs. 25,85 \pm $8,82 \mathrm{ng} / \mathrm{ml}$, normalgewichtig vs. übergewichtig: $\mathrm{p}=0,006$, normalgewichtig vs. adipös: $\mathrm{p}=$ 0,007, übergewichtig vs. adipös: $\mathrm{p}=0,828$ ).

Es zeigte sich eine inverse Korrelation zwischen dem sobR und dem BMI $(p<0,008$, $r=0,277)$, jedoch keine Korrelation zwischen dem sobR und dem Alter ( $p=0,871)$.

Der sobR-Spiegel unterschied sich nicht signifikant beim Vergleich von Patienten mit/ohne vorausgegangene venöse Thromboembolie, mit/ohne Lungenembolie-Risikofaktoren, mit/ohne Rechtherzbelastung, siehe Tabelle 3.10.

Tabelle 3.10: sobR-Werte in der Lungenemboliegruppe

\begin{tabular}{|llll|}
\hline & $\begin{array}{l}\text { Ereignis ja } \\
\mathrm{ng} / \mathrm{ml}\end{array}$ & $\begin{array}{l}\text { Ereignis nein } \\
\mathrm{ng} / \mathrm{ml}\end{array}$ & p-Wert \\
\hline Z.n. TVT/LE & $27,30 \pm 9,16$ & $29,96 \pm 12,97$ & 0,273 \\
& $(13,94-47,82)$ & $(11,50-100,10)$ & \\
Risikofaktoren & $29,10 \pm 13,08$ & $29,19 \pm 10,41$ & 0,751 \\
& $(11,50-100,10)$ & $(16,59-59,40)$ & \\
Rechtsherzbelastung & $31,13 \pm 15,76$ & $28,11 \pm 9,20$ & 0,529 \\
& $(16,59-100,10)$ & $(13,94-50,68)$ & \\
\hline
\end{tabular}


Im Folgenden werden die sobR-Werte der Kontrollgruppe in Subgruppen analysiert und verglichen.

Es bestand kein signifikanter Unterschied beim Vergleich der sobR-Spiegel von Frauen und Männern (28,44 \pm 7,59 ng/ml vs. 26,94 \pm 7,02 ng/ml, p = 0,335).

Normalgewichtige Patienten hatten signifikant höhere sobR-Werte als adipöse Patienten, kein signifikanter Unterschied ergab sich zwischen übergewichtigen und adipösen Patienten sowie zwischen normal und übergewichtigen Patienten $(30,86 \pm 7,14 \mathrm{ng} / \mathrm{ml}$ vs. $27,18 \pm 7,29 \mathrm{ng} / \mathrm{ml}$ vs. $23,98 \pm 6,41 \mathrm{ng} / \mathrm{ml}$, normalgewichtig vs. adipös: $\mathrm{p}=0,024$, normalgewichtig vs. übergewichtig: $p=0,121$, übergewichtig vs. adipös: $p=0,174$ ).

Auch in der Kontrollgruppe korrelierte der sobR-Spiegel invers mit dem BMI ( $p=0,010$, $r=0,410)$, jedoch nicht mit dem Alter $(p=0,626)$.

\subsubsection{Der Free-Leptin-Index (FLI) in der Fall- und der Kontrollgruppe}

Beim Vergleich des FLI, also dem Quotienten aus Leptin- und sobR-Spiegel als Maß für das freie und biologisch aktive Leptin, zwischen der Fallgruppe und der Kontrollgruppe zeigte sich kein signifikanter Unterschied $(1,00 \pm 1,34$ vs. $0,83 \pm 1,19$, $p=0,483)$.

Nachfolgend wird der FLI von Patienten der Fallgruppe in verschiedenen Subgruppen analysiert und verglichen:

Frauen hatten einen signifikant höheren FLI als Männer (1,25 $\pm 1,54$ vs. 0,47 $\pm 0,45(0,08$ 2,10, $\mathrm{p}=0,001$ ), siehe Abbildung 3.2. 


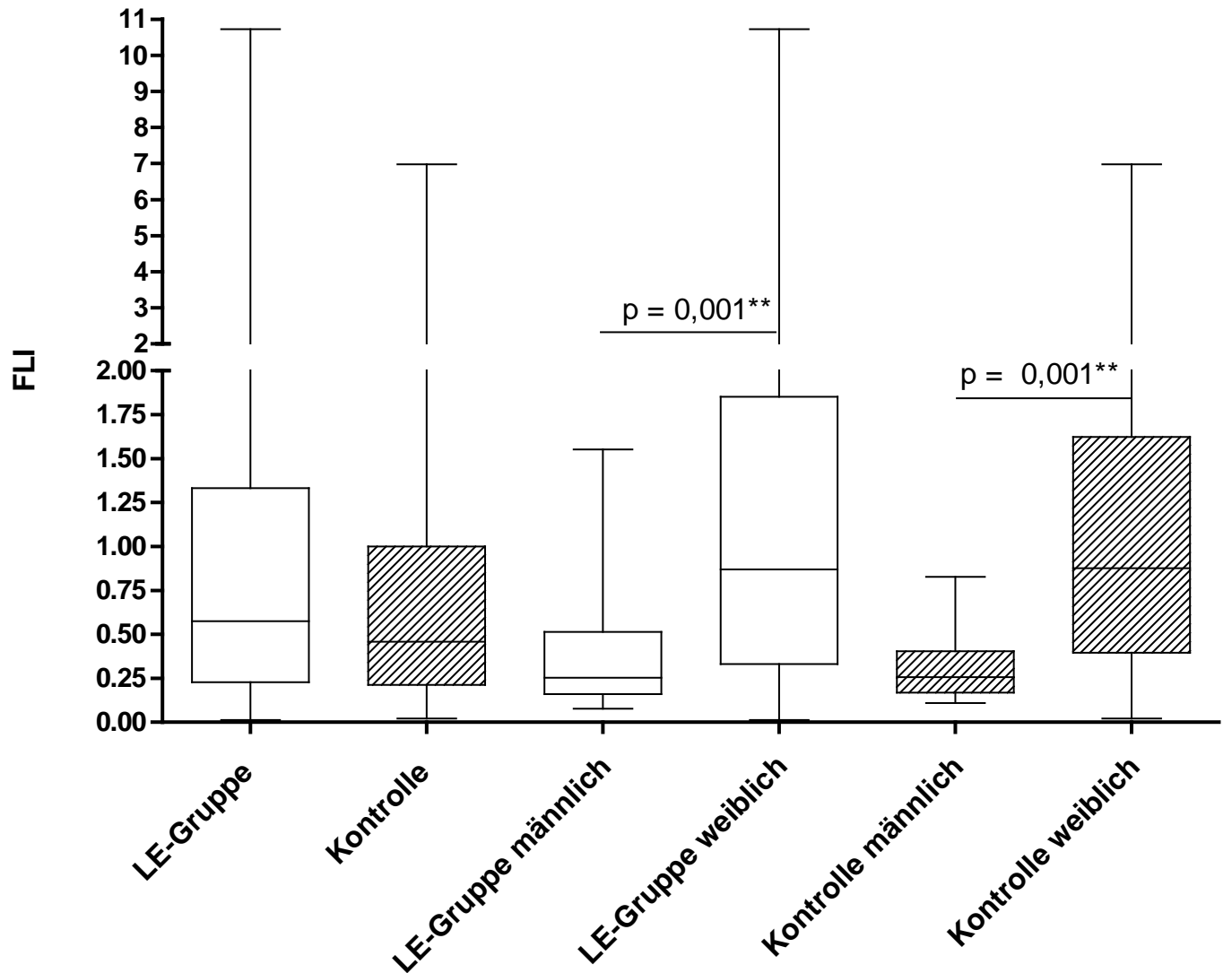

Abbildung 3.2: Darstellung der FLI von allen Patienten der Fall- und der Kontrollgruppe sowie unterteilt nach Geschlecht. Zur besseren Darstellung der Unterschiede der FLI im unteren Bereich ist die Ordinate in zwei Segmente mit verschiedenen Skalierungen unterteilt.

Adipöse Patienten hatten signifikant höhere FLI als übergewichtige und normalgewichtige Patienten, übergewichtige Patienten hatten signifikant höhere FLI als normalgewichtige Patienten (1,92 $\pm 1,97$ vs. $0,77 \pm 0,77$ vs. $0,40 \pm 0,42$, adipös vs. übergewichtig: $p<0,0001$, adipös vs. normalgewichtig: $p<0,0001$, übergewichtig vs. normalgewichtig: $p=0,015$ ). Der FLI korrelierte mit dem BMI $(\mathrm{p}<0,0001, \mathrm{r}=0,594)$, eine Korrelation mit dem Alter zeigte sich nicht $(\mathrm{p}=0,755)$.

Der FLI unterschied sich nicht signifikant bei Patienten mit/ohne vorausgegangene Thromboembolie, mit/ohne Risikofaktoren, mit/ohne Rechtsherzbelastung, siehe Tabelle 3.11 . 
Tabelle 3.11: FLI in der Lungenemboliegruppe

\begin{tabular}{|llll|}
\hline & Ereignis ja & Ereignis nein & p-Wert \\
\hline Z.n. TVT/LE & $1,39 \pm 1,99$ & $0,82 \pm 0,86$ & 0,145 \\
& $(0,02-10,73)$ & $(0,01-4,29)$ & \\
Risikofaktoren & $1,07 \pm 1,47$ & $0,82 \pm 0,96$ & 0,312 \\
& $(0,02-10,73)$ & $(0,01-4,29)$ & \\
Rechtsherzbelastung & $0,93 \pm 0,85$ & $0,98 \pm 1,56$ & 0,486 \\
& $(0,01-3,55$ & $(0,02-10,73)$ & \\
\hline
\end{tabular}

Nachfolgend wird der FLI in der Kontrollgruppe analysiert und in verschiedenen Subgruppen verglichen.

Frauen hatten einen signifikant höheren FLI als Männer (1,25 $\pm 1,48$ vs. 0,31 $\pm 0,19$, $\mathrm{p}=0,001$ ), siehe Abbildung 3.2.

Der FLI bei adipösen Patienten war signifikant höher als bei übergewichtigen und normalgewichtigen Patienten, übergewichtige Patienten wiesen einen signifikant höheren FLI auf als normalgewichtige Patienten (1,95 $\pm 1,90$ vs. $0,57 \pm 0,55$ vs. $0,30 \pm 0,33$, adipös vs. übergewichtig: $p=0,002$, adipös vs. normalgewichtig: $p=0,0003$, übergewichtig vs. normalgewichtig: $\mathrm{p}=0,038$ ).

Der FLI zeigte eine signifikante Korrelation mit dem BMI $(p<0,0001, r=0,590)$, kein signifikanter Zusammenhang bestand mit dem Alter $(\mathrm{p}=0,479)$.

\subsubsection{Der Adiponectinspiegel in der Fall- und der Kontrollgruppe}

Patienten mit einer akuten Lungenembolie hatten signifikant höhere Adiponectinwerte als Patienten in der Kontrollgruppe $(11,74 \pm 12,98 \mu \mathrm{g} / \mathrm{ml}$ vs. $7,04 \pm 3,54 \mu \mathrm{g} / \mathrm{ml}, \mathrm{p}=0,034)$, siehe Abbildung 3.3.

Nachfolgend werden die Adiponectinwerte in verschiedenen Subgruppen der Fallgruppe analysiert und verglichen:

Frauen hatten signifikant höhere Adiponectinwerte als Männer $(14,55 \pm 14,91 \mu \mathrm{g} / \mathrm{ml}$ vs. 6,10 $\pm 3,96 \mu \mathrm{g} / \mathrm{ml}, \mathrm{p}<0,0001)$, siehe Abbildung 3.3. 


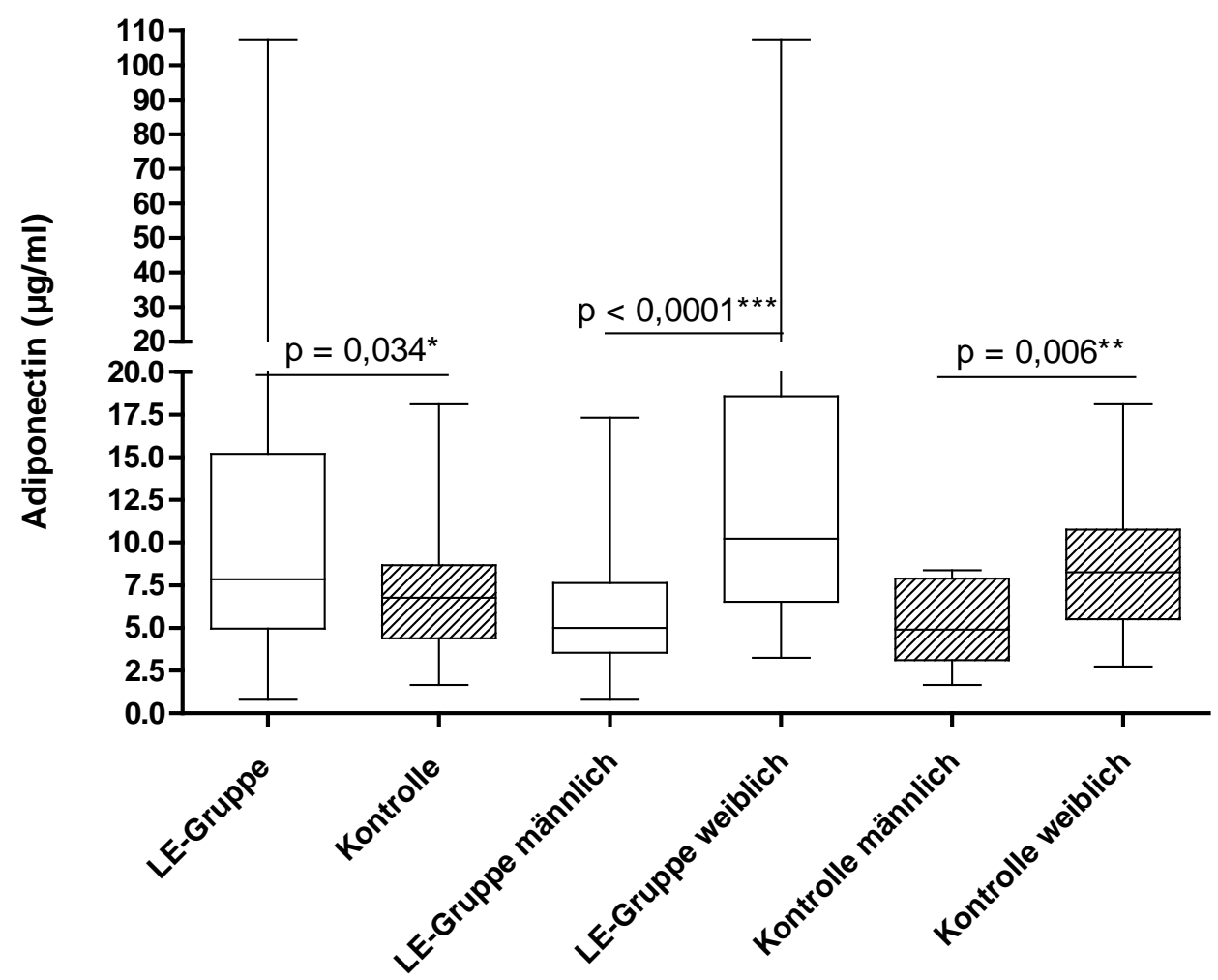

Abbildung 3.3: Darstellung der Adiponectinspiegel aller Patienten in der Fall- und der Kontrollgruppe sowie unterteilt nach Geschlecht. Zur besseren Darstellung der Adiponectinkonzentrationen im unteren Bereich ist die Ordinate in zwei Segmente mit verschiedenen Skalierungen unterteilt.

Normalgewichtige Patienten hatten signifikant höhere Adiponectinspiegel als adipöse Patienten, keine signifikanten Unterschiede bestanden zwischen normalgewichtigen und übergewichtigen Patienten sowie zwischen übergewichtigen und adipösen Patienten $(17,20 \pm 21,01 \mu \mathrm{g} / \mathrm{ml}$ vs. $10,21 \pm 8,23 \mu \mathrm{g} / \mathrm{ml}$ vs. $8,10 \pm 5,20 \mu \mathrm{g} / \mathrm{ml}$, normalgewichtig vs. adipös: $\mathrm{p}=0,031$, normalgewichtig vs. übergewichtig: $\mathrm{p}=0,110$, übergewichtig vs. adipös: $\mathrm{p}=0,416)$.

Der Adiponectinspiegel zeigte sowohl mit dem BMI $(\mathrm{p}<0,011, \mathrm{r}=0,276)$ als auch mit dem Alter ( $p<0,0001, r=0,032)$ eine signifikante Korrelation.

Keine signifikanten Unterschiede zeigten sich beim Vergleich von Patienten mit/ ohne vorausgegangene Thromboembolie, mit/ ohne Risikofaktoren, mit/ ohne Rechtsherzbelastung, siehe Tabelle 3.12. 
Tabelle 3.12: Adiponectinspiegel in der Lungenemboliegruppe

\begin{tabular}{|llll|}
\hline & $\begin{array}{l}\text { Ereignis ja } \\
\mu \mathrm{g} / \mathrm{ml}\end{array}$ & $\begin{array}{l}\text { Ereignis nein } \\
\mu \mathrm{g} / \mathrm{ml}\end{array}$ & p-Wert \\
\hline Z.n. TVT/LE & $14,54 \pm 21,29$ & $10,83 \pm 8,16$ & 0,967 \\
& $(2,28-107,40)$ & $(0,80-44,77)$ & \\
Risikofaktoren & $11,69 \pm 15,20$ & $10,89 \pm 7,251$ & 0,419 \\
& $(0,180-107,40)$ & $(2,31-28,79)$ & \\
Rechtsherzbelastung & $11,94 \pm 7,72$ & $12,51 \pm 16,15$ & 0,398 \\
& $(2,28-28,79)$ & $(2,14-107,40)$ & \\
\hline
\end{tabular}

Nachfolgend werden die Adiponectinwerte der Kontrollgruppenpatienten in verschiedenen Untergruppen analysiert und verglichen:

Weibliche Patienten hatten signifikant höhere Adiponectinspiegel als männliche Patienten (8,44 \pm 3,81 $\mu \mathrm{g} / \mathrm{ml}$ vs. 5,33 $\pm 2,27 \mu \mathrm{g} / \mathrm{ml}, \mathrm{p}=0,006)$, siehe Abbildung 3.3.

Keine signifikanten Unterschiede zeigten sich zwischen normalgewichtigen, übergewichtigen und adipösen Patienten $(7,90 \pm 4,75 \mu \mathrm{g} / \mathrm{ml}$ vs. 6,06 $\pm 2,24 \mu \mathrm{g} / \mathrm{ml}$ vs. $7,15 \pm 3,28 \mu \mathrm{g} / \mathrm{ml}$, normalgewichtig vs. übergewichtig: $\mathrm{p}=0,420$, normalgewichtig vs. adipös: $\mathrm{p}=0,792$, übergewichtig vs. adipös: $\mathrm{p}=0,454)$.

Weder mit dem BMI $(p=0,423)$ noch mit dem Alter $(p=0,111)$ zeigte sich eine signifikante Korrelation.

\subsubsection{Zusammenhang zwischen Leptin, sobR, Adiponectin und den kardialen Biomarkern}

In der Fallgruppe zeigte sich keine Korrelation von Leptin mit dem sobR $(p=0,151)$, Adiponectin ( $p=0,870)$, Troponin T $(p=0,628)$ und NT-pro BNP $(p=0,501)$.

Bei Patienten mit einer Lungenembolie korrelierte Adiponectin mit NT-pro BNP $(p=0,0004, r=0,366)$. Eine Korrelation zwischen Adiponectin und Troponin $\mathrm{T}$ bestand nicht $(\mathrm{p}=0,681)$.

In der Kontrollgruppe zeigte sich keine Korrelation zwischen Leptin und dem sobR $(p=0,295)$ sowie Leptin und Adiponectin $(p=0,517)$. 


\subsection{Parameter mit prognostischer Bedeutung für den Inhospital- Verlauf nach einer akuten Lungenembolie}

\subsubsection{Zusammenhang zwischen klinischen Parametern und dem Echokardiographiebefund mit dem Auftreten von Komplikationen}

Von 23 Patienten mit einer Synkope traten bei 8 Patienten Komplikationen auf (34,8 \%), jedoch nur bei 4 von 74 Patienten ohne Synkope (5,4 \%, p = 0,001, OR = 9,33, PPV = 0,35, NPV = 0,95). Patienten, die mit einer Synkope zur Aufnahme kamen, waren somit während des Klinikaufenthaltes signifikant häufiger von Komplikationen betroffen.

Von 34 Patienten mit Zeichen der Rechtsherzbelastung in der Echokardiographie traten bei 9 Patienten Komplikationen auf (26,5\%), jedoch nur bei 2 Patienten ohne Rechtsherzbelastungszeichen (4,4\%). Bei einem Patienten mit Komplikationen war in der Echokardiographie nicht beurteilbar, ob eine Rechtsherzbelastung vorlag. Patienten mit dem echokardiographischen Nachweis einer Rechtsherzbelastung waren somit signifikant häufiger von Komplikationen während des Klinikaufenthaltes betroffen als Patienten mit unauffälligem Echokardiographiebefund ( $p=0,007, \mathrm{OR}=7,9, \mathrm{PPV}=0,26, \mathrm{NPV}=0,96)$.

Von den Patienten mit Zeichen der Rechtsherzbelastung in der Echokardiographie verstarben 6 Patienten (17,6 \%), jedoch kein Patient ohne Zeichen der Rechtsherzbelastung (0 \%). Patienten mit Zeichen der Rechtsherzbelastung verstarben somit signifikant häufiger $(\mathrm{p}=0,004, \mathrm{OR}=212,0, \mathrm{PPV}=0,19, \mathrm{NPV}=1,0)$.

\subsubsection{Zusammenhang zwischen den kardialen Biomarkern mit dem Auftreten von Komplikationen}

Da Troponin T und NT-pro BNP eine prognostische Aussagekraft bei Patienten mit einer akuten Lungenembolie besitzen (siehe Einleitung, Abschnitt 1.4), wurden diese beiden Laborparameter bei allen Lungenemboliepatienten bestimmt.

Bei Aufnahme betrug der mittlere Troponin-T-Spiegel 0,05 \pm 0,10 ng/ml (0,005-0,50), nach 24 Stunden 0,06 $\pm 0,13 \mathrm{ng} / \mathrm{ml}(0,005-0,71)$.

Patienten mit Komplikationen hatten signifikant höhere Troponin-T-Werte als Patienten ohne Komplikationen $(0,11 \pm 0,14 \mathrm{ng} / \mathrm{ml}$ vs. 0,04 \pm 0,09 ng/ml, $\mathrm{p}=0,022)$.

Auch bei Patienten mit echokardiographisch nachgewiesener Rechtsherzbelastung war der Troponin-T-Spiegel signifikant höher als ohne Rechtsherzbelastung $(0,11 \pm 0,14 \mathrm{ng} / \mathrm{ml}$ vs. 
$0,04 \pm 0,09 \mathrm{ng} / \mathrm{ml}, \mathrm{p}=0,002)$. Für die weitere statistische Analyse wurde ein Cut-off-Wert von $\leq 0,03 \mathrm{ng} / \mathrm{ml}$ eingesetzt, der sich bei der akuten Lungenembolie mit einem negativ prädiktiven Wert von $98 \%$ und einem positiven prädiktiven Wert von $14 \%$ als sinnvoll erwiesen hatte (Konstantinides et al. 2002 a). Von 26 Patienten mit positivem Troponin-TWert traten bei 7 Patienten Komplikationen auf (36,8 \%), jedoch nur bei 5 von 70 Patienten mit negativem Troponin-T-Wert (7,1\%). Somit war das Auftreten von Komplikationen bei einem Troponin-T-Wert $>0,03 \mathrm{ng} / \mathrm{ml}$ signifikant häufiger $(\mathrm{p}=0,015, \quad \mathrm{OR}=4,79$, PPV $=0,27$, NPV = 0,93). Von den 26 Patienten mit Troponin-T-Werten über dem Cut-offWert wiesen 17 Patienten Rechtsherzbelastungszeichen auf (65,4\%), bei 17 von 70 Patienten mit Werten unter dem Cut-off-Level waren Rechtsherzbelastungszeichen nachweisbar (24,3\%). Somit hatten Patienten mit Troponin-T-Werten >0,03 ng/ml auch signifikant häufiger Rechtsherzbelastungszeichen in der Echokardiographie als Patienten mit normalem Biomarkerbefund $(p=0,0003, \mathrm{OR}=5,89, \mathrm{PPV}=0,65, \mathrm{NPV}=0,76)$. Die beschriebenen Zusammenhänge sind in Abbildung 3.4 graphisch dargestellt.

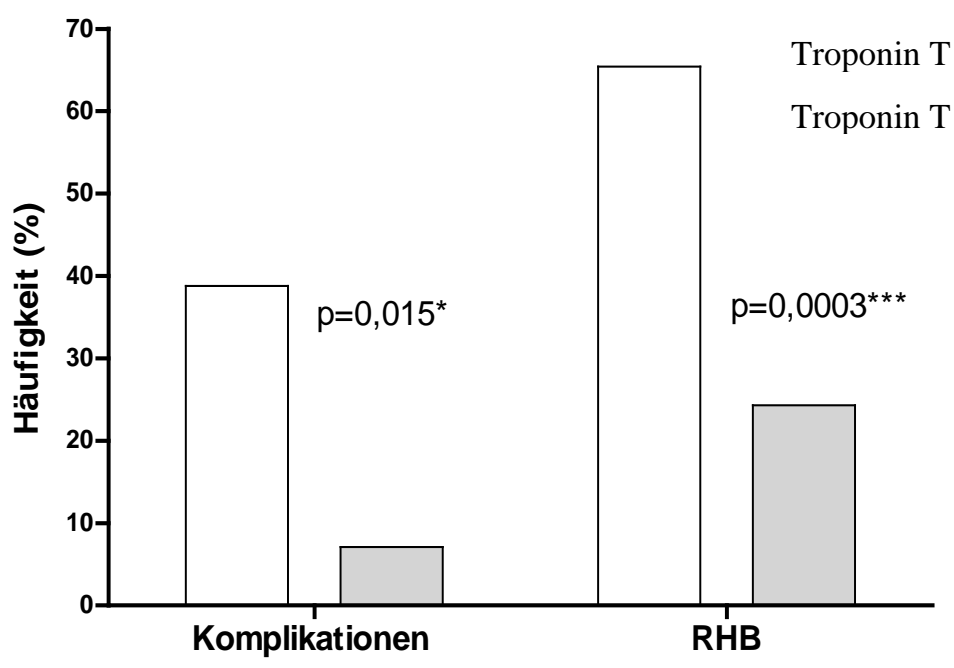

Abbildung 3.4: Darstellung der Häufigkeit von Komplikationen und echokardiographischen Rechtsherzbelastungszeichen bei Patienten mit Troponin-T-Werten ober- und unterhalb des Cut-offWertes von $0,03 \mathrm{ng} / \mathrm{ml}$.

Der NT-pro-BNP-Spiegel betrug bei Aufnahme $3.254 \pm 5.715 \mathrm{pg} / \mathrm{ml}$ und nach 24 Stunden $4.816 \pm 10.825 \mathrm{pg} / \mathrm{ml}$.

Patienten, bei denen Komplikationen eintraten, hatten signifikant höhere NT-pro-BNP-Werte als Patienten ohne Komplikationen $\quad(8.960 \pm 10.558 \mathrm{pg} / \mathrm{ml}$ vs. $2.449 \pm 4.175 \mathrm{pg} / \mathrm{ml}$, $\mathrm{p}=0,002)$. Patienten mit echokardiographischen Rechtsherzbelastungszeichen hatten signifikant höhere NT-pro-BNP-Spiegel als Patienten ohne Rechtsherzbelastungszeichen 
(6.384 $\pm 8205 \mathrm{pg} / \mathrm{ml}$ vs. $1.761 \pm 2.668 \mathrm{pg} / \mathrm{ml}, \mathrm{p}=0,0001)$. Für die weitere statistische Analyse wurde ein Cut-off-Wert von $\geq 1.000 \mathrm{pg} / \mathrm{ml}$ eingesetzt, den Binder et al. (2005) in einer vorausgegangenen Studie zur Bedeutung von NT-pro BNP bei der akuten Lungenembolie definiert hatten. Hierfür wurde hinsichtlich der prognostischen Bedeutung für einen komplikationsreichen Verlauf ein negativ prädiktiver Wert von $95 \%$ und ein positiv prädiktiver Wert von $25 \%$ angegeben. Von den 51 Patienten mit NT-pro-BNPWerten über dem Cut-off-Wert waren 11 Patienten von Komplikationen während des Krankenhausaufenthaltes betroffen (21,6\%), jedoch nur ein Patient mit Werten unter dem Cut-off-Wert (2,0\%). Patienten mit NT-pro-BNP-Werten $\geq 1.000 \mathrm{pg} / \mathrm{ml}$ waren somit signifikant häufiger von Komplikationen betroffen $(\mathrm{p}=0,004$, OR $=12,38, \mathrm{PPV}=0,122$, NPV $=0,98)$. Von den Patienten mit NT-pro-BNP-Spiegeln über dem Cut-off-Wert waren bei 27 Patienten echokardiographische Rechtsherzbelastungszeichen nachweisbar (52,9 \%), jedoch nur bei 7 von 46 Patienten mit Werten unter dem Cut-off-Wert (15,2\%). Patienten mit NT-pro-BNP-Werten $\geq 1.000 \mathrm{pg} / \mathrm{ml}$ wiesen somit signifikant häufiger echokardiographische Rechtsbelastungszeichen auf als Patienten mit normalem Biomarkerbefund ( $\mathrm{p}=0,0001, \mathrm{OR}=6,27, \mathrm{PPV}=0,53, \mathrm{NPV}=0,85)$. In Abbildung 3.5 sind diese Ergebnisse graphisch dargestellt.

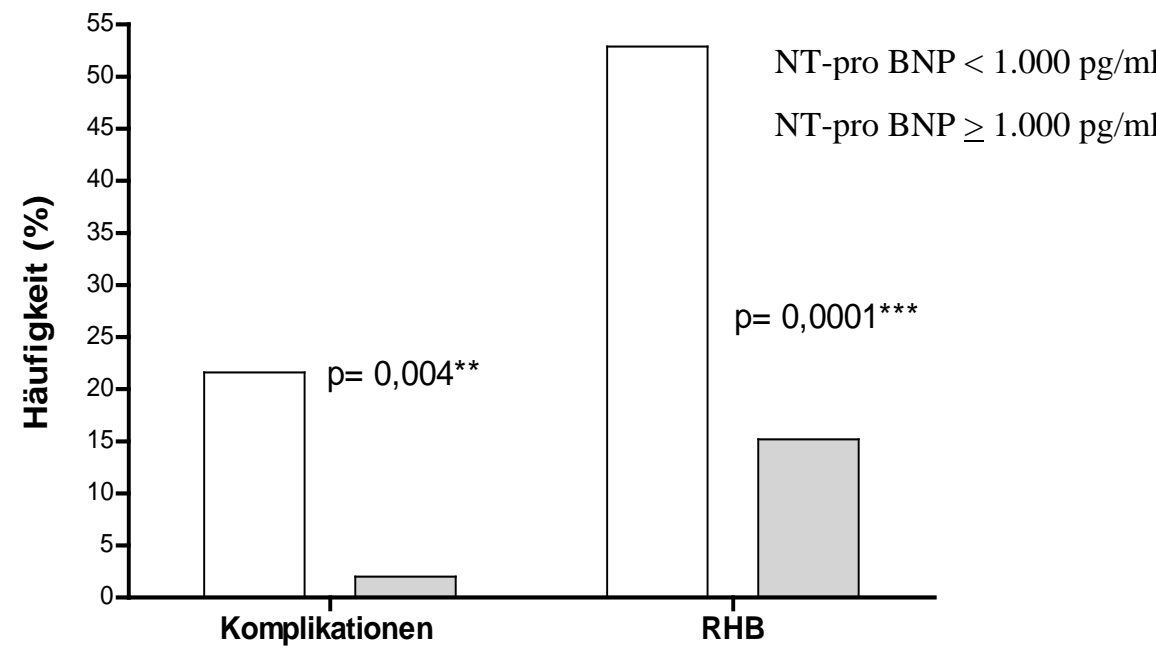

Abbildung 3.5: Darstellung der Häufigkeit von Komplikationen und echokardiographischen Rechtsherzbelastungszeichen bei Patienten mit NT-pro-BNP-Werten ober- und unterhalb des Cut-offWertes von $1000 \mathrm{pg} / \mathrm{ml}$. 


\subsubsection{Zusammenhang zwischen den Adipozytokinspiegeln mit dem Auftreten von Komplikationen}

Der Vergleich der Leptinwerte bei Lungenemboliepatienten mit und ohne Komplikationen ergab keinen signifikanten Unterschied $(12,58 \pm 11,08 \mathrm{ng} / \mathrm{ml}$ vs. 28,31 $\pm 41,71 \mathrm{ng} / \mathrm{ml}$, $\mathrm{p}=0,097)$.

Die sobR-Werte von Lungenemboliepatienten mit und ohne Komplikationen unterschieden sich ebenfalls nicht signifikant (31,03 $\pm 11,99 \mathrm{ng} / \mathrm{ml}$ vs. 28,68 $\pm 11,92 \mathrm{ng} / \mathrm{ml}, \mathrm{p}=0,293)$.

Damit ergab sich auch für den Vergleich des FLI bei Patienten mit und ohne Komplikationen kein signifikanter Unterschied $(0,492 \pm 0,419$ vs. $1,073 \pm 1,414, p=$ 0,111).

Auch die Adiponectinwerte bei Lungenemboliepatienten mit und ohne Komplikationen unterschieden sich nicht signifikant $(19,45 \pm 29,18 \mu \mathrm{g} / \mathrm{ml}$ vs. $10,55 \pm 7,90 \mu \mathrm{g} / \mathrm{ml}$, $\mathrm{p}=0,789)$.

\subsubsection{Prädiktoren für einen komplikationsreichen Inhospital-Verlauf bei Patienten mit einer akuten Lungenembolie}

Im Folgenden wurden die in Tabelle 3.13 aufgeführten Parameter bezüglich ihrer prognostischen Aussagekraft für den Inhospitalverlauf in einer univariaten logistischen Regressionsanalyse getestet. Für die Herzfrequenz hatte sich in der ROC-Analyse ein Cutoff-Wert von $\geq 105 / \mathrm{min}$ als sinnvoll erwiesen $(\mathrm{AUC}=0,771, \mathrm{OR}=8,59, \quad \mathrm{PPV}=0,29$, $\mathrm{NPV}=0,95$, Sensitivität $=0,75$, Spezifität $=0,74$ ). Dieser ist nahezu identisch zu der gängigen Definition einer Tachykardie mit einer Herzfrequenz von $\geq 100 / \mathrm{min}$. Der letztgenannte Wert wurde deshalb nachfolgend als Cut-off-Wert für die Herzfrequenz verwendet. Die AUCs für die Adipozytokine Leptin und Adiponectin betrugen 0,390 und 0,559 sowie für sobR 0,624. Für weitere Analysen wurden diese nicht-normalverteilten Parameter in ihren natürlichen Logarithmus (ln) transformiert, um eine kontinuierliche Risikobewertung vornehmen zu können.

Leptin erwies sich hier als signifikanter prognostischer Parameter für den Inhospital-Verlauf mit einer Odds ratio von 0,54 $(\mathrm{p}=0,036)$, d.h. ein Anstieg des lnLeptin um eine Standardabweichung ging mit einem niedrigeren Komplikationsrisiko im Inhospital-Verlauf einher (siehe Tabelle 3.13). Keine signifikante prognostische Bedeutung für den InhospitalVerlauf hatten der sobR und Adiponectin. 
Weitere prognostische Parameter waren ein Troponin-T-Wert $>0,03 \mathrm{ng} / \mathrm{ml}(\mathrm{p}=0,015)$, ein NT-pro-BNP-Wert $\geq 1000 \mathrm{pg} / \mathrm{ml} \quad(\mathrm{p}=0,018)$, eine akute Rechtsherzbelastung in der Echokardiographie $(p=0,006)$, eine Synkope bei Aufnahme $(p=0,001)$, eine Herzfrequenz $\geq 100 / \mathrm{min}(\mathrm{p}=0,015)$ sowie eine GFR $<60 \mathrm{ml} / \mathrm{min}(\mathrm{p}=0,010)$.

Im Gegensatz zu Leptin erwies sich der BMI, getestet als kontinuierliche Variable, nicht als signifikanter Prädiktor für Inhospital-Komplikationen $(p=0,548)$. Wurde lnLeptin um den BMI in der logistischen Regression korrigiert, so stieg die statistische Aussagekraft von Leptin an, d.h. die Odds ratio betrug 0,38 ( $\mathrm{p}=0,013$; KI 0,17-0,82). Der BMI verblieb als nicht-signifikanter Parameter $(p=0,371)$. Diese Analyse deutet auf einen vom BMI unabhängigen Effekt von Leptin als Prädiktor des Inhospital-Verlaufs hin.

Tabelle 3.13: Univariate Regressionsanalyse auf die Inhospital-Prognose

\begin{tabular}{|llll|}
\hline Parameter & p-Wert & OR & $\mathbf{9 5 \% ~ K I ~}$ \\
\hline lnLeptin & $\mathbf{0 , 0 3 6}$ & 0,54 & $0,30-0,96$ \\
lnsobR & 0,535 & 1,71 & $0,31-9,43$ \\
lnAdiponectin & 0,587 & 1,24 & $0,57-2,70$ \\
TnT $>0,03$ ng/ml & $\mathbf{0 , 0 1 5}$ & 4,79 & $1,36-16,82$ \\
NT-pro BNP $\geq 1000$ pg/ml & $\mathbf{0 , 0 1 8}$ & 12,38 & $1,53-100,15$ \\
akute RHB & $\mathbf{0 , 0 0 6}$ & 9,54 & $1,92-47,45$ \\
Synkope & $\mathbf{0 , 0 0 1}$ & 9,33 & $2,49-35,10$ \\
Dyspnoe & 0,273 & 0,38 & $0,67-2,14$ \\
BMI & 0,548 & 0,96 & $0,85-1,09$ \\
maligner Tumor & 0,471 & 1,69 & $0,41-7,04$ \\
HF $\geq 100 /$ min & $\mathbf{0 , 0 1 5}$ & 5,50 & $1,38-21,87$ \\
GFR $<60$ ml/min & $\mathbf{0 , 0 1 0}$ & 5,46 & $1,49-19,93$ \\
\hline
\end{tabular}

Die signifikanten prognostischen Parameter aus der univariaten Regressionsanalyse (Tabelle 3.13) wurden in einem multivariaten Modell getestet (siehe Tabelle 3.14). Als unabhängige prognostische Parameter für den Inhospital-Verlauf nach einer akuten Lungenembolie erwiesen sich in diesem Modell der $\operatorname{lnLeptin}(\mathrm{p}=0,028$, OR $=0,37)$ und ein erhöhter NTpro-BNP-Wert $(\mathrm{p}<0,001)$. 
Tabelle 3.14: Multivariate Regressionsanalyse auf die Inhospital-Prognose

\begin{tabular}{|lclc|}
\hline Parameter & p-Wert & OR & 95 \% KI \\
\hline lnLeptin & $\mathbf{0 , 0 2 8}$ & 0,37 & $0,16-0,90$ \\
Synkope & 0,174 & 3,87 & $0,55-27,26$ \\
TnT $>0,03 \mathrm{ng} / \mathrm{ml}$ & 0,952 & 0,94 & $<0,0001-7,19$ \\
NT-pro BNP $\geq 1000 \mathrm{pg} / \mathrm{ml}$ & $<\mathbf{0 , 0 0 1}$ & gegen unendlich & 0 bis gegen unendlich \\
GFR $<60 \mathrm{ml} / \mathrm{min}$ & 0,080 & 6,87 & $0,79-59,44$ \\
HF $\geq 100 / \mathrm{min}$ & 0,055 & 13,98 & $0,94-207,14$ \\
\hline
\end{tabular}

\subsection{Das Langzeit-Überleben nach einer akuten Lungenembolie}

Das Langzeit-Überleben der zwischen 2003 und 2006 in die Studie aufgenommenen Patienten mit einer Lungenembolie wurde in einem Follow-Up ausgewertet. Dieses wurde alle sechs Monate telefonisch beim Patienten oder Hausarzt erfragt. Jeder Patient sollte über 4 Jahre (1460 Tage), d.h. bis spätestens 2010 beobachtet werden. Bei 37 Patienten konnte der gesamte Beobachtungszeitraum nachverfolgt werden. Bei 60 Patienten war der Beobachtungszeitraum < 1460 Tage. Von diesen Patienten waren 27 vor Beendigung des Beobachtungszeitraums verstorben. Bei 34 Patienten war eine erneute Kontaktaufnahme nicht möglich, sodass das Langzeit-Überleben zu einem früheren Zeitpunkt bestimmt wurde (bei 16 Patienten im 4. Follow-up-Jahr, bei 8 Patienten im 3. Follow-up-Jahr, bei 10 Patienten davor). Insgesamt trat ein Ereignis, definiert als Tod im Follow-up-Zeitraum bei 27 Patienten, also 27,8 \% der Studienpopulation, auf.

In der univariaten Cox-Regressionsanalyse hinsichtlich des Langzeit-Überlebens hatte eine Herzfrequenz $\geq 100 /$ min einen negativen Einfluss auf das Überleben ( $p=0,033$ ). Litten die Patienten an einer malignen Tumorerkrankung, so hatten sie ein 3,6-fach $(p=0,002)$ beim Vorliegen einer GFR< $60 \mathrm{ml} / \mathrm{min}$ ein 2,5-fach schlechteres Langzeit-Überleben ( $\mathrm{p}=0,018$ ). Als der einzige bezüglich des Langzeit-Überlebens aussagekräftige Laborparameter erwies sich $\operatorname{lnLeptin}(\mathrm{p}=0,001)$. Ein Anstieg des lnLeptin um eine Standardabweichung bedeutete ein besseres Langzeit-Überleben $(\mathrm{HR}=0,54)$. Keine prognostische Aussage für das Langzeit-Überleben hatten der sobR und Adiponectin. Diese Ergebnisse sind in Tabelle 3.15 dargestellt. Im Gegensatz zu Leptin erwies sich in der Cox-Regression der BMI, getestet als kontinuierliche Variable, nicht als signifikanter Prädiktor für das Langzeit-Überleben $(p=0,280)$. Wurde lnLeptin um den BMI korrigiert, so war Leptin weiterhin ein 
signifikanter und vom BMI-unabhängiger Prädiktor ( $\mathrm{HR}=0,528, \mathrm{p}=0,007$; KI 0,33-0,84).

Der BMI verblieb als nicht-signifikanter Parameter $(p=0,586)$.

Tabelle 3.15: Univariate Cox-Regressionsanalyse auf das LangzeitÜberleben

\begin{tabular}{|llll|}
\hline Parameter & p-Wert & HR & $\mathbf{9 5 \% ~ K I ~}$ \\
\hline lnLeptin & $\mathbf{0 , 0 0 1}$ & 0,54 & $0,37-0,78$ \\
lnsobR & 0,679 & 1,27 & $0,41-3,87$ \\
lnAdiponectin & 0,387 & 1,25 & $0,76-2,07$ \\
TnT $>0,03$ ng/dl & 0,975 & 1,10 & $0,43-2,41$ \\
NT-pro BNP $\geq 1000$ pg/ml & 0,072 & 2,15 & $0,93-4,94$ \\
akute RHB & 0,225 & 1,66 & $0,73-3,77$ \\
Synkope & 0,071 & 2,11 & $0,94-4,73$ \\
Dyspnoe & 0,531 & 0,68 & $0,20-2.27$ \\
BMI & 0,280 & 0,957 & $0,88-1,04$ \\
maligner Tumor & $\mathbf{0 , 0 0 2}$ & 3,62 & $1,63-8,01$ \\
HF $\geq 100 /$ min & $\mathbf{0 , 0 3 3}$ & 2,33 & $1,07-5,08$ \\
GFR $<60$ ml/min & $\mathbf{0 , 0 1 8}$ & 2,57 & $1,17-5,64$ \\
\hline
\end{tabular}

Die nach der univariaten Cox-Regressionsanalyse signifikanten prognostischen Parameter für das Langzeit-Überleben (siehe Tabelle 3.15) wurden nachfolgend in einem multivariaten Modell getestet (Tab. 3.16). Dabei zeigte sich, dass lnLeptin wie auch die anderen getesteten Parameter unabhängige Prädiktoren für das Langzeit-Überleben nach einer akuten Lungenembolie sind.

Tabelle 3.16: Multivariate Regressionsanalyse auf das Langzeit-Überleben

\begin{tabular}{|llll|}
\hline Parameter & p-Wert & HR & $\mathbf{9 5 \% ~ K I ~}$ \\
\hline InLeptin & $\mathbf{0 , 0 0 1}$ & 0,551 & $0,39-0,78$ \\
HF $\geq 100 /$ min & $\mathbf{0 , 0 3 4}$ & 2,42 & $1,07-5,48$ \\
maligner Tumor & $\mathbf{0 , 0 0 1}$ & 4,14 & $1,76-9,76$ \\
GFR $<60 \mathrm{ml} /$ min & $\mathbf{0 , 0 0 7}$ & 2,98 & $1,34-6,63$ \\
\hline
\end{tabular}




\subsection{Der Zusammenhang zwischen dem Leptinspiegel mit dem Langzeit-Überleben}

Da in der multivariaten Regressionanalyse Leptin ein unabhängiger prognostischer Parameter für das Langzeit-Überleben war, es jedoch keinen für den Kliniker anwendbaren Cut-off-Wert gibt, wurde der Einfluss dieses Adipozytokins auf das Langzeit-Überleben anhand von Leptin-Tertilen genauer untersucht. Folgende Tertile wurden gebildet: Leptinwerte $<8,25 \mathrm{ng} / \mathrm{ml}$ (1.Tertil), Leptinwerte 8,25-21,94 ng/ml (2. Tertil) sowie Leptinwerte $>21,94$ ng/ml (3.Tertil). In der Kaplan-Meier-Kurve ist ein signifikant besseres Langzeit-Überleben für Patienten mit höheren Leptinwerten erkennbar (Logrank-Test: $p=0,014)$. Dies ist in Abbildung 3.7 graphisch dargestellt. Wurden nun die einzelnen Tertile direkt miteinander verglichen, so zeigte sich, dass Patienten des dritten Tertils ein signifikant besseres Langzeit-Überleben im Follow-up-Zeitraum aufwiesen als jene im zweiten und ersten Tertil. Kein signifikanter Unterschied bestand zwischen dem zweiten und ersten Tertil (Logrank-Test für 3. vs. 2. Tertil: $p=0,047,3$. vs. 1. Tertil: $p=0,008,2$. vs. 1. Tertil: $\mathrm{p}=0,506)$. 


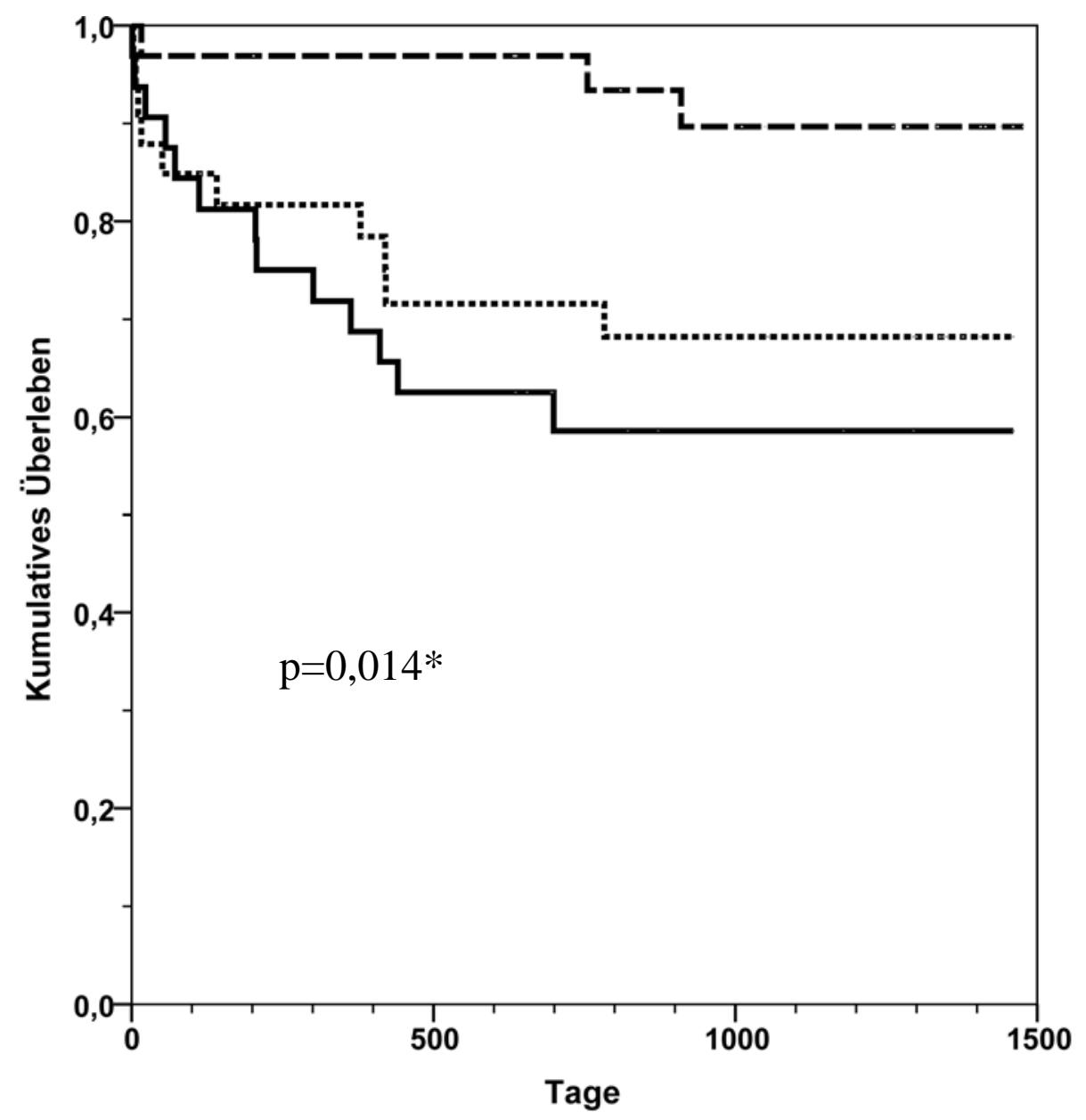

Abbildung 3.7: Langzeit-Überleben bei Patienten mit einer akuten Lungenembolie in Abhängigkeit vom Leptinspiegel, durchgezogen $=1$. Tertil $($ Leptin $<$ 8,25 ng/ml), Punkte $=2$. Tertil $($ Leptin 8,2521,94 ng/ml), Striche $=3$. Tertil (Leptin $>21,94$ ng/ml).

Nachfolgend wurde untersucht, ob das Auftreten von signifikanten Parametern aus der multivariaten Regressionsanalyse bezüglich des Langzeit-Überlebens (Malignom, GFR $<60 \mathrm{ml} / \mathrm{min}$, Synkope) sowie des BMI (aufgrund des Einflusses auf den Leptinspiegel) und des Alters sich signifikant zwischen den drei Leptin-Tertilen unterschied. Es zeigten sich keine Unterschiede in der Häufigkeit des Auftretens von Malignomen und von Synkopen zwischen den drei Tertilen. Auch das Alter und die GFR unterschieden sich zwischen den drei Tertilen nicht signifikant. Jedoch war - analog zur Korrelation von Leptin mit dem BMI (siehe Abschnitt 3.7.1) - der BMI im dritten Tertil signifikant höher als im zweiten und ersten Tertil, der BMI im zweiten Tertil war signifikant höher als im ersten Tertil (2. vs. 3. Tertil: $p=0,009$, 1. vs. 3. Tertil: $p<0,0001,1$. vs. 2. Tertil: $\mathrm{p}=0,006)$. Diese Ergebnisse sind in Tabelle 3.17 zusammengefasst. 
Tabelle 3.17: Malignome, Synkopen, Alter, BMI und GFR in den drei Leptin-Tertilen

\begin{tabular}{|c|c|c|c|}
\hline Parameter & $\begin{array}{l}\text { 1.Tertil } \\
(\mathrm{n}=32)\end{array}$ & $\begin{array}{l}\text { 2. Tertil } \\
(\mathrm{n}=33)\end{array}$ & $\begin{array}{l}\text { 3. Tertil } \\
(\mathrm{n}=32)\end{array}$ \\
\hline maligner Tumor & \multicolumn{3}{|c|}{$\begin{array}{l}\text { 1. vs. } 2 . \text { Tertil: } p=0,764,2 \text {. vs. } 3 \text {. Tertil: } p=0,733,1 \text {. vs. } 3 \text {. Tertil: } \\
p=0,509\end{array}$} \\
\hline Synkope & $\begin{array}{l}\text { 9/32 (28,1 \%) } \\
\text { 1. vs. 2. Tertil: } \\
p=0,774\end{array}$ & $\begin{array}{l}\text { 7/33 (21,2 \%) } \\
\text { 2. vs. 3. Tertil: } \mathrm{p}\end{array}$ & $\begin{array}{l}\text { 7/32 (21,9 \%) } \\
\text {. vs. 3. Tertil: }\end{array}$ \\
\hline Alter & $\begin{array}{l}63,25 \pm 15,02 \\
\text { 1. vs. 2. Tertil: } \\
p=0,925\end{array}$ & $\begin{array}{l}60,45 \pm 16,93 \\
\text { 2. vs. 3. Tertil: } \mathrm{p}\end{array}$ & $\begin{array}{l}63,41 \pm 14,77 \\
\text {. vs. 3. Tertil: }\end{array}$ \\
\hline BMI & $\begin{array}{l}24,99 \pm 2,66 \\
\text { 1. vs. 2. Tertil: } \\
\mathbf{p}<\mathbf{0 , 0 0 0 1}\end{array}$ & $\begin{array}{l}28,25 \pm 5,25 \\
\text { 2. vs. 3. Tertil: }\end{array}$ & $\begin{array}{l}31,83 \pm 6,82 \\
\text { 1. vs. 3. Tertil: }\end{array}$ \\
\hline GFR (ml/min) & $\begin{array}{l}73,29 \pm 31,07 \\
\text { 1. vs. 2. Tertil: } \\
p=0,387\end{array}$ & $\begin{array}{l}76,59 \pm 25,94 \\
\text { 2. vs. 3. Tertil: } \mathrm{p}\end{array}$ & $\begin{array}{l}65,32 \pm 24,40 \\
\text {. vs. 3. Tertil: }\end{array}$ \\
\hline
\end{tabular}

Da sich zwischen den Leptin-Tertilen signifikant unterschiedliche BMI-Werte gezeigt hatten, wurde auch der BMI in Tertilen hinsichtlich des Langzeit-Überlebens analysiert (1. Tertil: BMI < 25,6 kg/m², 2. Tertil: BMI 25,6-29,2 kg/m², 3. Tertil. BMI > 29,2 kg/m²). Hier ergaben sich beim Vergleich aller drei Tertile in der Kaplan-Meier-Kurve keine signifikanten Überlebensunterschiede (Logrank-Test: $\mathrm{p}=0$,088, siehe Abbildung 3.8). Beim Vergleich der Tertile untereinander zeigte sich jedoch im dritten BMI-Tertil ein signifikant besseres Überleben als im ersten Tertil $(p=0,041)$. Keine signifikanten Unterschiede ergaben sich zwischen dem dritten und zweiten Tertil $(p=0,890)$ sowie dem zweiten und ersten Tertil ( $p=0,074)$. 


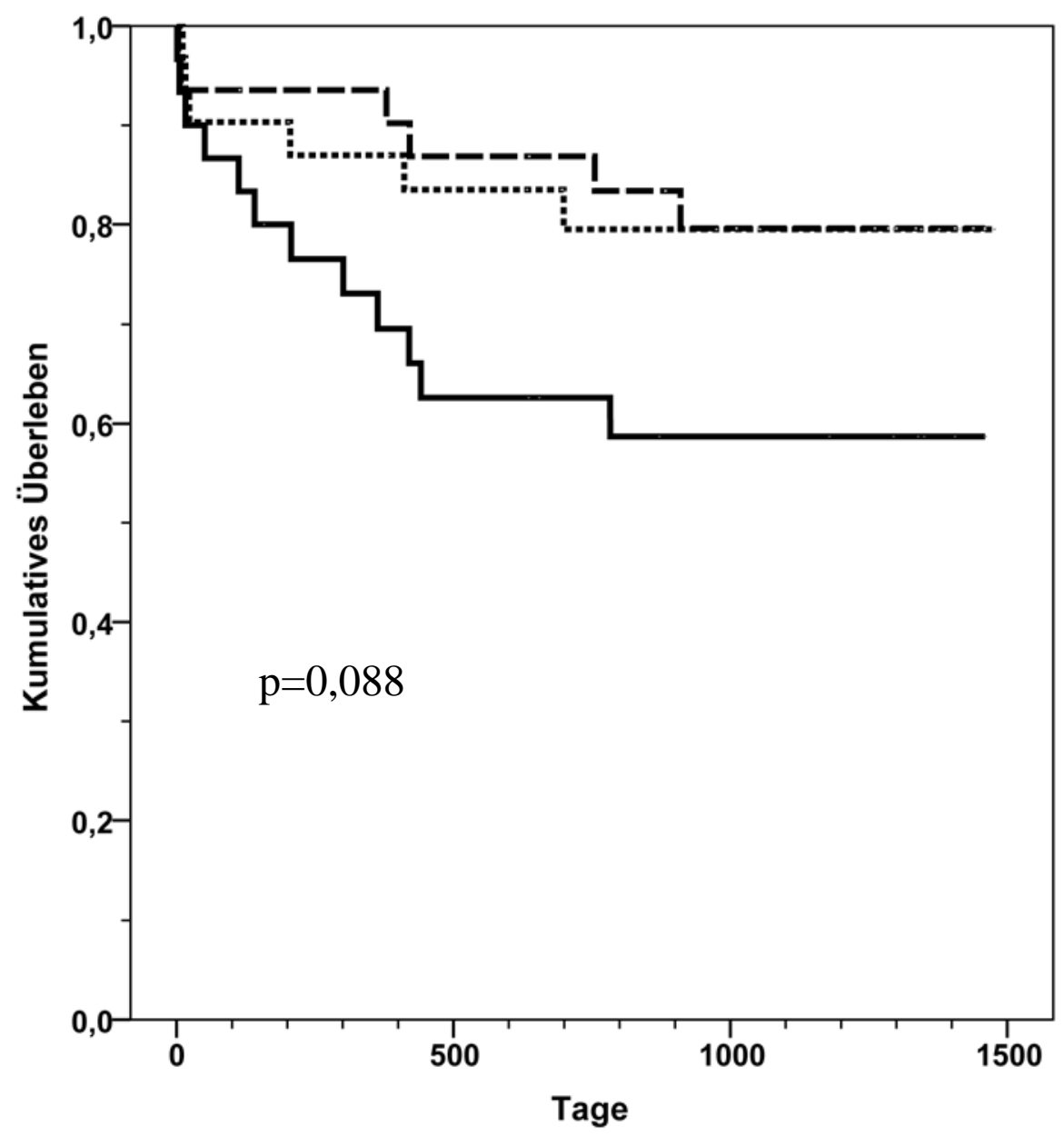

Abbildung 3.8: Langzeit-Überleben bei Patienten mit einer akuten Lungenembolie in Abhängigkeit vom BMI, durchgezogen $=1$. Tertil $\left(\right.$ BMI $\left.<25,6 \mathrm{~kg} / \mathrm{m}^{2}\right)$, Punkte $=2$. Tertil $($ BMI 25,6-29,2 kg/m²), Striche $=3$. Tertil (BMI $\left.>29,2 \mathrm{~kg} / \mathrm{m}^{2}\right)$. 


\section{Diskussion}

\subsection{Allgemeines}

Obwohl die frühzeitige Diagnose und Therapie für die Prognose der akuten Lungenembolie von entscheidender Bedeutung sind, bleibt ein hoher Prozentsatz dieses Krankheitsbildes unentdeckt. So ist in den USA die akute Lungenembolie noch immer die häufigste vermeidbare Todesursache unter Krankenhauspatienten (Anderson und Spencer 2003). Bei 90\% der Patienten, die an einer Lungenembolie versterben, wurde die Diagnose nicht oder zu spät gestellt und es erfolgte somit keine Therapie. Nur 10\% der Patienten verstarben nach Initiierung der Therapie (Dalen 2002). Dies zeigt, dass suffiziente Therapeutika zur Verfügung stehen, die Diagnostik aber noch immer problematisch ist. Durch die Entwicklung und Anwendung von standardisierten Diagnosealgorithmen und Verbesserungen im Bereich der bildgebenden Diagnostik (Computertomographie und Echokardiographie) konnten in den letzten Jahren auf dem Gebiet der Risikostratifikation und Diagnostik viele Fortschritte erzielt werden.

Neben den bekannten, in Abschnitt 1.5 der Einleitung aufgeführten Risikofaktoren, sind andere potentielle Einflussfaktoren bisher nur unzureichend untersucht. Gerade die Adipositas, deren gesundheitspolitische Bedeutung immer weiter zunimmt und deren Einfluss auf Volkskrankheiten wie die koronare Herzkrankheit gut untersucht ist (Wolk et al. 2003), scheint auch ein Risikofaktor für die Entstehung der Lungenembolie zu sein.

In der Nurses`Health Study, einer großen amerikanischen Längsschnittstudie, zeigte sich eine lineare Beziehung zwischen der Höhe des BMI und dem Lungenembolie-Risiko (Kabrhel et al. 2009). Abdominell betonte Fettleibigkeit erwies sich bei Patienten mit tiefer Beinvenenthrombose als Risikofaktor für die Progression zur Lungenembolie (Ögren et al. 2005). Bei Patienten nach einer Operation war die Adipositas ein Hauptrisikofaktor für eine fulminante Lungenembolie (Blaszyk und Björnsson 2000). Bei Männern im mittleren Alter stellte die Adipositas einen unabhängigen Risikofaktor für eine venöse Thromboembolie dar (Hansson et al. 1999). Eine mögliche Erklärung für diese Beobachtungen ist einerseits, dass durch die Adipositas die venöse Stase begünstigt wird. Andererseits wurden in den letzten Jahren über die endokrine Funktion des Fettgewebes neue wichtige Erkenntnisse gewonnen. So wurden bei adipösen Personen unter anderem erhöhte Spiegel der gerinnungsfördernden Faktoren Fibrinogen, Faktor-VII und Plasminogen-Aktivator-Inhibitor 1 nachgewiesen, die 
zu einer erworbenen Thrombophilie führen können (Tsai et al. 2002). Darüber hinaus konnte eine Gruppe von Proteohormonen, die von Adipozyten produziert und sezerniert werden, die so genannten Adipozytokine, identifiziert werden. Hierzu zählen neben TNF alpha auch Leptin und Adiponectin.

Schon seit ca. 15 Jahren ist die Funktion von Leptin als Regulatorhormon des Energie- und Fettstoffwechsels bekannt. Darüber hinaus scheint dieses Hormon noch zahlreiche andere Funktionen zu erfüllen (siehe Einleitung 1.6). So wurde für Leptin im Mausversuch ein fördernder Einfluss auf die Entstehung venöser Thromboembolien nachgewiesen (Konstantinides et al. 2004). In klinischen Studien hingegen ist die Bedeutung von Leptin bei venösen Thromboembolien bisher noch nicht untersucht worden.

Im Plasma liegt Leptin nicht nur in freier, sondern auch in gebundener Form vor. Das Hauptbindungsprotein im Serum ist der sobR, dessen genaue Funktion noch nicht vollständig geklärt ist, dem jedoch eine Regulatorfunktion zugeschrieben wird (Lammert et al. 2001). Der Free-Leptin-Index (FLI), also der Anteil des nicht Protein-gebundenen und frei im Plasma zirkulierenden Leptins, scheint der biologisch aktive Anteil des Leptins zu sein (Landt et al. 2000).

Während Leptin die Thromboseentstehung zu begünstigen scheint, erwies sich Adiponectin im Mausversuch als vasoprotektiv und antithrombogen (Kato et al. 2006). Zur Bedeutung von Adiponectin bei der akuten Lungenembolie existieren bisher keine klinischen Studien.

Unter der Annahme, dass Leptin ein thrombogener und Adiponectin ein antithrombogener Faktor ist, wurde in der vorliegenden Arbeit die Bedeutung dieser Adipozytokine bei der akuten Lungenembolie an einer Fallgruppe von 97 und einer Kontrollgruppe von 40 Patienten untersucht. Dabei sollten folgende Fragen beantwortet werden:

- Haben Patienten mit einer akuten Lungenembolie erhöhte Leptinspiegel und ist dies mit einer schlechten Prognose assoziiert?

- Haben Patienten mit einer akuten Lungenembolie erniedrigte Adiponectinspiegel und ist dies mit einer schlechten Prognose assoziiert? 


\subsection{Der prädiktive Wert etablierter Parameter einer myokardialen Ischämie und RV-Dysfunktion}

Bei 12,4\% der Patienten traten nach der Lungenembolie Komplikationen auf (Hypotonie, Katecholamingabe, Intubation, Reanimation, Tod infolge der Lungenembolie). Die Lungenembolie-assoziierte Mortalität betrug 6,2\% und lag somit im Bereich anderer prospektiver klinischer Lungenembolie-Studien (Kucher et al. 2003, Konstantinides et al. 2002 a), ein Patient erlag einem Malignom, sodass die Gesamt-Mortalität 7,2\% betrug.

Eine Synkope bei Aufnahme war ein Parameter mit prognostischer Bedeutung für eine erhöhte Komplikationsrate im Inhospital-Verlauf nach einer Lungenembolie ( $p=0,001$, OR = 9,33) Dies bestätigt die Erkenntnis, dass eine Synkope im Rahmen einer akuten Lungenembolie Ausdruck eines verminderten Herzzeitvolumens mit folgender zerebraler Minderperfusion und somit ein Zeichen eines komplikationsreichen Verlaufes ist (Torbicki et al. 2008).

In der Echokardiographie waren bei 42,5\% der Patienten mit einer Lungenembolie Zeichen der Rechtsherzbelastung nachweisbar. Diese waren mit einer signifikant höheren Komplikationsrate $(p=0,007, \mathrm{OR}=7,9)$ und einer signifikant höheren Mortalität $(\mathrm{p}=0,004, \quad \mathrm{OR}=212,0)$ assoziiert, welche mit Rechtsherzbelastung 17,6\%, ohne Rechtsherzbelastung 0 \% betrug. Ähnliche Zahlen publizierten auch Grifoni et al. (2000) nach einer Untersuchung von 209 Patienten mit einer akuten Lungenembolie. Bei 53\% der Patienten wurden echokardiographisch Rechtsherzbelastungszeichen nachgewiesen, die Mortalität bei diesen Patienten betrug $14 \%$, ohne Rechtsherzbelastung in der Echokardiographie lag sie bei $0 \%$. Die Bedeutung der Echokardiographie als essentieller Bestandteil der Risikostratifikation wird durch diese Zahlen unterstrichen.

Laborparameter mit prognostischer Bedeutung für einen komplikationsreichen Inhospitalverlauf waren Troponin T und NT-pro BNP. Die Troponin-T-Werte bei Patienten, bei denen Komplikationen auftraten, waren signifikant höher als bei Patienten ohne Komplikationen $(p=0,022)$. Bei einem Troponin-T-Spiegel $>0,03 \mathrm{ng} / \mathrm{ml}$ war die Komplikationsrate fast fünffach erhöht ( $\mathrm{p}=0,015$, OR =4,79). Dies bestätigt die Bedeutung von Troponin $\mathrm{T}$ als prognostischer Parameter für einen komplikationsreichen Verlauf nach einer akuten Lungenembolie (Konstantinides et al. 2002 a, Meyer et al. 2000).

Patienten mit Komplikationen wiesen auch signifikant höhere NT-pro-BNP-Werte auf $(p=0,002)$. Bei Werten $\geq 1000$ pg/ml war die Komplikationsrate 12-fach erhöht $(p=0,004$, 
$\mathrm{OR}=12,38)$. In der multivariaten Regressionsanalyse zeigte sich, dass ein erhöhter NT-pro BNP-Wert ein unabhängiger prognostischer Parameter für eine höhere Komplikationsrate im Inhospital-Verlauf ist $(\mathrm{p}<0,001$, OR = gegen unendlich). Dies ist im Einklang mit anderen Studien (Binder et al. 2005, Klok et al. 2008).

Die Studie bestätigt damit die Anwendung der etablierten Parameter zur Risikostratifizierung, zu denen das Vorliegen echokardiographischer Rechtsherzbelastungszeichen sowie ein erhöhter Troponin-T- und NT-pro BNP-Wert gehören.

Zu den Parametern, die für das Langzeit-Überleben von prädiktivem Wert waren, zählen eine Herzfrequenz $\geq 100 / \mathrm{min}$, ein Malignom sowie eine $\mathrm{GFR}<60 \mathrm{ml} / \mathrm{min}$. Dass eine Tachykardie mit einem schlechteren Überleben, vor allem bei kardiovaskulären Erkrankungen einhergeht, ist allgemein bekannt (Verrier und Tan 2009, Fox et al. 2007). Die schlechtere Überlebensrate bei einem Malignom und einer chronischen Niereninsuffizienz mit einer eingeschränkten GFR erklärt sich durch den konsumierenden Charakter dieser Erkrankungen.

\subsection{Die Bedeutung der Adipozytokine bei Patienten mit einer akuten Lungenembolie}

\subsubsection{Referenzwerte}

In der Literatur werden für Leptin sehr unterschiedliche Serum-Konzentrationen beschrieben. In der vorliegenden Arbeit lag der mittlere Leptinspiegel bei Patienten mit einer Lungenembolie bei 26,37 ng/ml, ohne Lungenembolie bei 20,32 ng/ml. Ähnliche Werte wurden von Havel et al. (1996) beobachtet. Viele Autoren berichten aber über niedrigere Werte, die bei normalgewichtigen Patienten im Bereich von 5-15,8 ng/ml angegeben werden (Considine et al. 1996, Wallace et al. 2001, Sinha et al. 1996). Dass in der vorliegenden Arbeit verglichen mit anderen Arbeiten hohe Leptinkonzentrationen gemessen wurden, hängt sicherlich, neben methodischen Unterschieden bei der Leptinmessung, mit den relativ hohen BMI Werten (28,4 bzw. 26,8 kg/m²) in beiden Gruppen zusammen.

Für den sobR im Serum werden in der Literatur Werte zwischen 17,9-129,2 ng/ml angegeben (Wu et al. 2002). Sowohl bei Patienten mit als auch ohne Lungenembolie lagen die sobRWerte in diesem Bereich. 
Der Referenzbereich für Adiponectin wird in der Literatur mit 3-30 $\mu \mathrm{g} / \mathrm{ml}$ angegeben (Hopkins et al. 2007). In diesem Bereich lagen auch die Adiponectin-Werte in beiden Gruppen (mit/ohne LE: 11,74 $\mu \mathrm{g} / \mathrm{ml}$ und $7.04 \mu \mathrm{g} / \mathrm{ml}$ ).

\subsubsection{Geschlechtsspezifische Unterschiede der Adipozytokine}

In beiden Gruppen war der Leptinspiegel bei Frauen höher als bei Männern. Diese Beobachtung bestätigt die Ergebnisse anderer Autoren (Yannakoulia et al. 2003, Ogawa et al. 2004), die als Ursache hierfür die unterschiedliche Verteilung der Fettdepots bei Frauen und Männern sowie die unterschiedlichen Konzentrationen der Geschlechtshormone sahen.

Der sobR-Spiegel bei Frauen und Männern unterschied sich in beiden Gruppen nicht. In der Literatur gibt es zu diesem Thema widersprüchliche Ergebnisse. Während zwei Arbeitsgruppen über höhere sobR-Spiegel bei Männern als bei Frauen berichteten (Ogawa et al. 2004, Yannakoulia et al. 2003), beobachteten van Dielen et al. (2002) keine signifikanten Unterschiede.

Aus diesen Ergebnissen ergab sich bei Frauen ein signifikant höherer FLI als bei Männern in beiden Gruppen, was sich aus den höheren Leptinspiegeln bei Frauen ergibt und die Ergebnisse von Ogawa et al. bestätigt (2004).

$\mathrm{Zu}$ geschlechtsspezifischen Unterschieden des Adiponectinspiegels gibt es in der Literatur unterschiedliche Angaben. Während Fernandez et al. (2006) bei Patienten mit tiefer Beinvenenthrombose keine geschlechtsspezifischen Unterschiede fanden, beschrieben andere Autoren bei Frauen höhere Adiponectinwerte als bei Männern (Kumada et al. 2003, Yannakoulia et al. 2003). Auch in dieser Arbeit hatten Frauen in beiden Gruppen höhere Adiponectinspiegel als Männer. Die Ursache hierfür könnte eine durch Testosteron verursachte Adiponectinsuppression bei Männern sein (Swarbrick und Havel 2008).

\subsubsection{Der Zusammenhang zwischen den Adipozytokinen mit dem Body- Mass-Index (BMI) und dem Alter}

Leptin zeigte in zahlreichen Studien eine positive Korrelation mit dem BMI (zum Beispiel Shimizu et al. 1997). Auch in der vorliegenden Arbeit zeigte sich eine positive Korrelation zwischen dem Leptinspiegel und dem BMI in beiden Gruppen. Diese Korrelation erschließt sich aus der Physiologie des Leptins, denn der Leptinspiegel ist umso höher, je mehr Fettgewebe vorhanden ist (siehe Einleitung 1.6). 
Im Gegensatz dazu zeigte sich in dieser Studie zwischen dem sobR-Spiegel und dem BMI bei Patienten mit und ohne Lungenembolie eine bekannte inverse Korrelation, was die Ergebnisse anderer Arbeiten bestätigt (Ogawa et al. 2004, Lahlou et al. 2002).

Der FLI korrelierte in der Fall- und der Kontrollgruppe mit dem BMI. Bei steigendem BMI steigt also der Leptinspiegel, der sobR-Spiegel sinkt und dadurch steigt der Anteil an freiem Leptin. Dies bestätigt die Beobachtung, dass bei normalgewichtigen Patienten der Hauptteil des Leptins in gebundener Form vorliegt (Sinha et al. 1996).

Für Adiponectin zeigen die Ergebnisse dieser Arbeit eine negative Korrelation mit dem BMI in der Fallgruppe, dies bestätigt die Ergebnisse anderer Arbeitsgruppen (Matsuzawa et al. 2004, Poehls et al. 2009). In der Kontrollgruppe bestand dieser Zusammenhang nicht.

Eine Abhängigkeit der Leptin- und sobR-Konzentration sowie des FLI vom Alter fand sich in dieser Arbeit nicht. Jedoch bestand bei Patienten mit einer Lungenembolie eine positive Korrelation zwischen Adiponectin und dem Alter. Dieser Zusammenhang wurde bereits mehrfach beobachtet, so auch in der Rancho-Bernardo-Studie, einer große Kohortenstudie zum gesunden Altern mit über 1500 Patienten (Laughlin et al. 2007) und der Health-ABCStudie, einer großen prospektiven Studie zur Bedeutung der körperlichen Konstitution auf die Mortalität bei über 3000 Patienten (Poehls et al. 2009). In der Kontrollgruppe bestand dieser Zusammenhang nicht.

\subsubsection{Der Zusammenhang der Adipozytokine mit den kardialen Biomarkern}

Eine Korrelation zwischen Leptin einerseits sowie sobR, Adiponectin und den kardialen Biomarkern (Troponin T und NT-pro BNP) andererseits bestand nicht.

Zwischen sobR und Adiponectin zeigte sich in beiden Gruppen eine positive Korrelation, die so auch schon beschrieben wurde (Ogawa et al. 2004), wobei die Ursache hierfür unklar ist. Zwischen dem sobR und den kardialen Biomarkern hingegen zeigte sich keine Abhängigkeit.

Bei Patienten mit einer Lungenembolie korrelierte Adiponectin mit NT-pro BNP. Dieser Zusammenhang wurde bereits bei Patienten mit einer chronischen Herzinsuffizienz beschrieben (Kistorp et al. 2005). Kein Zusammenhang bestand zwischen Adiponectin und Troponin $\mathrm{T}$. 


\subsubsection{Haben Patienten mit einer akuten Lungenembolie erhöhte Leptin- und erniedrigte Adiponectinspiegel?}

Die Leptinspiegel bei Patienten mit und ohne Lungenembolie unterschieden sich nicht signifikant. In experimentellen Arbeiten hatte sich gezeigt, dass Leptin die Entstehung arterieller und venöser Thrombosen begünstigt (Konstantinides et al. 2001 a und 2004). An Mäusen konnten durch die Injektion von Thrombozyten-Aktivatoren (Kollagen und Adrenalin) Thromboembolien im arteriellen und venösen System ausgelöst werden. Als Ursache hierfür wird die direkte aktivierende Wirkung von Leptin auf Thrombozyten gesehen (Giandomenico et al. 2005, Nakata et al. 1999, Dellas et al. 2007). Dass dies in der vorliegenden Arbeit nicht bestätigt werden konnte, könnte in der untergeordneten Rolle der Thrombozytenaggregation bei der Entstehung venöser Thrombosen begründet sein. Hier ist vor allem die Strömungsverlangsamung und die Aktivierung der plasmatischen Gerinnung entscheidend.

Patienten mit einer Lungenembolie hatten signifikant höhere Adiponectinwerte als Patienten ohne Lungenembolie. Aufgrund der Erkenntnisse experimenteller Arbeiten bestand die Hypothese, dass Adiponectin vor Thrombosen schützt (Kato et al. 2006), dementsprechend wäre bei Patienten mit einer Lungenembolie ein niedriger Adiponectinspiegel zu erwarten gewesen. In den letzten Jahren zeigte sich, dass Adiponectin auch einen kardialen Ursprung und Einfluss zu haben scheint. Pineiro et al. (2005) wiesen sowohl in Kardiomyozyten der Maus als auch in menschlichen Herzmuskelzellen Adiponectin-m-RNA nach, was Ding et al. (2007) an isolierten Herzmuskelzellen von Ratten bestätigten. Zudem wurde die Expression der Adiponectin-Rezeptoren AdipoR1 und R2 auf Kardiomyozyten nachgewiesen (Fujioka et al. 2006). Takano et al. (2007) bestätigten diese Ergebnisse in einer klinischen Studie bei Patienten mit Herzinsuffizienz: Messungen des Adiponectinspiegels in der Aorta, dem Koronarsinus und den peripheren Venen zeigten, dass der Adiponectinspiegel im Koronarsinus höher war als in der Aorta, was auf eine kardiale Sekretion des Adiponectins hindeutet. Adiponectin scheint also kardial sezerniert zu werden und über Adiponectin-Rezeptoren auch eine direkte kardiale Wirkung zu haben. Im Mausversuch war Adiponectin kardio-protektiv und verminderte die Apoptoserate von Herzmuskelzellen nach einer myokardialen Ischämie mit folgender Reperfusion (Shibata et al. 2005). Eine Hyperadiponectinämie bei Lungenemboliepatienten könnte somit Ausdruck 
einer kardialen Sekretion und Wirkung des Adiponectins infolge des oxidativen Stresses nach einer Lungenembolie sein.

Auch die wiederholt beschriebene Korrelation zwischen Adiponectin und den natriuretischen Peptiden deutet in diese Richtung. In der vorliegenden Arbeit zeigte sich eine Korrelation zwischen Adiponectin und NT-pro BNP. Dieser Zusammenhang scheint über zyklisches Guanosin Monophosphosphat (cGMP), einen second messenger der kardialen natriuretischen Peptide vermittelt zu werden (Tanaka et al. 2008). Tsutamoto et al. (2007) zeigten, dass BNP die m-RNA-Bildung und Sekretion des Adiponectins in Adipozyten in vitro erhöht und dass dies über cGMP als Second Messenger erfolgt. Auch wenn sich die Adiponectinspiegel bei Patienten mit und ohne echokardiographische Rechtsherzbelastung in der vorliegenden Arbeit nicht signifikant unterschieden, so ist die positive Korrelation mit NT-pro BNP ein Hinweis darauf, dass die Hyperadiponectinämie nach einer Lungenembolie Folge der rechtsventrikulären Druckbelastung sein könnte und dass NT-pro BNP, welches bei Rechtsherzbelastung vermehrt sezerniert wird, auch zu einem Anstieg des Adiponectinspiegels führt. Da Adiponectin ein Hormon mit einem niedrigen Molekulargewicht ist (24,6 kDA), könnte es schnell ins Blut gelangen und somit ein sensitiver Parameter zum Nachweis einer Rechtsherzbelastung sein.

Patienten mit einer Lungenembolie waren im Schnitt älter als Patienten ohne Lungenembolie, auch wenn dieser Unterschied nicht signifikant war $(\mathrm{p}=0,051)$. Da der Adiponectin-Spiegel in der Fall-, jedoch nicht in der Kontrollgruppe mit dem Alter korrelierte, könnte dies ebenfalls zu dem höheren Adiponectin-Spiegel bei den Lungenemboliepatienten beigetragen haben, ein mit zunehmendem Alter ansteigender Adiponectinspiegel ist ja mehrfach beschrieben worden (siehe Kapitel 4.3.3). Der SerumKreatininspiegel in der Fallgruppe war ebenfalls höher als in der Kontrollgruppe ( $\mathrm{p}=0,011)$. Guebre-Egziabher et al. (2005) hatten bei Patienten mit Niereninsuffizienz erhöhte Adiponectin-Spiegel beobachtet, sodass dieser Sachverhalt zu den höheren Adiponectinwerten bei Patienten mit einer Lungenembolie beitragen könnte.

Abschließend lässt sich in Beantwortung der Fragestellung (siehe Kap. 1.7 und Überschrift des Kap. 4.3.5) aus dieser Studie ableiten: Patienten mit einer Lungenembolie hatten keinen erhöhten Leptinspiegel, aber signifikant erhöhte Adiponectinwerte. 


\subsubsection{Haben die Adipozytokine eine prognostische Bedeutung?}

Adiponectin, sobR und der FLI hatten weder für die Komplikationsrate während des Krankenhausaufenthalts noch für das Langzeit-Überleben nach einer akuten Lungenembolie eine prognostische Bedeutung.

Im Gegensatz dazu erwies sich Leptin als signifikanter Prädiktor, sowohl für die InhospitalKomplikationsrate als auch für das Langzeit-Überleben. Bemerkenswert ist dabei, dass ein erhöhter Leptinwert mit einer niedrigeren Komplikations- bzw. Mortalitätsrate einherging. Dies wird bestätigt durch Analysen der Leptin-Tertile, wo sich ein signifikant besseres Langzeit-Überleben bei höheren Leptinwerten zeigte (Logrank-Test: $\mathrm{p}=0,014$ ). Dabei ergaben die Vergleiche des Alters, der Häufigkeit von Malignomen sowie der GFR zwischen den drei Tertilen keine signifikanten Unterschiede. Inwiefern der BMI einen Einfluss auf diese Ergebnisse hatte, ist schwierig zu beantworten. Zunächst stellte der BMI als kontinuierlich getestete Variable in der logistischen Regression selber keinen signifikanten Parameter auf die Inhospital-Prognose und den Langzeitverlauf dar. Wurden unabhängig vom Leptin, BMI-Tertile gebildet, so waren die Überlebenskurven der drei BMI-Tertile nicht signifikant unterschiedlich (Logrank-Test: $\mathrm{p}=0$,088), ganz im Gegensatz zu den statistisch signifikanten Unterschieden der Leptin-Tertile. Bei der Korrektur von Leptin (lnLeptin) um den BMI in der Regressionsanalyse verblieb Leptin ein signifikanter und vom BMI unabhängiger - Parameter. Demzufolge ist Leptin in den Endpunktanalysen ein vom BMI ein unabhängiger Prädiktor für den Inhospital- und Langzeitverlauf und zwar im Sinne von einer verbesserten Prognose bei erhöhten Leptinwerten. Demgegenüber muss die bekannte und auch in dieser Studie bestätigte enge Korrelation zwischen Leptin und dem BMI ( $<<0,0001 \mathrm{r}=0,561)$ berücksichtigt werden. Zusätzlich fanden sich in der deskriptiven Statistik signifikant höhere BMI-Werte in den prognostisch relevanten oberen Leptin-Tertilen. Auch wenn die Überlebenskurven der drei BMI-Tertile sich nicht signifikant unterschieden (s.o.), so ergab jedoch der direkte Vergleich der Tertile untereinander ein besseres Überleben im dritten BMI-Tertil gegenüber dem ersten Tertil $(p=0,041)$. Die deskriptiven Analysen zeigen also zumindest einen gewissen Zusammenhang zwischen einem hohen BMI und einem verbesserten Überleben.

Die niedrigere Inhospital-Komplikationsrate und das bessere Langzeit-Überleben bei höheren Leptinwerten widersprechen auf den ersten Blick bisherigen Erkenntnissen. Die Adipositas und damit ein hoher BMI prädisponieren für zahlreiche Folgeerkrankungen mit einer erhöhten Mortalität, sodass bei Patienten mit einem hohem BMI und einem hohen 
Leptinspiegel eine schlechtere Prognose zu erwarten gewesen wäre. Der signifikant höhere BMI im dritten Leptin-Tertil und die bessere Überlebensrate des dritten verglichen mit dem ersten BMI-Tertil könnten zunächst darauf hindeuten, dass der BMI einen gewissen Einfluss hat. Dass ein erhöhter BMI nicht zwangsläufig, wie bisher angenommen, mit einer schlechteren Überlebensrate einhergeht, hatte sich in den letzten Jahren wiederholt gezeigt und wird mit dem Begriff „obesity paradox" beschrieben. So liegt in den USA der BMI mit der niedrigsten Mortalität im mittleren Alter bei $27 \mathrm{~kg} / \mathrm{m}^{2}$, bei Patienten über 70 Jahren sogar zwischen 27-35 kg/m² (Flegal et al. 2005). Übergewichtige Personen sind von einer niedrigeren Mortalität als normalgewichtige Personen betroffen, während adipöse und sehr adipöse Patienten eine deutlich erhöhte Mortalität aufweisen.

Verschiedene Arbeiten zeigen aber auch, dass eine Hyperleptinämie unabhängig vom BMI ein Parameter für eine gute Prognose bei bestimmten Erkrankungen ist, so dass auch eine BMI-unabhängige Wirkung von Leptin mit der verbesserten Prognose der Lungenemboliepatienten denkbar wäre, worauf die Endpunktanalysen zur Inhospital- und Langzeitprognose deuten. So wurde bei Patienten mit einer dialysepflichtigen chronischen Niereninsuffizienz ein niedriger Leptinspiegel als ein unabhängiger Prädiktor für eine erhöhte Mortalität beschrieben (Scholze et al. 2007). Die Leptinspiegel bei Patienten, die eine Sepsis überlebten, waren deutlich höher als bei Patienten, die diese nicht überlebten (Bornstein et al. 1998). Bei Mäusen verbesserte exogen zugeführtes rekombinantes Leptin den Verlauf einer septischen Arthritis (Hultgren und Tarkowski 2001), darüber hinaus scheint Leptin bei Mäusen einen stärkenden Effekt auf das Immunsystem zu haben (Faggioni et al. 2000). Bei Patienten mit einem Kolon Karzinom korrelierte die LeptinExpression mit den Zeichen des guten Outcomes (Paik et al. 2009). Leptin scheint darüber hinaus durch eine lokale kardiale Wirkung die reparativen Umbauvorgänge am ischämisch geschädigten Herzen positiv zu beeinflussen. Purdham et al. (2004) beobachteten eine kardiale Sekretion von Leptin an Rattenherzen und fanden im Myokard von Ratten drei verschiedene Formen des Leptinrezeptors. Im Mausversuch konnte gezeigt werden, dass Leptin nach einer chronisch ischämischen Schädigung des Herzens die Schwere der kardialen Dysfunktion reduziert (McGaffin et al. 2008). An Kardiomyozyten beim Menschen und bei Ratten wurde ein stimulierender Einfluss von Leptin auf das Wachstum beobachtet (Tajmir et al. 2004). Leptin scheint also direkte, BMI-unabhängige kardioprotektive Effekte zu besitzen. Demgegenüber stehen allerdings die Erkenntnisse, dass Leptin die Thrombozyten direkt stimuliert und die Ausbildung arterieller Thromben fördert (Dellas et al. 2007). Dabei ist hervorzuheben, dass der Effekt von Leptin auf die 
Thrombozytenaggregation unabhängig vom BMI ist (Dellas et al. 2008). Dies in Zusammenhang mit klinischen Studien (Wallace et al. 2001) führte dazu, dass eine Hyperleptinämie als unabhängiger kardiovaskulärer Risikofaktor beschrieben wird. Die zitierten Arbeiten zeigen also, dass die pleiotropen Effekte von Leptin sowohl protektive als auch viele nachteilige Auswirkungen haben können, die wiederum vom BMI abhängig als auch unabhängig sein können.

Abschließend lässt sich in Beantwortung der Fragestellung (siehe Kap. 1.7 und Überschrift von Kapitel 4.3.6) aus dieser Studie ableiten: erhöhte Leptinspiegel gehen mit einer verbesserten Akut- und Langzeitprognose bei Patienten mit einer akuten Lungenembolie einher. Als Prädiktor ist Leptin dabei unabhängig vom BMI. Darüber hinaus gibt es aber auch ein besseres Überleben im obersten BMI-Tertil im Sinne des „obesity paradox“ sowie signifikant erhöhte BMI-Werte in den prognostisch relevanten Leptin-Tertilen. Adiponectin hatte keinen Einfluss auf die Prognose.

\subsection{Limitationen der vorliegenden Studie}

Limitationen der vorliegenden Arbeit ergeben sich durch die geringe Fallzahl in der Fallund Kontrollgruppe und durch die niedrige absolute Zahl von Patienten mit Komplikationen. Der mittlere BMI lag in beiden Gruppen im Bereich von Übergewicht, was aufgrund seiner Komplexität weitergehende Einflüsse, unabhängig von den Adipozytokinen, auf den Akut- und Langzeitverlauf haben könnte. Die Patienten mit einer akuten Lungenembolie waren relativ alt und wiesen einen erhöhten Serum-Kreatininspiegel auf. All diese Faktoren können die Serumspiegel von Leptin und Adiponectin beeinflussen und so die Aussagekraft der vorliegenden Ergebnisse einschränken.

Mit dem gewählten Studiendesign und der gewählten N-Zahl sind verschiedene Fragestellungen, z.B. ob der BMI, ob Leptin und Adiponectin Risikofaktoren für das Auftreten einer akuten Lungenembolie sind, nicht ausreichend sicher zu beantworten. Hierzu wäre die Durchführung einer großen Kohortenstudie nötig.

\subsection{Ausblick}

Ein erhöhter Leptinspiegel war in der vorliegenden Studie ein prognostischer Parameter für eine niedrigere Inhospital-Komplikationsrate und ein besseres Langzeit-Überleben nach einer akuten Lungenembolie. Als Prädiktor war Leptin dabei unabhängig vom BMI. Welche 
systemischen oder lokalen kardialen Leptinwirkungen Einfluss auf die Prognose haben, wäre Gegenstand weiterer experimenteller Studien. Darüber hinaus waren hohe BMI-Werte im dritten BMI-Tertil mit einem besseren Überleben assoziiert - passend zu anderen Berichten des „obesity paradox“.

Die Adiponectinwerte bei Patienten mit einer akuten Lungenembolie waren signifikant erhöht. Wahrscheinlich ist eine kardiale Sekretion und Wirkung des Adiponectins als Ursache hierfür zu sehen. Die Korrelation mit NT-pro BNP und Ergebnisse anderer Studien über den Einfluss von BNP auf die Adiponectinsynthese deuten darauf hin. Somit könnte Adiponectin ein neuer sensitiver Parameter zum Nachweis von Rechtsherzbelastungszeichen nach einer akuten Lungenembolie sein. Dies wäre in weiteren klinischen und experimentellen Untersuchungen zu klären. 


\section{Zusammenfassung}

In der vorliegenden Arbeit wurde die Bedeutung der Adipozytokine Leptin und Adiponectin untersucht. In experimentellen Arbeiten hatte sich gezeigt, dass Leptin sowohl zur Entstehung arterieller als auch venöser Thromboembolien beiträgt, Adiponectin hingegen erwies sich als antithrombogener Faktor. Somit wurde die Hypothese aufgestellt, dass Patienten mit einer Lungenembolie hohe Leptin- und niedrige Adiponectinspiegel aufweisen und diese einen Einfluss auf die Prognose haben. Dies wurde in einer prospektiven Fall-Kontroll-Studie an 97 Patienten mit einer akuten Lungenembolie und 40 Kontrollpatienten mit Ausschluss einer Lungenembolie untersucht. Das Überleben der Patienten der Fallgruppe wurde durch ein Follow-Up über vier Jahre erhoben.

Der Leptinspiegel bei Patienten mit einer Lungenembolie unterschied sich nicht signifikant von Patienten ohne Lungenembolie (26,37 $\pm 39,54 \mathrm{ng} / \mathrm{ml}$ vs. 20,32 $\pm 25,84 \mathrm{ng} / \mathrm{ml}, \mathrm{p}=0,497)$. Jedoch war ein höherer Leptinspiegel ein prognostischer Parameter für eine niedrigere Inhospital-Komplikationsrate, definiert als Tod infolge einer Lungenembolie, Reanimation, Intubation, Katecholaminbedarf oder Hypotonie $(\mathrm{p}=0,028, \mathrm{OR}=0,37)$, und für ein besseres Langzeit-Überleben ( $\mathrm{p}=0,001, \mathrm{HR}=0,55)$. Als Prädiktor war Leptin dabei unabhängig vom BMI, was auf direkte systemische oder kardiale Wirkungen hindeutet, jedoch in weiteren Studien untersucht werden müsste. Darüber hinaus bestand bei hohen BMI-Werten ein besseres Langzeit-Überleben und die oberen Leptin-Tertile wiesen signifikant höhere BMI-Werte auf. Somit könnte eine Ursache für ein besseres Überleben bei höherem BMI im „obesity paradox“ liegen, also der Tatsache, dass übergewichtige Patienten eine niedrigere Mortalität aufweisen, wie es in zahlreichen anderen Studien beobachtet wurde.

Patienten mit einer akuten Lungenembolie hatten signifikant höhere Adiponectinwerte als Patienten ohne Lungenembolie $(11,74 \pm 12,98 \mu \mathrm{g} / \mathrm{ml}$ vs. 7,04 $\pm 3,54 \mu \mathrm{g} / \mathrm{ml}, \mathrm{p}=0,034)$. Adiponectin korrelierte bei den Lungenemboliepatienten mit NT-pro BNP, einem sensitiven Biomarker für eine rechtsventrikuläre Funktionsstörung $(p=0,0004 \quad r=0,366)$. Ein Zusammenhang mit anderen Parametern, die in der vorliegenden Arbeit mit einer schlechten Prognose in der Akutphase vergesellschaftet waren, bestand hingegen nicht. Im Gegensatz zu Leptin besaß Adiponectin jedoch keinen prädiktiven Wert für die Inhospital-Komplikationsrate $(p=0,587)$ und das Langzeit-Überleben ( $p=0,387)$. Entgegen der Erwartung, dass Adiponectin anti-thrombogene Eigenschaften besitzt, könnten die höheren Adiponectinwerte bei Patienten mit einer Lungenembolie auf eine kardiale Sekretion und Wirkung von Adiponectin hinweisen. Ein erhöhter Adiponectinspiegel nach einer Lungenembolie könnte Folge der 
rechtsventrikulären Druckbelastung sein, wie durch die positive Korrelation mit NT-pro BNP angedeutet wird. Damit könnte Adiponectin ein neuer sensitiver Parameter zur Erfassung der rechtsventrikulären Dysfunktion nach einer Lungenembolie sein. 


\section{Literaturverzeichnis}

American Thoracic Society (1999): The Diagnostic Approach to Acute Venous Thromboembolism. Am J Respir Crit Care Med; 160, 1043-1066.

Anderson FA, Spencer FA (2003): Risk Factors for Venous Thromboembolism. Circulation; 107: I-9- I-16.

Binder L, Pieske B, Olschewski M, Geibel A, Klostermann B, Reiner C, Konstantinides S (2005): N-Terminal Pro-Brain Natriuretic Peptide or Troponin Testing Followed by Echocardiography for Risk Stratification of Acute Pulmonary Embolism. Circulation; 112, 1573-1579.

Blaszyk H, Björnsson J (2000): Factor V Leiden and Morbid Obesity in Fatal Postoperative Pulmonary Embolism. Arch Surg; 135, 1410-1413.

Bodary PF, Westrick RJ, Wickenheiser KJ, Shen Y, Eitzman DT (2002): Effect of Leptin on Arterial Thrombosis Following Vascular Injury in Mice. JAMA; 287, 1706-1709.

Bornstein SR, Licinio J, Tauchnitz R, Engelmann L, Negrao AB, Gold P, Chrousos GP (1998): Plasma Leptin Levels are Increased in Survivors of Acute Sepsis: Associated Loss of Diurnal Rhythm in Cortisol and Leptin Secretion. J Clin Endocrinol Metab; 83, 280-283.

Considine RV, Sinha MK, Heiman ML, Kriauciunas A, Stephens TW, Nyce MR, Ohannesian JP, Margo CC, Mc Kee LJ, Bauer TL, Caro JF (1996): Serum Immunoreactive-Leptin Concentrations in normal-weight and obese Humans. N Engl J Med; 334, 292-295.

Dalen JE (2002): Pulmonary Embolism: What Have We Learned Since Virchow. Chest; $\underline{122}$, 1440-1456.

Dellas C, Schäfer K, Rohm IK, Lankeit M, Leifheit M, Loskutoff DJ, Hasenfuss G, Konstantinides S (2007): Leptin signalling and leptin-mediated activation of human platelets: importance of JAK2 and the phospholipases C gamma2 and A2. Thromb Haemost; $\underline{98}$, 10631071.

Dellas C, Schäfer K, Rohm I, Lankeit M, Ellrot T, Faustin V, Riggert J, Hasenfuss G, Konstantinides S (2008): Absence of leptin resistance in platelets from morbidly obese individuals may contribute to the increased thrombosis risk in obesity. Thromb Haemost; 100 (6), 1123-1129.

Dempfle CE (2005): D-Dimer testing and venous thromboembolism: four view points. J Thromb Haemost; $\underline{3}$, 377-379. 
Ding G, Qin Q, He N, Francis-David SC, Hou J, Ricks E, Yang Q (2007): Adiponectin and its receptors are expressed in adult ventricular cardiomyocytes and upregulated by activation of peroxisome proliferators-activated receptor $\mu$. J Mol Cell Cardiol; $\underline{43}$, 73-84.

Elbatarny HS, Maurice DH (2005): Leptin-mediated Activation of human platelets: involvement of a leptin receptor and phosphodiesterase 3A-containing cellular signaling complex. Am J Physiol Endocrinol Metab; 289, E 695- E 702.

Faggioni R, Moser A, Feingold K, Grunfeld C (2000): Reduced Leptin Levels in Starvation Increase Susceptibility to Endotoxic Shock. Am J Pathol; 156, 1781-1787.

Fernandez JA, Pecheniuk NM, Deguchi H, Elias DJ, Griffin JH (2006): Is Adiponectin implicated in venous thromboembolism? J Thromb Haemost; 4, 1151-1152.

Ferrari E, Imbert A, Chevalier T, Mihoubi A, Morand P, Baudouy M (1997): The ECG in pulmonary embolism. Predictive value of negative T-waves in precordial leads- 80 case reports. Chest; 111 , 537-543.

Flegal KM, Graubard BI, Williamson DF, Gail MH (2005): Excess Deaths Associated With Underweight, Overweight, and Obesity. JAMA; 293, 1861-1867.

Fox K, Borer JS, Camm AJ, Danchin N, Ferrari R, Lopez Sendon JL, Steg PG, Tardif JC, Tavazzi L, Tendera M; Heart Rate Working Group (2007): Resting heart rate in cardiovascular disease. J Am Coll Cardiol; 무, 823-830.

Fujioka D, Kawabata K-I, Saito Y, Kobayashi T, Nakamura T, Komada Y, Takano H, Obata J-e, Kitta Y, Umetani K, Kugiyama K (2006): Role of adiponectin receptors in endothelin-induced cellular hypertrophy in cultured cardiomyocytes and their expression in infarcted heart. Am J Physiol Heart Circ Physiol; 290, 2409-2416.

Giandomenico G, Dellas C, Czekay RP, Koschnick S, Loskutoff DJ (2005): The Leptin Receptor System of Human Platelets. J Thromb Haemost; 3 (5), 1042-1049.

Goldhaber SZ (2002): Echocardiography in the Management of Pulmonary Embolism. Ann Intern Med; 136, 691-700.

Goldhaber SZ, Elliott GC (2003): Acute Pulmonary Embolism: Part 1. Epidemiology, Pathophysiology, and Diagnosis. Circulation; 108, 2726-2729.

Goldhaber SZ, Grodstein F, Stampfer MJ, Manson JE, Colditz GA, Speizer FE, Hennekens CH (1997): A prospective study of risk factors for pulmonary embolism in women. JAMA; $\underline{277}$, 642-645. 
Grifoni S, Olivetto I, Cecchini P, Pieralli F, Camaiti A, Santoro G, Conti A, Agnelli G, Berni G (2000): Short-Term Clinical Outcome of Patients With Acute Pulmonary Embolism, Normal Blood Pressure, and Echocardiographic Right Ventricular Dysfunction. Circulation; 101, 28172822.

Guebre-Egziabher F, Bernhard J, Funahashi T, Hadj-Aissa A, Fouque D (2005): Adiponectin in chronic kidney disease is related more to metabolic disturbances than to decline in renal function. Nephrol Dial Transplant; 20, 129-134.

Hansson P-O, Eriksson H, Welin L, Svärdsudd K, Wilhelmsen L (1999): Smoking and Abdominal Obesity: Risk Factors for Venous Thromboembolism Among Middle-aged Men: “The Study of Men born in 1913”. Arch Intern Med; 159, 1886-1890.

Havel PJ, Kasim-Karakas S, Mueller W, Johnson PR, Gingerich RL, Stern JS (1996): Relationship of Plasma Leptin to Plasma Insulin and Adiposity in Normal Weight and Overweight Women: Effects of Dietary Fat Content and Sustained Weight Loss. J Clin Endocrinol Metab; 81, 4406-4413.

Hopkins TA, Ouchi N, Shibata R, Walsh K (2007): Adiponectin actions in the cardiovascular system; Cardiovasc Res; 74, 11-18.

Houseknecht KL, Baile CA, Matteri RL, Spurlock ME (1998): The Biology of Leptin: a Review. J Anim Sci; $\underline{76}$, 1405-1420.

Hultgren OH, Tarkowski A (2001): Leptin in septic arthritis: decreased levels during infection and amelioration of disease activity upon its administration. Arthritis Res; $\underline{3}$, 389-394.

Kabrhel C, Varraso R, Goldhaber SZ, Camargo CA (2009): Prospective study of BMI and the risk of pulmonary embolism in women. Obesity; 17, 2040-2046.

Kalra SP (2008): Central leptin insufficiency syndrome: an interactive etiology for obesity, metabolic and neural diseases and for designing new therapeutic interventions. Peptides; $\underline{29}$, 127-138.

Kato H, Kashiwagi H, Shiraga M, Tadokoro S, Kamae T, Ujiie H, Honda S, Miyata S, Ijiri Y, Yamamoto J, Maeda N, Funahashi T, Kurata Y, Shimomura I, Tomiyama Y, Kanakura Y (2006): Adiponectin Acts as an Endogenous Antithrombotic Factor. Arterioscler Thromb Vasc Biol; 26, 224-230.

Kintscher U (2007): Does Adiponectin resistance exist in chronic heart failure? Eur Heart J; $\underline{28}$, 1676-1677.

Kistorp C, Faber J, Galatius S, Gustafsson F, Frystyk J, Flyvberg A, Hildebrandt P (2005): Plasma Adiponectin, Body Mass Index, and Mortality in Patients With Chronic Heart Failure. Circulation; 112: 1756-1762. 
Klok FA, Mos ICM, Huisman MV (2008): Brain-Type Natriuretic Peptide Levels in the Prediction of Adverse Outcome in Patients with Pulmonary Embolism. Am J Respir Crit Care Med; 178 , 425-430.

Konstantinides S, Schäfer K, Loskutoff DJ (2001 a): The Prothrombotic Effects of Leptin. Possible Implications for the Risk of Cardiovascular Disease in Obesity. Ann NY Acad Sci; 947, 134-141.

Konstantinides S, Schäfer K, Koschnick S, Loskutoff DJ (2001 b): Leptin-dependent platelet aggregation and arterial thrombosis suggests a mechanism for atherothrombotic disease in obesity. J Clin Invest; 108, 1533-1540.

Konstantinides S, Geibel A, Olschewski M, Kasper W, Hruska N, Jäckle S, Binder L (2002 a): Importance of Cardiac Troponins $\mathrm{I}$ and $\mathrm{T}$ in Risk Stratification of Patients With Acute Pulmonary Embolism. Circulation; 106, 1263-1268.

Konstantinides S, Geibel A, Heusel G, Heinrich F, Kasper W for the Management Strategies and Prognosis of Pulmonary Embolism-3 Trial Investigators (2002 b): Heparin plus Alteplase compared with Heparin alone in Patients with submassive Pulmonary Embolism. N Engl J Med; 347, 1143-1150.

Konstantinides S, Schäfer K, Neels J, Dellas C, Loskutoff DJ (2004): Inhibition of Endogenous Leptin Protects Mice From Arterial and Venous Thrombosis. Arterioscler Thromb Vasc Biol; 24, 2196-2201.

Konstantinides S, Janssens U, Mayer E, Hasenfuß G (2009): Kommentar zu den ESC-Leitlinien „Guidelines on Diagnosis and Management of Acute Pulmonary Embolism.“ Kardiologe; $\underline{3}$, 272-282.

Kreit JW (2004): The Impact of Right Ventricular Dysfunction on the Prognosis and Therapy of Normotensive Patients With Pulmonary Embolism. Chest; 125, 1539-1545.

Kucher N, Luder CM, Dörnhöfer T, Windecker S, Meier B, Hess OM (2003): Novel Management strategy for patients with suspected pulmonary embolism. Eur Heart J; 24, 366376.

Kucher N, Tapson VF, Goldhaber SZ; DVT FREE Steering Committee (2005): Risk factors associated with symptomatic pulmonary embolism in a large cohort of deep vein thrombosis patients. Thromb Haemost; 93, 494-498.

Kucher N, Rossi E, De Rosa M, Goldhaber SZ (2006): Massive Pulmonary Embolism. Circulation; 113 , 577-582. 
Kumada M, Kihara S, Sumitsuji S, Kawamoto T, Matsumoto S, Ouchi N, Arita Y, Okamoto Y, Shimomura I, Hiraoka H, Nakamura T, Funahashi T, Matsuzawa Y and for the Osaka CAD Study Group (2003): Association of Hypoadiponectinemia With Coronary Artery Disease in Men. Arterioscler Thromb Vasc Biol; 23, 85-89.

Lahlou N, Issad T, Lebouc Y, Carel J-C, Camoin L, Roger M, Girard J (2002): Mutations in the Human Leptin and Leptin Receptor Genes as Models of Serum Leptin Receptor Regulation. Diabetes; $\underline{51}$, 1980-1985.

Lammert A, Kiess W, Bottner A, Glasow A, Kratzsch J (2001): Soluble Leptin Receptor Represents the Main Leptin Binding Activity in Human Blood. Biochem Biophys Res Commun; $\underline{283}, 982-988$.

Landt M, Parvin CA, Wong M (2000): Leptin in Cerebrospinal Fluid from Children: Correlation with Plasma Leptin, Sexual Dimorphism, and Lack of Protein Binding. Clin Chem; $\underline{46: 6}$, 854858.

Laughlin GA, Barrett-Connor E, May S, Langenberg C (2007): Association of Adiponectin with Coronary Heart Disease and Mortality: The Rancho Bernardo Study. Am J Epidemiol; 165 (2), 164-174.

Leyva F, Godsland IF, Ghatei M, Proudler AJ, Aldis S, Walton C, Bloom S, Stevenson JC (1998). Hyperleptinemia as a Component of a Metabolic Syndrome of Cardiovaskular Risk. Arterioscler Thromb Vasc Biol; 18, 928-933.

Matsuzawa Y, Funahashi T, Kihara S, Shimomura I (2004): Adiponectin and Metabolic Syndrome. Arterioscler Thromb Vasc Biol; 24, 29-33.

McGaffin KR, Sun C-K, Rager JJ, Romano LC, Zou B, Mathier MA, O’Doherty RM, McTiernan CF, O`Donnell CP (2008): Leptin signalling reduces the severity of cardiac dysfunction and remodelling after chronic ischaemic injury. Cardiovasc Res, $\underline{77}$, 54-63.

Meyer T, Binder L, Hruska N, Luthe H, Buchwald AB (2000): Cardiac Troponin I Elevation in Acute Pulmonary Embolism Is Associated With Right Ventricular Dysfunction. J Am Coll Cardiol; 36, 1632-1636.

Miniati M, Prediletto R, Formichi B, Marini C, Di Ricco G, Tonelli L, Allescia G, Pistolesi M (1999): Accuracy of Clinical Assessment in the Diagnosis of Pulmonary Embolism. Am J Resp Crit Care Med; $\underline{159}$, 864-871.

Nakata M, Yada T, Soejima N, Maruyama I (1999): Leptin Promotes Aggregation of Human Platelets via the Long Form of Its Receptor. Diabetes; 48, 426-429. 
Ogawa T, Hirose H, Yamamoto Y, Nishikai K, Miyashita K, Nakamura H, Saito I, Saruta T (2004): Relationships Between Serum Soluble Leptin Receptor Level and Serum Leptin and Adiponectin Levels, Insulin Resistance Index, Lipid Profile, and Leptin Receptor Gene Polymorphisms in the Japanese Population. Metabolism; 53-7, 879-885.

Oger E (2000): Incidence of venous thromboembolism: a community-based study in Western France. EPI-GETBP Study Group. Group d`Etudes de la Thrombose de Bretagne Occidentale. Thromb Haemost; $\underline{\text { 83, 657-660. }}$

Ögren M, Eriksson H, Bergqvist D, Sternby N-H (2005): Subcutaneous fat accumulation and BMI associated with risk for pulmonary embolism in patients with proximal deep vein thrombosis: a population study based on 23.796 consecutive autopsies. J Int Med; 258: 166-171.

Paik SS, Jang SM, Jang KS, Lee KH, Choi D, Jang SJ (2009): Leptin expression correlates with favorable clinicopathologic phenotype and better prognosis in colorectal adenocarcinoma. Ann Surg Oncol; 16, 297-303.

Pineiro R, Iglesias MJ, Gallego R, Raghay K, Eiras S, Rubio J, Dieguez C, Gualillo O, Gonzalez-Juanatey JR, Lago F (2005): Adiponectin is synthesized and secreted by human and murine cardiomyozytes. FEBS Lett; $\underline{579}$, 5163-5169.

Poehls J, Wassel C, Harris TB, Havel PJ, Swarbrick MM, Cummings SR, Newman AB, Satterfield S, Kanaya AM for the Health ABC study (2009): Association of Adiponectin and Mortality in Older Adults: Health ABC Study. Diabetologia; 52, 591-595.

Purdham DM, Zou M-X, Rajapurohitam V, Karmazyn (2004): Rat heart is a site of leptin production and action. Am J Physiol Heart Circ Physiol; 287, 2877-2884.

Rodger MA, Carrier M, Jones GN, Rasuli P, Raymond F, Djunaedi H, Wells PS (2000): Diagnostic Value of Arterial Blood Gas Measurement in Suspected Pulmonary Embolism. Am J Respir Crit Care Med; 162, 2105-2108.

Ryo M, Nakamura T, Kihara S, Kumada M, Shibazaki S, Takahashi M, Nagai M, Matsuzawa Y, Funahashi T (2004): Adiponectin as a Biomarker of the Metabolic Syndrome. Circ J; $\underline{68}$, 975981.

Scarpace P, Zhang Y (2008): Leptin resistance: a predisposing factor for diet-induced obesity. Am J Physiol Regul Integr Comp Physiol; 296, R 493-R500.

Schoepf JU, Goldhaber SZ, Costello P (2004): Spiral Computed Tomography for Acute Pulmonary Embolism. Circulation; 109, 2160-2167.

Scholze A, Rattensperger D, Zidek W, Tepel M (2007): Low Serum Leptin Predicts Mortality in Patients with Chronic Kidney Disease Stage 5. Obesity; 15, 1617-1622. 
Shibata R, Sato K, Pimentel DR, Takemura Y, Kihara S, Ohashi K, Funahashi T, Ouchi N, Walsh K (2005): Adiponectin protects against myocardial ischemia-reperfusion injury through AMPK- and COX-2-dependent mechanisms. Nat Med; 11, 1096-1103.

Shimizu H, Shimomura Y, Hayashi R, Ohtani K, Sato N, Futawatari T, Mori M (1997): Serum Leptin Concentration is associated with Total Body Fat Mass, but not abdominal fat distribution. Int J Obes; 21, 536-541.

Sinha MK, Opentanova I, Ohannesian JP, Kolaczynski JW, Heiman ML, Hale J, Becker GW, Bowsher RR, Stephens TW, Caro JF (1996): Evidence of Free and Bound Leptin in Human Circulation. J Clin Invest; $\underline{98}$, 1277-1282.

Stein PD, Henry JW (1995): Prevalence of Acute Pulmonary Embolism Among Patients in a General Hospital and at Autopsy. Chest; 108, 978-981.

Sugimura K, Sakuma M, Shirato K (2006): Potential Risk Factors and Incidence of Pulmonary Thromboembolism in Japan- Results from an Overview of Mailed Questionnaires and a Matched Case-Control-Study. Circ J; 70, 542-547

Swarbrick MM, Havel PJ (2008): Physiological, pharmacological, and nutricional regulation of circulating adiponectin concentrations in humans. Metab Syndr Relat Disord; $\underline{6}$, 87-102.

Tajmir P, Ceddia RB, Li R-K, Coe IR, Sweeney G (2004): Leptin Increases Cardiomyocyte Hyperplasia via Extracellular Signal-Regulated Kinase-and Phosphatidylinositol 3-KinaseDependent Signaling Pathways. Endocrinology; $\underline{145}$, 1550-1555.

Takano H, Obata J-e, Kodama Y, Kitta Y, Nakamura T, Mende A, Kawabata K-I, Saito Y, Fujioka D, Kobayashi T, Yano T, Sano K, Kugiyama K (2007): Adiponectin is released from the heart in patients with heart failure. Int J Cardiol; 132, 221-226.

Tanaka T, Tsutamoto T, Nishiyama K, Sakai H, Fujii M, Yamamoto T, Horie M (2008): Impact of Oxidative Stress on Plasma Adiponectin in Patients With Chronic Heart Failure. Circ J; $\underline{72}$, 563-568.

Tartaglia LA (1997): The Leptin Receptor. J Biol Chem; 272, 6093-6096.

The Christopher Study Investigators (2006): Effectiveness of Managing Suspected Pulmonary Embolism Using a Algorithm Combining Clinical Probability, D-Dimer-Testing and Computed Tomography. JAMA; 295, 172-179.

Torbicki A, Chairperson, Perrier A, Konstantinides S, Agnelli G, Galie N, Prusczyk P, Bengel F, Brady AJB, Ferreira D, Janssens U, Klepetko W, Mayer E, Remy-Jardin M, Bassand J-P (2008). Guidelines on the diagnosis and management of acute pulmonary embolism of the European Society of Cardiology (ESC). Eur Heart J; 29, 2276-2315. 
Tsai AW, Cushman M, Rosamond WD, Heckbert SR, Polak JF, Folsom AR (2002): Cardiovascular Risk Factors and Venous Thromboembolism Incidence. Arch Intern Med; 162, 1182-1189.

Tsutamoto T, Tanaka T, Sakai H, Ishikawa C, Fujii M, Yamamoto T, Horie M (2007): Total and high molecular weight adiponectin, haemodynamics, and mortality in patients with chronic heart failure. Eur Heart J; 28, 1723-1730.

Van Dielen FMH, Van 'T Veer C, Buurman WA, Greve JWM (2002): Leptin and Soluble Leptin Receptor Levels in Obese and Weight-Losing Individuals. J Clin Endocrinol Metab; 87, 1708-1716.

Verrier RL, Tan A (2009): Heart Rate, Autonomic Markers, and Cardiac Mortality. Heart Rhythm; $\underline{6}, 68-75$.

Wallace AM, McMahon AD, Packard CJ, Kelly A, Sheperd J, Gaw A, Sattar N; on behalf of WOSCOPS Executive Committee (2001): Plasma Leptin and the Risk of Cardiovascular Disease in the West of Scotland Coronary Prevention Study (WOSCOPS). Circulation; 104, 3052-3056.

Wolk R, Berger P, Lennon RJ, Brilakis ES, Somers VK (2003): Body Mass Index. A Risk Factor for Unstable Angina and Myocardial Infarction in Patients With Angiographically Confirmed Coronary Artery Disease. Circulation; 108, 2206-2211.

Wu Z, Bidlingmaier M, Liu C, De Souza EB, Tschöp M, Morrison KM, Strasburger CJ (2002): Quantification of the Soluble Leptin Receptor in Human Blood by Ligand-Mediated Immunofunctional Assay. J Clin Endocrinol Metab; 87, 2931-2939.

Yannakoulia M, Yiannakouris N, Blüher S, Matalas A-L, Klimis-Zacas D, Mantzoros CS (2003): Body Fat Mass and Macronutrient Intake in Relation to Circulating Soluble Leptin Receptor, Free Leptin Index, Adiponectin and Resistin Concentrations in Healthy Humans. J

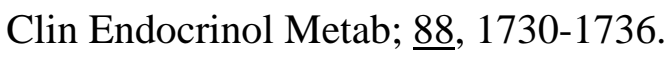




\section{Anhang: Dokumentationsbogen und Wells-Score}






\begin{tabular}{|c|c|c|c|c|c|}
\hline \multicolumn{3}{|c|}{ Diagnostik IV: Pulmonalisangiographie } & \multicolumn{3}{|c|}{ Therapie } \\
\hline \multirow{3}{*}{$\begin{array}{l}\text { 49. Durchgeführt } \\
\text { 50. Gefäßokklusion: 25-50\% }\end{array}$} & ja & nein & \multirow[b]{2}{*}{ 64. Henarin (PTT >60s) } & \multirow[t]{2}{*}{ ja } & nein \\
\hline & & & & & \\
\hline & & & 65. Thrombolyse & & \\
\hline $51-75 \%$ & & & initial ( $\leq 24$ Stunden $)$ & & \\
\hline$>75 \%$ & & & spät (ab 24 Stunden) & & \\
\hline & & & 66. Thrombusfragme & & \\
\hline \multicolumn{3}{|c|}{ Diagnostik V: Tiefe Venenthrombose } & 67. Operative Embolekt. & & \\
\hline \multirow{2}{*}{$\begin{array}{l}\text { 52. Sonographie durchgeführt } \\
\text { 53. Phlebographie durchgeführt }\end{array}$} & & & 68. Cava-Schirm & & \\
\hline & & & 69. Orale Antikoagulation & & \\
\hline 54. Unterschenkelthrombose & & & \multicolumn{3}{|c|}{ Medikation } \\
\hline 55. Oberschenkelthrombose & & & \multirow{2}{*}{$\begin{array}{l}\text { 70. Insulin } \\
\text { 71. Orales Antidiabetikum }\end{array}$} & & \\
\hline 56. Beckenvenenthrombose & & & & & \\
\hline 57.Obere Körperhälfte & & & \multicolumn{3}{|c|}{ Verlauf } \\
\hline \multicolumn{3}{|c|}{ Diagnostik VI: Lungenszintigramm } & \multirow{4}{*}{$\begin{array}{l}\text { 72. Katecholaminbedürftig } \\
\text { 73. Intubation } \\
\text { 74. Reanimation } \\
\text { 75. Tod des Patienten }\end{array}$} & & \\
\hline \multirow{5}{*}{$\begin{array}{l}\text { 58. Durchgeführt } \\
\text { 59. LE hochwahrscheinlich } \\
\text { Segment: } \\
\text { 60. Befund unsicher } \\
\text { 61. LE unwahrscheinlich }\end{array}$} & & & & & \\
\hline & & & & & \\
\hline & & & & & \\
\hline & & & . & & \\
\hline & & & & & \\
\hline \multicolumn{3}{|c|}{ Diagnostik VII: Spiral-CT } & & & \\
\hline \multirow{2}{*}{$\begin{array}{l}\text { 62. Durchgeführt } \\
\text { 63. Gefäßokklusion: 25-50\% }\end{array}$} & & & & & \\
\hline & & & & & \\
\hline $51-75 \%$ & & & & & \\
\hline$>75 \%$ & & & & & \\
\hline
\end{tabular}




\section{Wells-Score}

$\begin{array}{ll}\text { vorausgegangene LE oder TVT } & 1,5\end{array}$

vorausgegangene Immobilisation oder Operation $\quad 1,5$

Krebserkrankung 1

Hämoptysen 1

Herzfrequenz $\geq 100 /$ min $\quad 1,5$

klinische Zeichen einer TVT 3

andere Diagnose weniger wahrscheinlich als LE 3

Klinische Wahrscheinlichkeit

$\begin{array}{ll}\text { niedrig } & 0-1\end{array}$

$\begin{array}{ll}\text { mittel } & 2-6\end{array}$

$\begin{array}{ll}\text { hoch } & \geq 7\end{array}$ 


\section{Danksagung}

Zu besonderem Dank bin ich Frau PD. Dr. Claudia Dellas verpflichtet. Sie hat durch ihre engmaschige Betreuung bei der Durchführung dieser Arbeit sowie ihre konstruktiven Vorschläge und wissenschaftlichen Anregungen wesentlich zum Gelingen dieser Arbeit beigetragen.

Bedanken möchte ich mich auch bei Herrn Prof. Dr. Stavros Konstantinides für die Überlassung des Themas dieser Doktorarbeit und für seine Unterstützung vor allem bei der Durchführung des praktischen Teils dieser Arbeit.

Den Ärzten und MTA`s der zentralen Notaufnahme, der anästhesiologischen und internistischen Intensivstationen sowie des Herzkatheterlabors im Universitätsklinikum Göttingen danke ich für ihre freundliche und tatkräftige Unterstützung bei der Patientenrekrutierung. Für die Analysen der Blutproben möchte ich mich bei den MTA's der Arbeitsgruppe von Frau PD. Dr. Dellas und Herrn Prof. Konstantinides recht herzlich bedanken. 


\section{Lebenslauf}

Mein Name ist Christian Reiner, ich wurde am 11.10.1979 in Kassel geboren. Meine Mutter, Marie-Therese Reiner ist Apothekerin und Chemie-Assistentin, mein Vater, Dr. Hans Reiner ist Apotheker. Meine Schwester Dr. Susanne Reiner ist ebenfalls Apothekerin.

Von 1986 bis 1990 besuchte ich die Ernst-Leinius-Grundschule in Kassel, von 1990 bis 1999 das Friedrichsgymnasium in Kassel, wo ich am 16.06.1999 das Abitur ablegte.

Von 1999 bis 2000 absolvierte ich meinen zwölfmonatigen Zivildienst als OP-Pflegekraft im Burgfeld-Krankenhaus in Kassel, wo ich auch mein Krankenpflege-Praktikum ableistete.

Zum Wintersemester 2000 begann ich mein Studium der Humanmedizin an der GeorgAugust-Universität Göttingen. Im Jahr 2004 begann ich meine Dissertation an der GeorgAugust-Universität Göttingen zur ,, prognostischen Bedeutung der Adipozytokine Leptin und Adiponectin bei der akuten Lungenembolie", zunächst unter der Betreuung von Herrn Prof. Stavros Konstantinides, seit 2009 unter der Betreuung von Frau PD. Dr. Claudia Dellas. Neben dem Studium arbeitete ich mehrere Jahre als wissenschaftliche Hilfskraft in der Abteilung Klinische Chemie am Universitätsklinikum Göttingen. Famulaturen absolvierte ich in der Chirurgie und Inneren Medizin (Kardiologie, internistische Notaufnahme) in Göttingen sowie in der Orthopädie in Konstanz.

Die ärztliche Vorprüfung bestand ich im September 2002, den ersten Abschnitt der ärztlichen Prüfung im August 2003, den zweiten Abschnitt der ärztlichen Prüfung im März 2006.

Mein praktisches Jahr absolvierte ich in Kapstadt, Südafrika (Innere Medizin), Wanganui, Neuseeland und Sydney, Australien (Orthopädie) sowie Oldenburg (Chirurgie). Im April 2007 bestand ich den dritten Abschnitt der ärztlichen Prüfung.

Hiernach begann ich meine Weiterbildung zum Facharzt für Kardiologie. Von Oktober 2007 bis zum Mai 2008 war ich als Assistenzarzt in der ersten medizinischen Klinik am Städtischen Krankenhaus Kiel tätig, von August 2008 bis April 2010 als Assistenzarzt in der Klinik für Innere Medizin in der Helios Mariahilf Kinik Hamburg. Seit April 2010 arbeite ich als Assistenzarzt in der Abteilung Kardiologie im Albertinen-Krankenhaus Hamburg. 